\title{
HAWT Performance With Dynamic Stall
}

\section{A Subcontract Report}

B. D. HIbbs

AeroVironment, Inc.

Monrovia, California

February 1986

Prepared under Subcontract No. PF94847JR

Solar Energy Research Institute

A Division of Midwest Research institute

1617 Cole Boulevard

Golden, Colorado 80401

Prepared for the

U.S. Department of Energy

Contract No. DE-AC02-83CH10093 
STR -2732

SEP

PREFACE

This report was prepared by Bart D. Bibs, of AeroVironment, Inc., under subcontract No. PF94847JR for the Rockwell International Corporation, which operated the Wind Energy Research Center under their contract No. DE-AC04-76DP03533. As of October 1, 1984, the Wind Energy Research Institute is under the operation of the Solar Energy Research Institute, which coordinated the completion and publication of this report under Subtask No. 4807.10 .

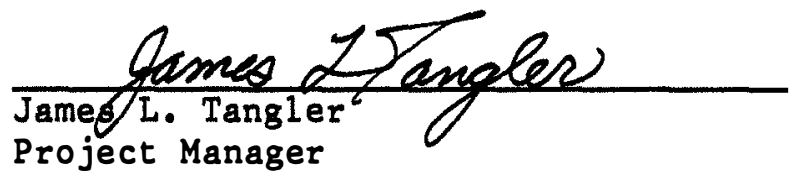

Approved for

SOLAR ENERGY RESEARCH INSTITUTE

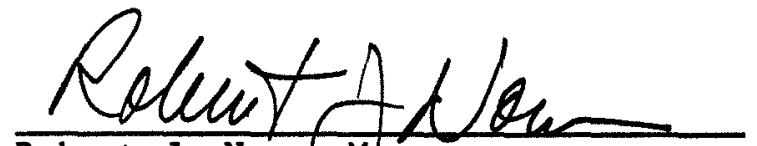

Robert J. Noun ( Manager

Wind Research Bunch

Donalefthiteri

D. W. Richie, Director

Solar Electric Research Division 


\section{ABSTRACT}

The effects of flow nonuniformities on the performance of a horizontal axis wind turbine are calculated taking dynamic stall into account. The well-known program PROP is modified to incorporate the above effects, and exercised to produce quantitative comparisons with the uniform flow case.

After study of various existing models, the MIT model (developed in 1983) is used to represent dynamic stall. This model is considered to provide sufficient accuracy for turbine performance analysis and yet is relatively simple. Using reduced frequency as a parameter, it predicts dynamic lift coefficients substantially higher than the static maximum values and includes a crude model of the vortex roll-off phenomenon. An associated model for drag is used.

The dynamic stall model was tested against experimental data for three typical reduced frequencies. Good instantaneous correlation is obtained, while a comparison of average values of 1 ift and drag coefficient over a cycle show excellent correlation.

This model has been incorporated into PROP and, in addition, data input has been modified to accept more general geometry specification. The analytical features of PROP have been extended so that fluid mechanics at each radial station vary as the blade rotates, making it possible to represent a flow which is not uniform across the disk.

The nonuniformities are wind shear, modeled by a power law; tower wake, modeled by an approximate Gaussian deficit; yaw, modeled by additional flows in the rotor-disk plane and large-scale turbulence, modeled by an axial flow with sinusoidal temporal changes in magnitude.

Representative turbines used to exercise the model are the Westinghouse Mod 0 and the Enertech 44/25. The comparison of field test data from the units with model predicted performance is good, lending credence to the basic PROP model. The effects of nonuniformities (using parameters typical of normal wind turbine environments) with and without the dynamic stall are then calculated. Modeling the dynamic stall is shown to have little effect, of the order of a few percent, on the performance. This is principally due to the compensating effects of increased dynamic 1 ift and increased dynamic drag. It is further shown that the performance with nonuniform flow compared with the uniform flow case differs by only a few percent.

The new PROP model provides a powerful general capability to handle nonuniform flows rationally. The results indicate that the performance in these cases is not greatly different from the uniform flow situation, indicating that over a cycle the rotating blade acts as a very effective averaging mechanism. However, the instantaneous changes in rotor loads due to nonuniformities are significant and can be predicted with the new program. 
TABLE OF CONTENTS

Page

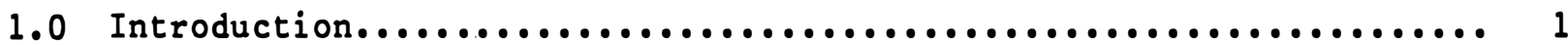

2.0 Dynamic stall Model................................... 3

2.1 Available Methods.................................... 3

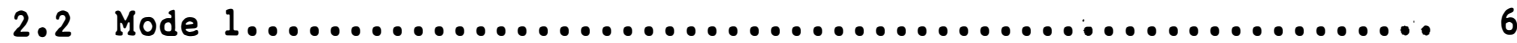

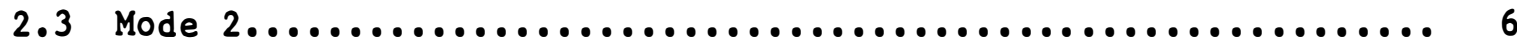

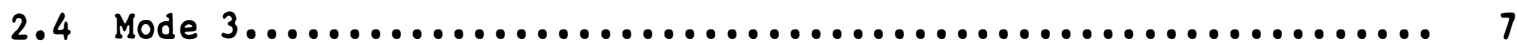

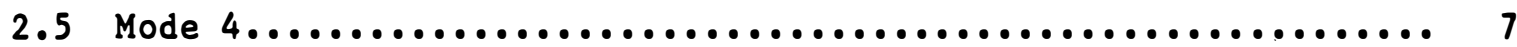

3.0 Modifications to PROP................................... 15

3.1 Nonuniform Flow Models............................... 19

3.2 Momentum Theory....................................... 20

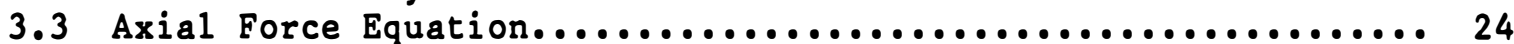

3.4 Circumferential Force Equation.......................... 25

3.5 Tip Loss Correction................................ 27

4.0 Test Cases.......................................... 31

4.1 Test Case Results.................................. 32

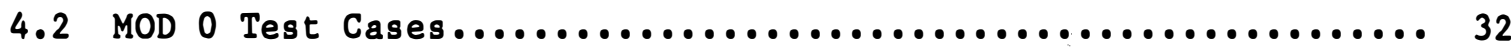

4.3 Enertech Test Cases.................................... 46

5.0 Conclusions......................................... 53

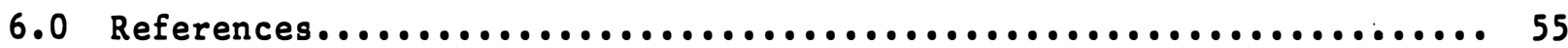

Appendix A Notes on Nomenclature............................. 56 Appendix B User's Guide for the Program PROP....................... 58

Appendix C Example Runs of the PROP Code........................ 65 


\section{LIST OF FIGURES}

Page

2-1. Dynamic Airfoil Characteristics for the NACA 0012, Comparison between Theory and Experiment for a Reduced Frequency of $0.1, \alpha,=10^{\circ} \pm 5^{\circ}$.

2-2. Dynamic Airfoil Characteristics for the NACA 0012, Comparison between Theory and Experiment for a Reduced Frequency of $0.2, \alpha,=10^{\circ} \pm 5^{\circ}$

2-3. Dynamic Airfoil Characteristics for the NACA 0012, Comparison between Theory and Experiment for a Reduced Frequency of $0.15, \alpha,=10^{\circ} \pm 5^{\circ}$

2-4. Dynamic Stall Hysteresis Loop for the NACA 0012,

Comparison between Theory and Experiment for a Reduced

Frequency of $0.15, \alpha=15^{\circ} \pm 10^{\circ}$

3-1. Mod 0 Turbine Performance Prediction with 5, 10,

and 20 Analysis Stations along the Blade.................... 16

3-2. Flow Velocities as Experienced by a Blade Element..............

3-3 Relationships between $\underline{a}$ and $\mathrm{C}_{\mathrm{H}}$, Theory and

Experiment ........................................

4-1. Mod 0 Performance in Uniform Flow, Comparison to

Experimental Data...................................

4-2. Mod 0 Performance with Wind Shear

4-3. Lift and Drag Coefficient Time Histories for the Mod 0

Turbine $B l a d e$ at $R / R=0.75$ and a Tip Speed Ratio of 4.2,

both with and without the Effects of Dynamic Stall..............

4-4. Lift and Drag Coefficient Time Hysteresis for the Mod 0

Turbine $B l a d e$ at $R / R=0.75$ and a Tip Speed Ratio of $4.2, \ldots \ldots \ldots$

4-5. Mod 0 Performance with Wind Shear and Tower Shadow,

Drag Rise during Dynamic Stall not Included...................

4-6. Mod 0 Performance with Tower Shadow........................ 40

4-7. Mod 0 Performance with Wind Shear and Tower Shadow............ 41

4-8. Mod 0 Performance with $20^{\circ}$ Yaw Error..................... 42

4-9. Mod 0 Performance with Wind Shear, Tower Shadow, and

Yaw Error.......................................... 


\section{LIST OF FIGURES (Continued)}

Page

4-10. Mod 0 Performance with Two Cycle per Revolution

Turbulence.............................................. 44

4-11. Mod 0 Performance with Three Cycles per Revolution

Turbulence...........................................45

4-12. Enertech $44 / 25$ Performance, Uniform Flow................. 46

4-13. Enertech 44/25 Performance with Tower Shadow................. 48

4-14. Enertech $44 / 25$ Performance wtih $20^{\circ}$ Yaw Error............... 49

4-15. Enertech 44/25 Performance in Two Cycles per

Revolution Turbulence...................................49

4-16. Enertech 44/25 Performance in Three Cycles per

Revolution Turbulence................................... 51

4-17. Enertech 44/25 Performance with Wind Shear, Tower Shadow

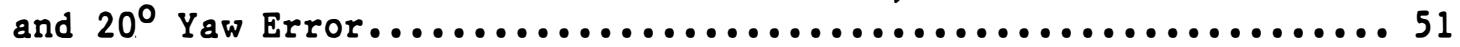




\section{SEPI}

\section{LIST OF TABLES}

$\underline{\text { Page }}$

2-1. Static Airfoil Data for the NACA 0012 used in Theoretical Dynamic Stall Predictions..............................

2-2. Average Lift andDrag Coefficent Values for the NACA 0012 Airfoil during Dynamic Stall................................. 10

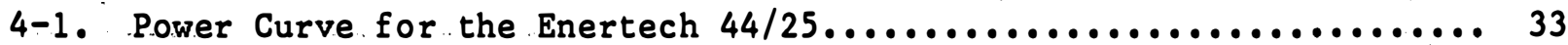




\section{SECTION 1.0}

\section{INTRODUCTION}

The phenomenon of dynamic stall can occur whenever the angle of attack of an airfoil increases relatively quickly from below to above the angle of stall. When this happens, the flow over the airfoil can remain attached at angles of attack above the angle at which steady-state (static case) flow separation normally occurs. This results in the airfoil generating higher lift forces than would otherwise be possible. In extreme cases, the 1 ift coefficient can be increased by a factor of two or three by this dynamic effect. The flow over the airfoil can then separate suddenly, resulting in a rapid decrease in lift and an increase in drag. In the case of wind turbine rotors, the angle of attack can vary due to the effects of tower shadow, wind shear, off-axis operation, and turbulence. As a result, the turbine blades can experience lift forces that are different (usually larger) than would be expected from static performance alone.

The increased lift forces will have two main effects on the turbine: increased blade bending loads, and a performance change. The effect of dynamic stall on blade loads has been examined by Noll and Ham (1983). In their report, the effects of tower shadow and unsteady winds were examined. Here the effect on output power under the influence of the four unsteady flows given above is examined by introducing dynamic stall effects into the PROP computer codes (Hibbs and Radkey 1983).

The PROP code is well suited for performance prediction, but due to the assumptions used in the code it is not well suited for structural loads. PROP makes a rigid rotor assumption. In order to properly predict loads, it is necessary to include the effects of blade elasticity, teeter, and tower elasticity. These effects result in blade motions not experienced by a rigid rotor. Such motions can be expected to affect the rotor structural loads.

Current computer codes do a good job of finding the turbine performance when the flow over the blades is attached. For most turbines this corresponds to light wind conditions with the power output below rated. In stronger winds, many turbines are stall controlled to limit power output by allowing the flow to separate from the rotor blades. In these conditions the computer predictions tend to be inaccurate. Generally they underpredict the output power, sometimes by very large amounts. One possible reason this may be happening is that the flow is remaining attached at higher angles of attack than those associated with static stall due to the effects of dynamic stall. Thus, it is desirable to quantify the effects of dynamic stall on wind turbine performance.

The purpose of this project is to modify the PROP computer code (Hibbs and Rodkey 1983) to include the effects of nonuniform flow and dynamic stall. The project is divided into three parts. The first part is to select an appropriate dynamic stall model. The second part is to modify PROP as required. Finally, the new computer program is exercised on several test cases. 
The first part of the project starts with an examination of the available dynamic stall models as given in the literature. Current understanding of dynamic stall is not sufficient to calculate the blade forces from first principles of fluid mechanics. Thus, most models are empirical in nature. A model must be selected that is easy to use, gives reasonable results, and is compatible with the PROP computer code. The dynamic stall model is discussed in Section 2.0 .

Next, the PROP code must be modified. These modifications include several changes made by Rocky Flats (Tangler 1983) as well as those needed for this project. The new code is required to handle the four nonuniform flow cases given above either singly or together. It must be possible to include the effects of dynamic stall as desired. A complete description of the modifications is given in Section 3.0.

The code was exercised by examining the performance predictions of two turbines under various conditions of wind shear, tower shadow, and the other nonuniform flow conditions. Predictions with and without the effects of dynamic stall are made and compared with actual turbine performance. The full results are given in Section 4.0 . 
SECTION 2.0

DYNAMIC STALL MODEL

Dynamic stall is a highly complex phenomenon. It involves time-dependent interactions between potential flow and viscous flow effects. These complexities make it very difficult to determine the forces on an airfoil theoretically, that is, from the airfoil shape and the time history of the flow alone. As a result, most models that predict the airfoil forces during dynamic stall are empirical in nature. Essentially, these models are sets of equations that $f i t$ the experimental data. These equations are also based on knowledge of the physical mechanism of dynamic stall. The resulting methods thus require some experimental data on a given airfoil to create a model to predict its behavior. In general, methods that rely on a more extensive data base for a given airfoil will give better predictions.

In this project it is desirable to get a first look at the effects of dynamic stall on rotor power output. Thus it is necessary to have a method that gives good predictions of the dynamic 1 ift and drag forces, but frequently, because of other inaccuracies, a complicated model giving the best possible prediction is not justified. This means a simpler method can be used. All dynamic stall methods require some input data for use in finding the airfoil characteristics. A method that requires only the static airfoil lift and drag data will in principle be simplest.

Another consideration in choosing a dynamic stall model is the ease with which it can be incorporated into the PROP code. The PROP code must find the 1 ift coefficient and drag coefficient of an airfoil at a given angle of attack. These coefficients can then be used to find the forces for a blade element. When unsteady flows are to be taken into account it is necessary to find the forces on each blade element at several azimuthal stations during rotation. If dynamic stall effects are to be considered, then the number of circumferential stations that must be considered can be quite large, say over 100. In addition, the conditions at past stations affect the forces developed at a future station. The history of the blade element must be remembered by the code that implements the dynamic stall method. It is desirable to use a method that has the least parameters involved in remembering the necessary information.

A further complication is that the PROP code solves for the performance of each station in an iterative manner. The section 1 ift and drag coefficients must be computed for several different angles of attack at each station during this iterative procedure, keeping the past history the same. The chosen dynamic stall method must be adaptable to this solution method to be usable in PROP.

\subsection{AVAILABLE METHODS}

Several available dynamic stall methods have been reviewed in the report of Noll (1983). The methods reviewed are the Boeing-Vertol (sometimes known as the Gormont method), UTRC, MIT, Lockheed, and Sikorsky methods. The descrip- 
tion of these methods is not repeated here. Noll concluded that the MIT model was the best one to use for turbine blade work. This model incorporates aspects of both the Boeing-Vertol method and the sikorsky method. From the Boeing-Vertol method, the MIT method borrows the equations used to predict the angle of attack at which dynamic stall occurs. From the Sikorsky method comes the equations that model the lift and drag coefficients during and after dynamic stall. The MIT method results in a fairly accurate prediction of dynamic stall as a result.

There are, in addition, newer methods not covered by the Noll report, since they were published at a later date. The two more interesting of these are the new UTRC (Gangwani 1981) method and the Tran and Petot (Rogers 1984) method. Both methods are highly accurate, but have drawbacks that limit their usefulness to this program.

The new UTRC method uses an effective angle of attack equation to determine the airfoil characteristics. The method uses this effective angle in a set of equations to find the airfoil 1 ift and drag coefficients under unsteady conditions. These equations require several (about 20) constants that must be found by a least square curve fit of test data, which must cover a wide range of dynamic conditions to be useful. Any airfoil for which such dynamic data are not available cannot be modeled via this method. This strong reliance on test data makes this method undesirable for use here.

The Tran and Petot method uses differential equations to find the unsteady lift coefficient. It is of interest because the method does not have"modes" that must be switched on and off as the airfoil goes from one condition to another. The solution to the differential equation is sufficient. This makes the method very suitable for being incorporated into a computer code. Unfortunately, it requires several coefficients, each of which is particular to the airfoil and is a function of angle of attack. In addition, it does not give results for the airfoil drag coefficient, but only its lift coefficient. Both of these characteristics make it unsuitable for use here.

Both the new UTRC method and the Tran and Petot method can be expected to give quite accurate predictions. However, both require considerable tunnel data on the airfoil to be modeled, data that must be taken as the airfoil undergoes dynamic stall. Such data are available for some airfoils, but usually only the type of airfoils that would be used on a helicopter. Data needed for airfoils used in wind turbine work are generally not available.

The MIT model gives some of the best results of the methods examined by Noll, but is inferior to the two methods given above. The MIT model has the advantage that it is simple, easy to use, and has been used before. It will work for any airfoil for which static airfoil data are available. Thus, the turbine designer need not be concerned about finding and analyzing dynamic stall data for the airfoil selected for a particular turbine design. With the MIT model incorporated into PROP, turbine analysis with dynamic stall can be carried out for a little more effort than finding turbine performance without dynamic stall effects being considered. 
It is felt that for most turbine work these advantages outweighed the importance of any inaccuracies the MIT model might have with respect to the more advanced models. This is especially true at this early stage of the work. If simple models show that important new insights can be gained from the consideraton of dynamic stall, then the extra effort can be expanded to develop the more complex models.

In the future it may be desirable to work on one of these more advanced methods so it can be used for turbine performance prediction. Thus, it was decided to modify PROP in such a way to permit the later inclusion of almost any generally dynamic stall model with little effort.

The mechanism of the MIT model consists of four regimes or modes. In this description the parts of the model associated with determining the moment coefficient have been left out. This is a significant simplification and is acceptable because PROP does not need moment coefficient data to predict power output.

First, the method starts by using the standard airfoil data (Mode 1). When the angle of attack increases from below the static stall value to above, the method extrapolates the lift coefficient up to a higher value than given by the static data (Mode 2). As the angle of attack continues to increase, the method computes the dynamic stall angle, which is a function of the rate of increase in angle of attack. Once the dynamic stall angle is reached, the method models the dynamic stall process (Mode 3 ). During dynamic stall, a vortex forms near the leading edge of the airfoil and rolls off along the upper surface of the airfoil and off the trailing edge, accompanied by a sudden increase in the airfoil lift coefficient. The magnitude of this increase is a function of the rate of increase in angle of attack at the moment of dynamic stall. The lift coefficient then remains at this elevated level until the angle of attack begins to decrease. After the decrease has begun, the lift and drag coefficients exponentially decay to their static values (Mode 4). When the coefficients are sufficiently close to the static values, the method resumes using them as it did at the beginning. Thus we return to Mode 1.

A problem with the method as described lies in the assumption that the dynamic lift coefficient remains at an elevated level until the angle of attack begins to decrease. Consider the case of a wind turbine operating with a tower wake. Assume that when the blade is outside the tower wake the flow is separated, but it is attached while in the tower wake. The blade will experience dynamic stall when it leaves the wake. However, with the method described above, the lift coefficient will remain at a high value for virtually the entire blade rotation. This is because the angle of attack will increase as the blade leaves the wake and then stay high for most of the rest of the rotation until the blade reenters the wake.

A better model of dynamic stall would be to have the 1 ift coefficient remain at its elevated level for a fixed amount of time regardless of the airfoil motion. The length of time to be used is related to the movement of the separation vortex down the airfoil. 
When putting the method into the computer program, it is convenient to divide it into several modes. Each mode contains rules for determining the 1 ift and drag coefficients as well as when to switch modes.

In preparation to use the method, it is necessary to find the static stall angle, $\alpha_{s s}$. This angle is defined as the angle at which the lift coefficient slope has a value of 0.05 per degree. With this angle known, as well as the static stall 1 ift coefficent, $C_{L_{s}}$, the method starts with Mode 1.

\subsection{MODE 1}

The lift and drag coefficients are determined from the static values. These values are input parameters to the program and are particular to the airfoil used on the turbine. The lift and drag coefficient values are specified at several different angles of attack and at several blade radial stations. Coefficient values at intermediate angles and stations are formed by 1 inear interpolation. The method continues to stay in Mode 1 until the angle of attack increases from below the static stall angle to above. Then the method goes to Mode 2.

\subsection{MODE 2}

In Mode 2, the method finds the 1 ift coefficient from the following equation:

$$
C_{L}=C_{L_{s s}}+0.1\left(\alpha-\alpha_{s s}\right)
$$

The drag coefficient is found from the static values. The method also finds the angle of dynamic stall, $\alpha_{\mathrm{ds}}$ :

$$
\alpha_{d s}=\alpha_{s s}+\gamma\left(\frac{\dot{\alpha} c}{2 V}\right)^{1 / 2}
$$

where $\dot{\alpha}$ is the rate of change of $\alpha$ with time, $V$ is the local relative speed, and $C$ the local chord, while $\gamma$ is a constant, having dimensions of an angle, and weakly dependent on the airfoil. If $\gamma$ is not known for a given airfoil, a value of one radian is recommended. It is convenient to put this equation into the following form:

$$
a_{d s}=a_{s s}+\gamma\left(\frac{d a}{d \theta} \frac{C}{2 R}\right)^{1 / 2}
$$

where $d \alpha / d \theta$ is the rate of change of $\alpha$ with respect to $\theta$, the blade circumferential position, and $R$ is the radius of the station under consideration; it is assumed that the tip speed ratio is high enough that $V$ is closely approximated by the circumferential blade velocity. If the angle of attack is below the dynamic stall angle, then the method stays in Mode 2, otherwise it goes to 
Mode 3. The position at which dynamic stall occurs, ${ }^{\theta} \mathrm{ds}$, is saved, and the maximum 1 ift coefficient is found from the following algorithm:

if

$$
C_{L_{\max }}=C_{L_{s s}}+40\left|\frac{d \alpha}{d \theta} \quad \frac{C}{R}\right|
$$

$$
\mathrm{C}_{L_{s s}}+0.1\left(\alpha_{\mathrm{ds}}-\alpha_{s s}\right)<\mathrm{C}_{L_{\max }}<\mathrm{C}_{L_{s s}}+2.0
$$

while if

$$
40 \frac{\mathrm{d} \alpha}{\mathrm{d} \theta} \frac{\mathrm{C}}{\mathrm{R}}>2: \mathrm{C}_{\mathrm{L}_{\max }}=\mathrm{C}_{\mathrm{L}_{\mathrm{ss}}}+2
$$

and if

$$
40\left|\frac{\mathrm{d} \alpha}{\mathrm{d} \theta}\right| \frac{\mathrm{C}}{\mathrm{R}}<0.1\left(\alpha_{\mathrm{ds}}-\alpha_{\mathrm{ss}}\right): \quad \mathrm{C}_{\mathrm{L}_{\max }}=\mathrm{C}_{\mathrm{L}_{\mathrm{ss}}}+0.1\left(\alpha_{\mathrm{ds}}-\alpha_{\mathrm{ss}}\right) .
$$

\subsection{MODE 3}

This mode finds the forces during the vortex rolloff period of the dynamic stall. The vortex is assumed to form at the leading edge of the airfoil and convect downstream at half the forward speed of the airfoil. While the vortex is between the leading edge and the midchord point of the airfoil, the lift coefficient is found as in Mode 2, by extrapolating the lift coefficient to the current angle of attack. However, the lift coefficient is not allowed to increase above $C_{L}$. The drag coefficient is found by assuming the airfoil acts like a fullymalled flat plate, that is:

$$
C_{D}=C_{L} \sin \alpha
$$

After the vortex passes the airfoil midchord point, the lift coefficient is set to $\mathrm{C}_{\mathrm{L}}$. The drag coefficient is found from the stalled flat plate asusmption ${ }^{2}$ above. When the vortex passes the trailing edge, the method saves the current blade position, $\theta_{0}$, and goes to Mode 4 .

\subsection{MODE 4}

This is the exponential decay mode or the recovery mode. The 1 ift and drag coefficients are found from the following equations:

$$
\begin{aligned}
& C_{L}=C_{L_{S}}+\left(C_{L_{\max }}-C_{L_{s}}\right) e^{\left(\theta-\theta_{0}\right)} \frac{\frac{2 R}{C}}{} \\
& C_{D}=C_{D_{S}}+\left(C_{D_{\max }}-C_{D_{S}}\right) e^{\left(\theta-\theta_{0}\right)^{\frac{2 R}{C}},}
\end{aligned}
$$


where $C_{L}$ and $C_{D}$ are the lift and drag coefficient values at the end of Mode 3, max $C_{L}$ affax $C_{D}$ are the values that the airfoil would have under static conditiofs. Modes 4 stays in effect until the lift and drag coefficient values are within $1 \%$ of the static values. The method then returns to Mode 1.

It is important to determine how well the model predicts the coefficient values during dynamic stall. This can be done by comparing results from the model with wind tunnel test results. A good set of dynamic stall data was taken by McCroskey (1983). He examined several airfoils under different conditions of oscillation frequency, amplitude, and mean angle of attack. All dynamic lift and drag coefficients were taken with the airfoil undergoing simple sinusoidal oscillations. In addition, static data were taken for each airfoil. The static data were taken for angles up to $30^{\circ}$ and are thus quite suitable for use in the dynamic stall model without having to make any assumptions about the coefficients at high angles.

It was decided to check the MIT model against data for the NACA 0012 airfoil. The static data for this airfoil measured by McCrosky are given in Table 2-1. These data are somewhat smoothed from the original data. Three dynamic cases were examined. Two of the cases had a mean angle of attack of $10^{\circ}$, and oscillated $\pm 5^{\circ}$. The reduced frequency, $k$, for these cases was 0.1 and 0.2 , where $k$ is defined as:

$$
k=\frac{\omega C}{2 V},
$$

where $w$ is the angluar oscillation frequency.

The third case had an average angle of attack of $15^{\circ}$ and oscillated $\pm 10^{\circ}$. The reduced frequency was 0.15 for this case. The test cases cover a range of conditions for which significant dynamic stall effects take place, and can be expected to occur for wind turbine blades. For these three cases, the step size was taken as $1 / 120$ of a complete cycle. Trials with other step signs (not shown) showed this size to be a good compromise between speed and accuracy; further reductions in the step size result in negligible improvements in accuracy. This step was also used for the wind turbine analysis cases.

There is one significant difference in this comparison. The test data were taken with airfoil angle of attack variations caused by airfoil rotation about the quarter chord point.. In the MIT theoretical model case, airfoil angle of attack changes are caused by changes in the vertical component of the velocity. This is equivalent to a heaving motion of the airfoil. The difference in the motions of these two cases can be expected to cause some differences in the two curves. 
Table 2-1. Static Airfoil Data for the NACA 0012 Used in Theoretical Dynamic Stall Predictions

\begin{tabular}{cccc}
\hline$\alpha$ & $C_{L}$ & $\alpha$ & $C_{D}$ \\
\hline 0 & 0 & 0 & 0.006 \\
5 & 0.68 & 5 & 0.009 \\
10 & 1.11 & 10 & 0.013 \\
13.4 & 1.36 & 13.4 & 0.018 \\
15 & 1.19 & 15 & 0.150 \\
17.5 & 1.08 & 20 & 0.286 \\
20 & 1.05 & 25 & 0.440 \\
25 & 1.02 & 30 & 0.630 \\
30 & 0.97 & & \\
\hline
\end{tabular}

Figure 2-1 shows the results for the first case. Here the 1 ift coefficient and drag coefficient are shown as a function of time, as measured by angular position. The angular position varies by $360^{\circ}$ for each complete cycle. Both the computed and experimental values are shown on the figure along with the curve that results when dynamic effects are ignored, called the static case. The predicted lift coefficient has a somewhat lower peak value, and peaks at a later time than do the data. There is a significant hysteresis lift loss between $\theta=200^{\circ}$ and $300^{\circ}$ in the experiment that is not predicted by the theory. The predicted drag curve is somewhat narrower and higher than the data.

The next case is shown in Figure 2-2. Here again the maximum lift coefficient is underpredicted, and there is a similar phase shift and hysteresis loss.

The third case is shown in Figure 2-3. For this case the lift coefficient is predicted quite well. The peak value is overpredicted, but the general shape of the curve is matched fairly closely although there is the same hysteresis loss around $\theta=300^{\circ}$. The same is true for the drag curve, except the peak value occurs too soon. Figure 2-4 shows the hysteresis loop for this case. Again, the overprediction of lift for the latter quarter of the loop is apparent.

These examples show that the MIT method is capable of reproducing experimental data on a qualitative level, but is not highly accurate on a quantitative level. In all the cases examined, the minimum lift coefficient is not well predicted (the hysteresis effect). The lift coefficient values given by the data are sometimes lower than would be expected from static data. A review of 
the MIT method shows that it will never give a lift coefficient below the static values. The question that must be addressed is if the model results are good enough for turbine power output prediction.

The lift force produced by the airfoil contributes to power output. The drag force reduces power output. The average contribution to power output from each of these forces is approximated by their average values. Thus, a comparison can be made between the model and the data by comparing the average coefficient values over the course of one oscillation. In the case of drag, this comparison is quite reasonable: the power lost is almost directly proportional to the drag at any time; hence the average power lost is approximately proportional to the average drag coefficient. In the case of the lift coefficient, using the average value for comparison is not as good a measure since the contribution to output power tends to increase with lift at a rate greater than a linear rate. Even so, the average value can still give some indication of what is going on.

The average values of 1 ift and drag coefficients $\left(\bar{C}_{L}, \bar{C}_{D}\right)$ for the three cases are shown in Table 2-2. Note that in all three cases the drag coefficient is underpredicted and the lift coefficient is overpredicted. This would indicate that predictions of power output would be high; however, the predicted average values are within $10 \%$ to $20 \%$ of the data averages.

To further evaluate the effect of the inaccuracies in the model, it was decided to conduct a sensitivity study. This consists of analyzing one test case with the drag $r i s e$ at stall eliminated. Instead, the static drag coefficient data will be used. This will significantly lower the average drag coefficient value and provide an upper bound to the power output estimate due to the effects of dynamic stall. The results of this case are presented in Section 4.0 .

Table 2-2. Average Lift and Drag Coefficient

Values for the NACA 0012 Airfoil

During Dynamic Stall

\begin{tabular}{lccc}
\hline Reduced frequency & 0.1 & 0.2 & 0.15 \\
Alpha range & $10^{0} \pm 5^{\circ}$ & $10^{\circ} \pm 5^{\circ}$ & $15^{0} \pm 10^{\circ}$ \\
$\overline{\mathrm{C}}_{\mathrm{L}}$, theory & 1.09 & 1.11 & 1.298 \\
$\overline{\mathrm{C}}_{\mathrm{L}}$, experiment & 0.994 & 0.94 & 1.148 \\
$\overline{\mathrm{C}}_{\mathrm{D}}$, theory & 0.0557 & 0.0812 & 0.242 \\
$\overline{\mathrm{C}}_{\mathrm{D}}$, experiment & 0.0675 & 0.0938 & 0.255 \\
\hline
\end{tabular}




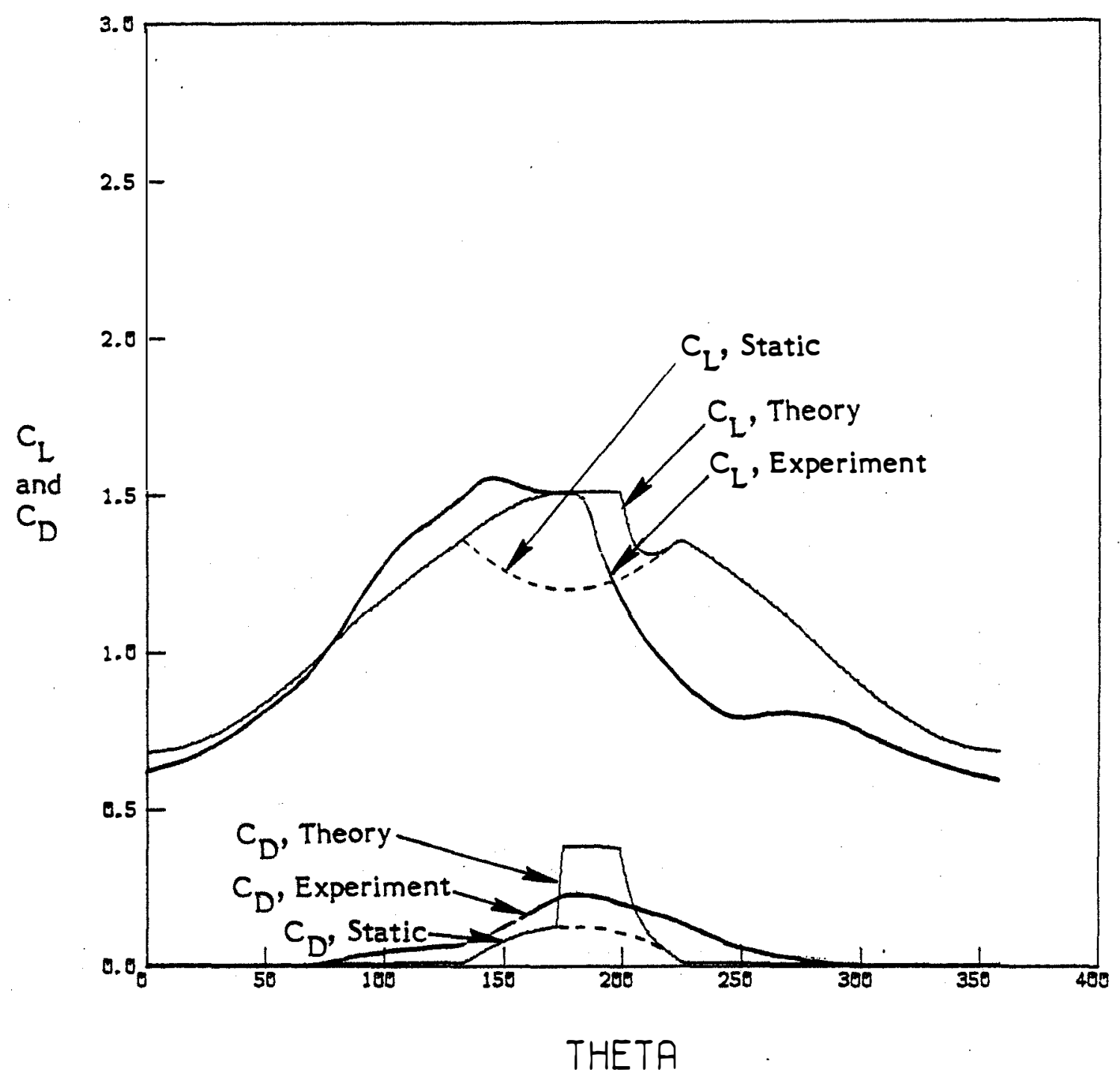

Figure 2-1. Dynamic Airfoil Characteristics for the NACA 0012, Comparison between Theory and Experiment for a Reduced Frequency of $0.1, \alpha=10^{\circ} \pm 5^{\circ}$ 


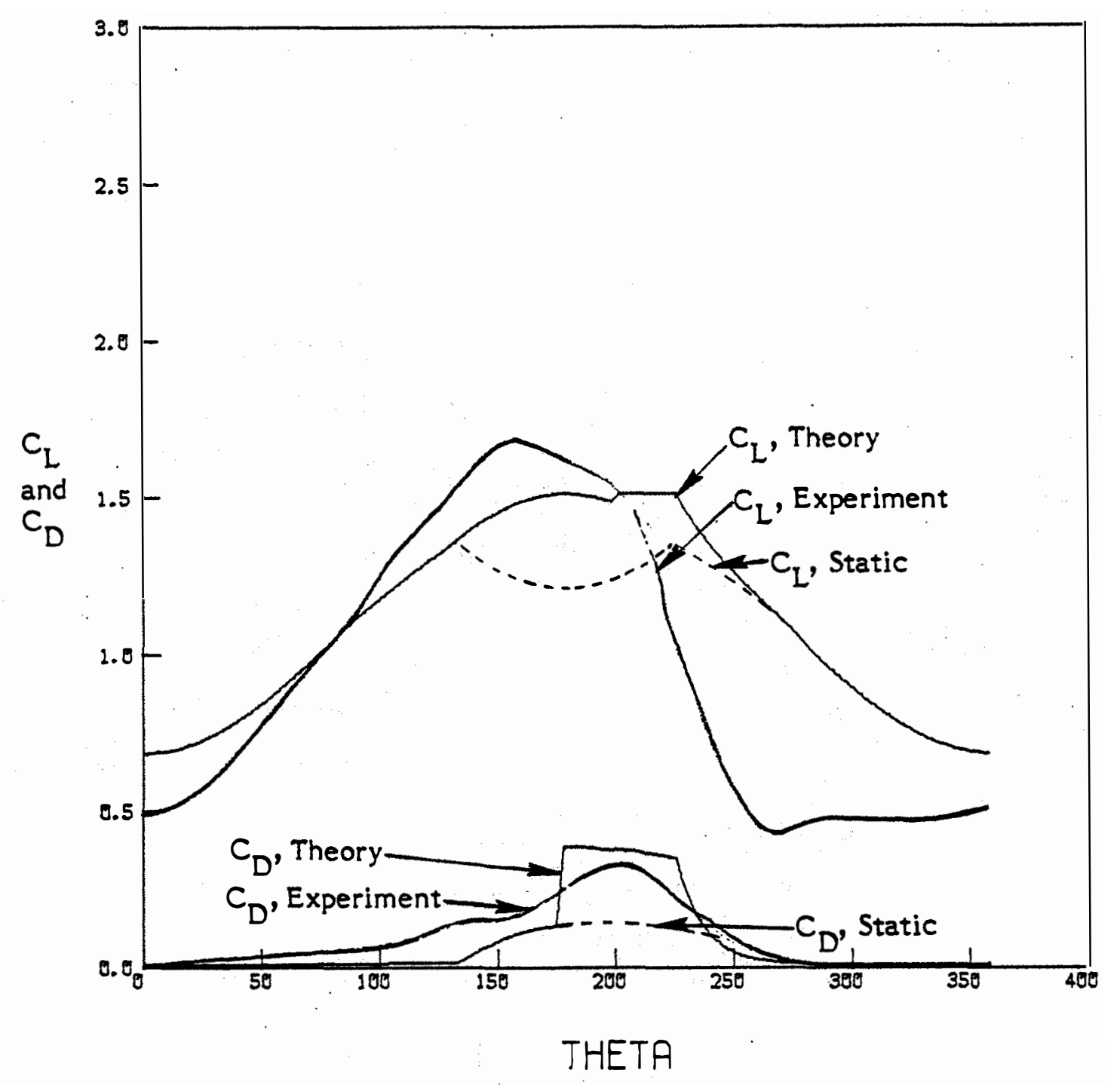

Figure 2-2. Dynamic Airfoil Characteristics for the NACA 0012, Comparison between Theory and Experiment for a Reduced Frequency of $0.2, \alpha=10^{6} \pm 5^{\circ}$ 


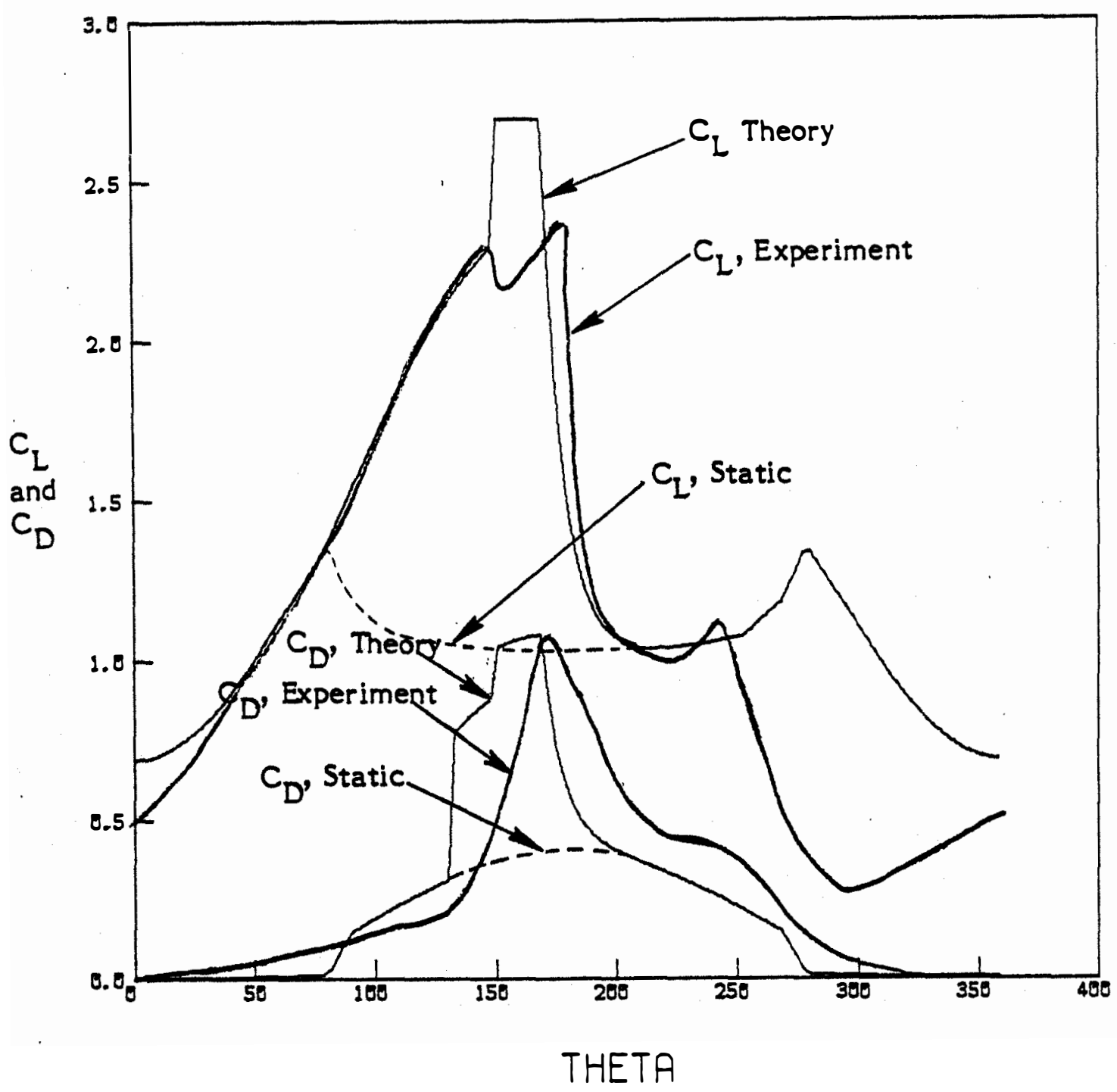

Figure 2-3. Dynamic Airfoil Characteristics for the NACA 0012 , Comparison between Theory and Experiment for a Reduced Frequency of $0.15, \alpha=15^{\circ} \pm 10^{\circ}$ 


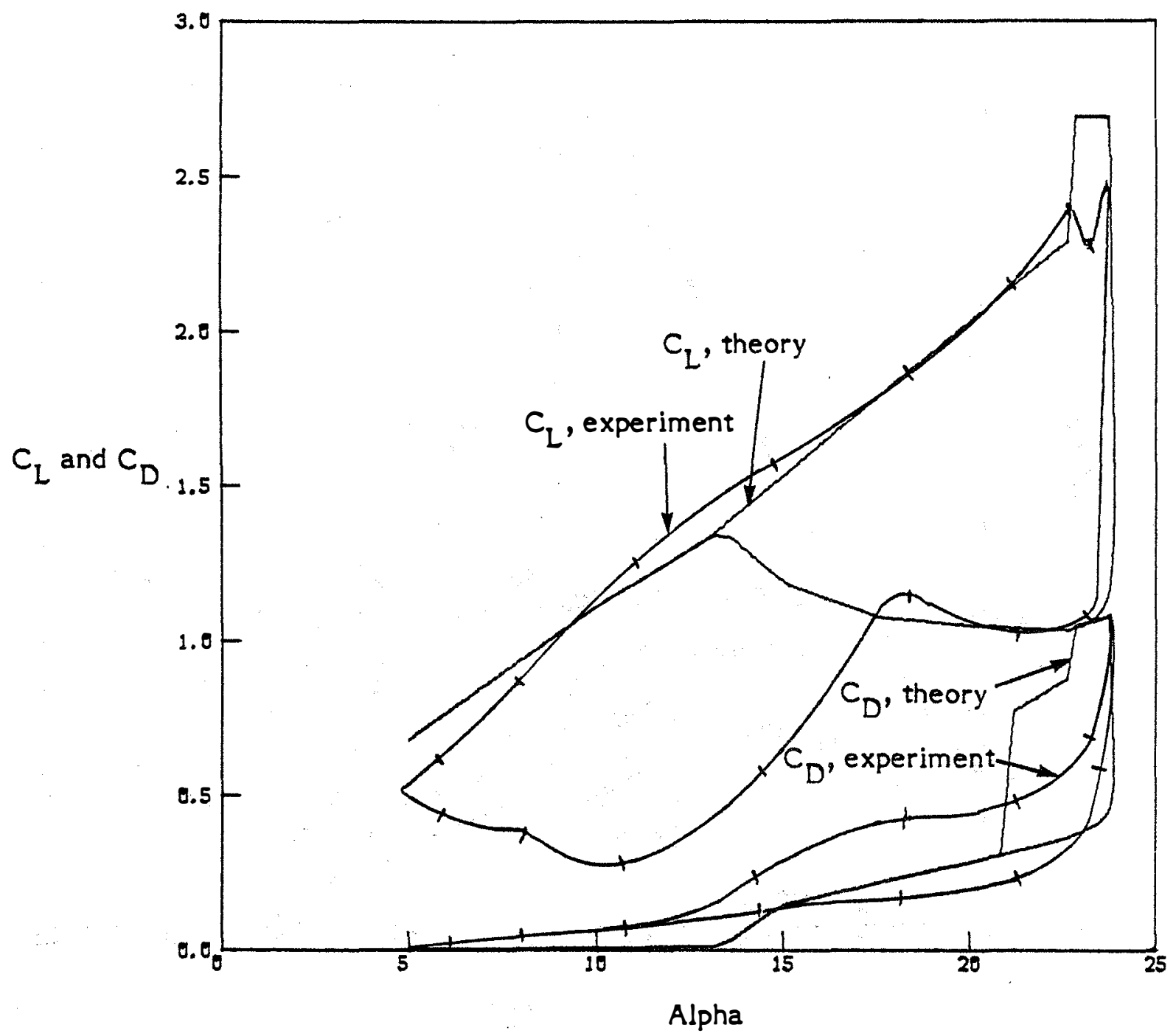

Figure 2-4. Dynamic Stall Hysteresis Loop for the NACA 0012, Comparison between Theory and Experiment for a Reduced Frequency of $0.15, \alpha=15^{\circ} \pm 10^{\circ}$ 


\section{SECTION 3.0}

\section{MODIFICATIONS TO PROP}

Several modifications have been made to the rotor analysis program PROP. The modifications cover changes made by Rocky Flats, changes required for this program, and several additional changes to improve the useability of the code.

Rocky Flats has made extensive use of the PROP code and has made several changes (Tangler 1983). The computation of dimensional values has been added. The original version computed only dimensionless values, whereas the new program, given the rotor diameter, rate of rotation, and fluid density, will find the shaft power output, thrust, and wind speed at each tip speed ratio. These values are computed under the assumption that the rotor rate of rotation is fixed. For turbines driving synchronous generators, the assumption is exact. For turbines driving induction generators, it is not quite exact due to generator slip. It is recommended here to use the rate of rotation of the blade when at full power.

Another modification is varying the number of radial stations at which the analysis is carried out. The original program used 10 radial stations evenly spaced from the axis of rotation to the tip. The new code allows an arbitrary number of analysis points to be defined over an arbitrary radius range. In addition, Rocky flats added the capability of nonuniform spacing the analysis points, with the points clustered near the ends of the radius (the rotor tip). However, trials with this option have shown that it makes little difference, so it was not included in the new version of PROP being developed here. Figure 3-1 shows the effect of varying the number of radial stations. The power versus wind speed curve is shown for a MOD-0 wind turbine with 5, 10 , and 20 radial stations spaced along the blade. Note that the case with only five stations has an irregular curve. This is caused by each station undergoing stall at different times. As there are only five stations, when one stalls out it has a major effect on the overall output curve. Increasing the number of stations to 10 results in a much smoother curve. Here the contribution from each station is sufficently small that stalling of a station does not have a major effect on the overall curve. Increasing the number of stations to 20 causes only a small change in the power curve.

From these results it appears that 10 to 20 radial stations will be sufficient for most work. It was decided to use 15 stations for the test cases reported here.

The last modification made by Rocky Flats was to the post-stall data synthesization routine. This routine defines the 1 ift and drag coefficient values at angles of attack above the highest value available from the data. The old version of PROP contained a routine that assumed the forces developed by the stalled airfoil are normal to the chord line. The stalled airfoil will as a result develop zero force parallel to the chord line.

However, test data on stalled airfoils indicate that some amount of chordwise force is in fact generated. To account for this force, more advanced methods of modeling post-stall airfoil characteristics have been developed. One 


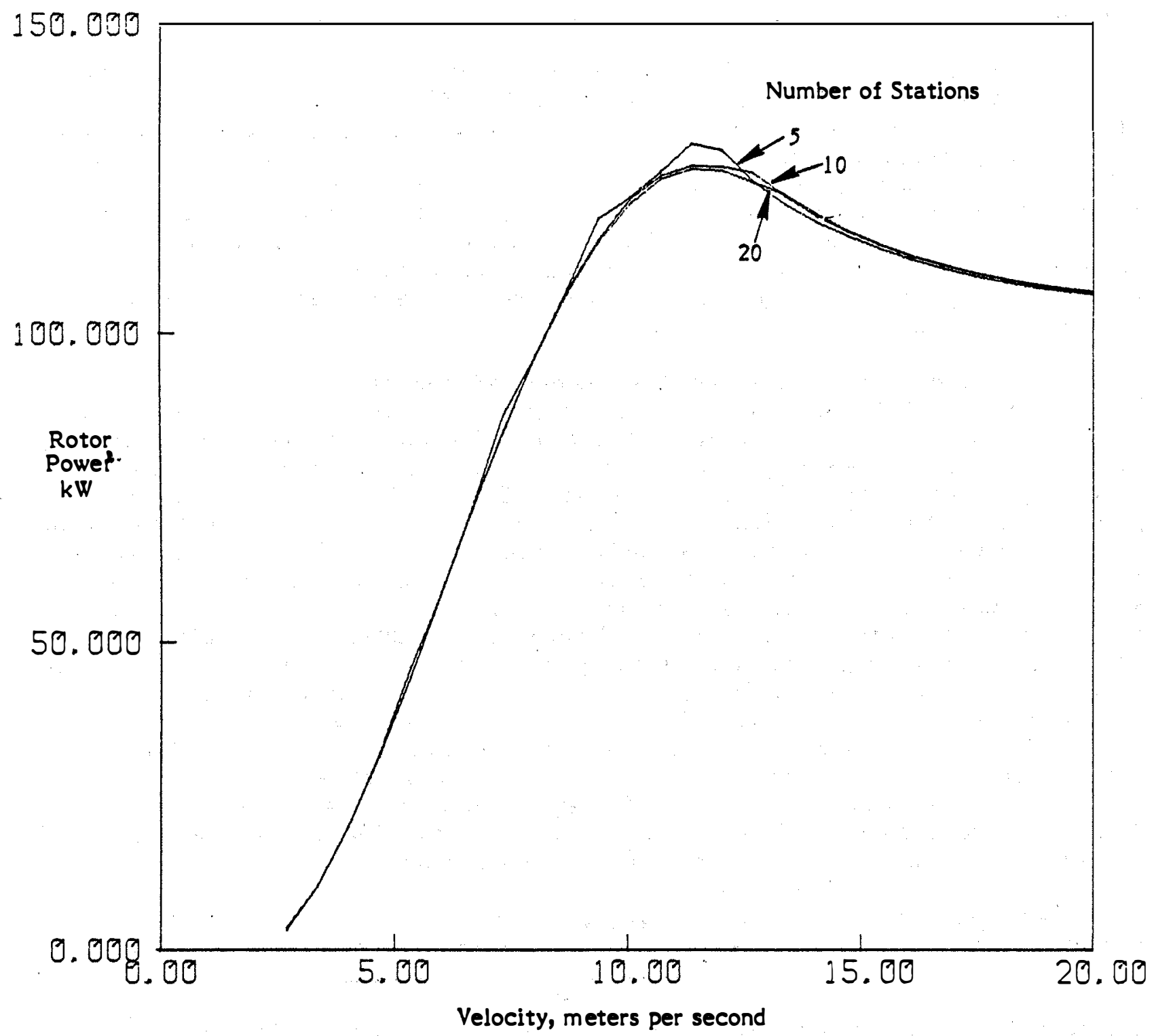

Figure 3-1. Mod 0 Turbine Performance Prediction with 5, 10, and 20 Analysis Stations along the Blade. 
method developed by Viterna and Corrigan (1981) has been modified by Tangler and Ostowari (1984). The modifications are based on nonrotating tests made or several airfoils at high angle of attack.

Lift coefficient:

$$
C_{L}=\frac{C_{D_{\max }}}{2} \sin 2 \alpha+A_{2} \frac{\cos ^{2} \alpha}{\sin \alpha}
$$

where

$$
A_{2}=\left(C_{L_{s}}-C_{D_{\max }} \sin \alpha_{s} \cos \alpha_{s}\right) \frac{\sin \alpha_{s}}{\cos ^{2} \alpha_{s}}
$$

$\alpha_{s}=$ angle of attack at stall, or the highest angle for which data are available

$\mathrm{C}_{\mathrm{L}_{\mathrm{s}}} \quad=\mathrm{C}_{\mathrm{L}}$ at $\alpha_{\mathrm{s}}$

$C_{D_{\max }}=\frac{1+0.065 \mathrm{AR}}{(0.9+t / c)}$

$\mathrm{AR} \quad=$ aspect ratio

t/c = nondimensional airfoil thickness

Drag coefficient for $\alpha=27.5^{\circ}$ to $90^{\circ}$

$$
C_{D}=C_{D_{\max }} \sin \alpha+\left(C_{D_{s}}-C_{D_{\max }} \sin \alpha_{s}\right) \frac{\cos \alpha}{\cos \alpha_{s}}
$$

For a less than $27.5^{\circ}$, use these values to determine $C_{D}$ :

$\begin{array}{cc}\underline{\alpha} & \underline{C} \underline{D} \\ 15^{\circ} & 0.100 \\ 20^{\circ} & 0.175 \\ 25^{\circ} & 0.275 \\ 27.5^{\circ} & 0.365\end{array}$

with intermediate values found by 1 inear interpolation. 
These equations have been incorporated into the new version of PROP. When using them, it is generally best to input data for the airfoil lift coefficient up to the stall angle or beyond. The input drag coefficient data should be as extensive as possible, with the last point being on the curve defined by the $\alpha$ versus $C_{D}$ data given above. The angle $\alpha_{s}$ is taken to be the largest angle input by the user.

The post-stall synthesization routine given by Viterna and Corrigan (1981) is shown below:

Lift coefficient: same as given above

Drag coefficient: a greater than stall

$$
\begin{aligned}
& C_{D_{\max }}=1.11+0.018 \mathrm{AR} \\
& C_{D}=\beta_{1} \sin ^{2} \alpha+\beta_{2} \cos \alpha
\end{aligned}
$$

where

$$
\begin{gathered}
\beta_{1}=C_{D_{\max }} \\
\beta_{2}=\frac{C_{D_{s}}-C_{D_{\max }} \sin ^{2} \alpha_{s}}{\cos \alpha_{s}}
\end{gathered}
$$

Use of these equations in PROP tends to give a higher prediction of peak power output, as they tend to give a lower estimate for $C_{D}$. PROP can easily be modified to use these equations.

It is important to note that the use can bypass the post-stall routines simply by entering in $C_{L}$ and $C_{D}$ data for angles up to $90^{\circ}$. PROP will not resort to these routines until angles outside of the range defined by the user are encountered.

The original version of PROP required the blade chord, twist, and airfoil lift and drag characteristics to be defined at each of the 10 radial stations. With the new ability to vary the number of radial stations at which the analysis is carried out, it is inconvenient to define the blade parameters at each station. PROP was thus modifed to allow the blade parameters to be defined at an arbitrary number of radial points, arbitrarily spaced. The chord and twist at any station along the blade is then found by linear interpolation. For blades that are linearly tapered and twisted, only two radial points need be input. For more complex shapes, a larger number of points can be defined as required. 
The airfoil characteristics are also defined at these arbitrarily selected radial points, with 1 ift and drag coefficient values at other stations being found by linear interpolation. The method used is as follows. For a given angle of attack and radial station, the lift and drag coefficients are found for the neighboring points where the airfoil characteristics are defined. Once these values are known, the lift and drag values at the station of interest are found by linear interpolation.

Note that this method determines the static airfoil coefficients. If dynamic stall is involved, then these static values must be used by the dynamic stall model. As the dynamic stall model requires only the past history of the coefficients and angle of attack, and the current static coefficients, this method of finding the static coefficients is completely compatible with the dynamic stall model.

\subsection{NONUNIFORY FLOW MODELS}

The PROP program has been modified to accept several new nonuniform flows caused by wind shear, tower shadow, off-axis flow, and turbulence. Each of these conditions can be used during the analysis of a turbine, either singly or together.

The wind shear model utilized was developed for the original PROP code. It assumes that the wind speed varies with height as defined by the power law:

$$
v=v_{0}\left(\frac{h}{h_{0}}\right) a
$$

where $V$ is the wind velocity at height $h$ and $V_{0}$ is the wind velocity at height $h_{0}$. The power law exponent is $\alpha$. The inputs required by the wind shear model are the ratio of the rotor hub height to the rotor radius, and the power law exponent.

The tower shadow model is used to describe the wake behind the tower as seen by the blade. The wake is assumed to have constant width and to extend from the bottom of the rotor disk to hub height. The velocity deficit in the wake at any distance $Y$ from the wake centerline is defined by:

$$
V_{x}=V_{0}\left[1-V_{D} \cos ^{2}\left(\pi Y / Y_{W}\right)\right],
$$

where $V_{D}$ is the maximum velocity deficit at the wake centerline, and $Y_{Y}$ is the total wake width. Both $V_{D}$ and $Y_{w}$ are needed as input parameters to describe the tower shadow. They can be obtained either via experimental data or estimated from the tower diameter $D_{t}$ and drag coefficient $C_{D t}$ (Schlichting 1968). The wake width and deficit are approximately:

$$
Y_{w}=C_{D t} D_{t} / V_{D}
$$


with

$$
V_{D}=\left(\frac{C_{D t} D_{t}}{X}\right)^{1 / 2}
$$

where $\mathrm{X}$ is the distance downstream of the tower centerline. Theory indicates that in the far wake the velocity distribution will approximate a Gaussian curve while in the near wake the velocity curve will be sharper edged and almost rectangular. It is felt that the cosine-squared curve used here is a good compromise between these two extremes and will be adequate for most work.

The yaw error model requires only the yaw error angle as input. The yaw error procedure is fully described in section 3.2, which describes momentum theory. There are several ways a turbine can be operating in off-axis flow. The most obvious is through a yaw tracking error. The flow will also be offaxis in the case of a vertical component in the wind, or if the rotor shaft is set off horizontal, with a shaft tilt. The program is set up to handle yaw errors only in the horizontal plane, not in the vertical. However, if yaw error is used alone, without wind shear or tower shadow, then off-axis errors in the vertical plane can be simulated.

The turbulence model impresses a sinusoidally varying wind on the turbine. In other words, the speed across the entire disk varies with time but not with space: at any instant the speed experienced by the whole disk is the same. This carries the implication that the scale of the turbulence is significantly larger than the disk diameter. The frequency of the variation and its amplitude are input parameters. The frequency is defined as a multiple of the rotor rotation frequency. Usually, an integer multiple should be used so that an integer number of turbulent cycles will take place over one blade rotation. In addition, recent studies of the turbulence spectra as seen by a rotating blade show that most of the turbulent energy is concentrated at the harmonics of the blade rotation frequency. Thus, choosing integer multiples of the rotor frequency for the turbulence frequency would seem most appropriate.

\subsection{MOMENTUY THEORY}

To accept the nonuniform flows, standard momentum/strip theory must be modified. It is necessary to consider the effects of cross flow caused by yaw and variations in the axial flow velocity. These modifications are introduced below.

The following definitions are used in this analysis. The length of the rotor blade, measured from the center of rotation to the blade tip, is defined as $R_{T}$. The rotor cone angle is $\Psi$. The projected rotor radius is thus $R_{T} \cos \Psi$. The dimensional blade chord, $c$, and rotor radial position, $r$, normalized by $R_{T}$, give $C$ and $R$ respectively. The mean velocity of the flow impingent on the rotor at hub height is $V_{0}$. This value is used to normalize all other veloci- 
ties. At any given point, on the rotor disc, the flow can be resolved into three components:

$v_{x}$, the axial component, which is normalized to $v_{x}=v_{x} / v_{0}$

$v_{r}$, the radial component, perpendicular to the axis of rotation, which is normalized to $v_{r}=v_{r} / v_{0}$

$v_{c}$, the circumferential component, which is normalized to $v_{c}=v_{c} / v_{0}$.

The tip speed ratio, $x$, is defined as:

$$
\mathrm{X}=\frac{\Omega \mathrm{R}_{\mathrm{T}} \cos \Psi}{\mathrm{V}_{0}}
$$

where $\Psi$ is the rate of rotation in radians per second. The flow velocities as experienced by a blade element at distance $r$ from the hub are shown in Figure 3-2. The flow velocity perpendicular to the cone of rotation is $v_{i}$ :

$$
v_{i}-v_{x}(1-a) \cos \Psi+v_{r} \sin \Psi,
$$

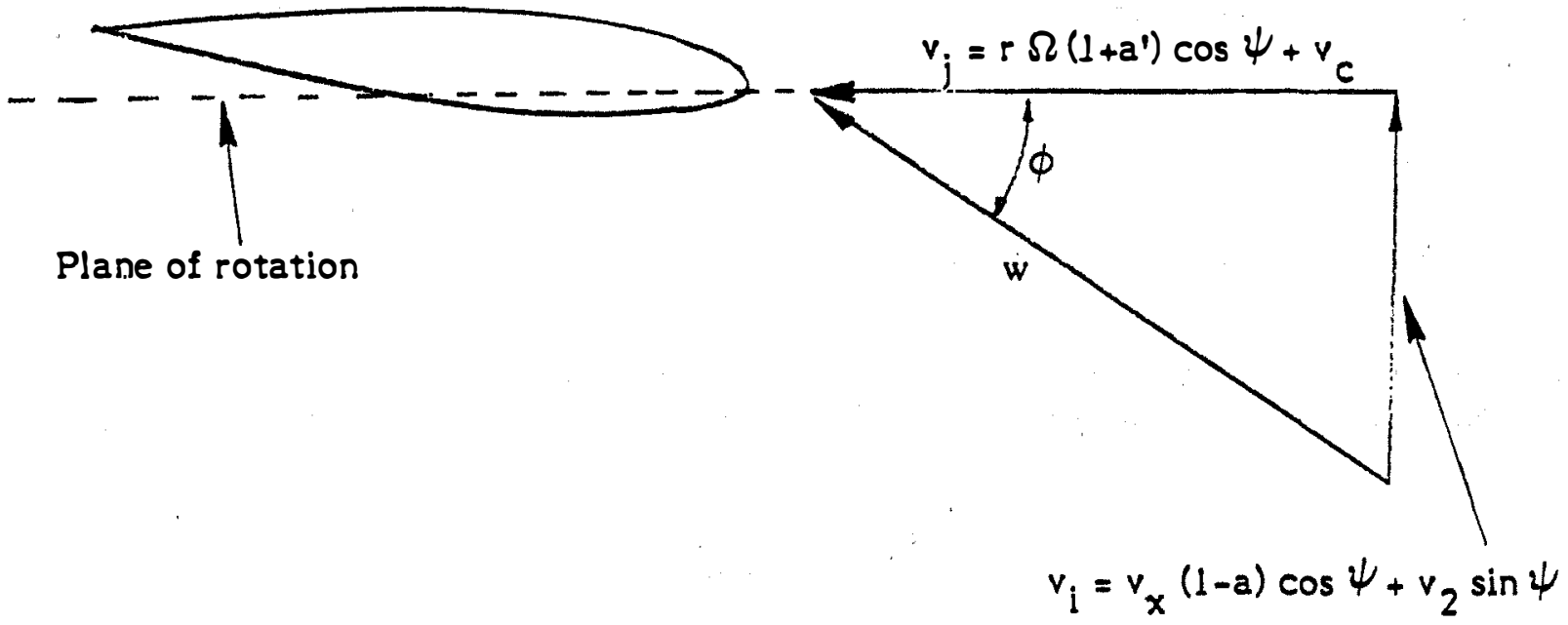

Figure 3-2. Flow Velocities as Experienced by a Blade Element 
where $a$ is the axial interference factor. This normalizes to:

$$
V_{i}=V_{x}(1-a) \cos \psi+V_{r} \sin \Psi .
$$

The flow component parallel to the plane of rotation, $v_{j}$, is:

$$
v_{j}=r \Omega\left(1+a^{\prime}\right) \cos \psi+v_{c},
$$

where $a^{\prime}$ is the circumferential interference factor. This normalizes to:

$$
v_{j}=R x\left(1+a^{\prime}\right)+v_{c} \cdot
$$

The flow component along the length of the blade is ignored in this analysis. The total normalized flow component as seen by the blade is $W$ and is given by:

$$
w=v_{i}^{2}+v_{j}^{2} 1 / 2
$$

The local inflow angle as seen by the blade is $\phi$ and is given by:

$$
\phi=\operatorname{atan}\left(v_{i} / v_{j}\right)
$$

The local rotor solidity, $\sigma$, is the portion of any given annulus covered by blades, and is given by:

$$
\sigma=\frac{B C}{2 \pi R \cos \Psi}
$$

where $B$ is the number of blades.

The velocities $v_{x}, v_{r}$, and $v_{f}$ are functions of the nonuniform flows. $v_{0}$ is the mean hub height wind speed seen by the rotor. The local total velocity $v_{e}$ is equal to:

$$
v_{e}=\left(v_{x}^{2}+v_{r}^{2}+v_{c}^{2}\right)^{1 / 2}
$$


and can be found from the nonuniform flows:

$$
v_{e}=V_{0} c_{w} c_{s} c_{t}
$$

where $C_{w}$ is the wind shear component:

$$
\mathrm{C}_{\mathrm{w}}=\frac{\mathrm{H}+\mathrm{Z}}{\mathrm{H}} \propto \text {, }
$$

where $\mathrm{H}$ is the ratio of hub height to rotor radius, $\mathrm{Z}$ is the normalized height of the blade element relative to the hub, and $\alpha$ is the wind shear exponent. $C_{s}$ is the tower shadow coefficient, given by:

$$
C_{s}=1-V_{D} \cos ^{2}\left(\pi Y / Y_{w}\right)
$$

when

$$
\mathrm{Y}<\mathrm{Y}_{\mathrm{W}} / 2 \text { and } \mathrm{Z}<0 \text {. }
$$

$C_{t}$ is the turbulence coefficient, given by:

$$
c_{t}=1+T_{i} \cos \left(\theta T_{f}\right)
$$

where $T_{i}$ is the turbulence intensity, $T_{f}$ is the turbulence frequency divided by the blade rotational frequency, and $\theta$ is the blade rotational position.

The velocities $V_{x}, V_{r}$, and $V_{c}$ are as follows:

$$
\begin{aligned}
& v_{x}=v_{e} \cos \gamma \\
& v_{c}=v_{e} \sin \gamma \cos \theta \\
& v_{r}=v_{e} \sin \gamma \sin \theta
\end{aligned}
$$

where $\gamma$ is the yaw angle.

Blade annulus theory assumes that each blade element is independent of the others. The forces developed by a blade element are equated to the change in momentum of the flow through the annulus swept out by the blade element. In this way the interference variables $a$ and $a^{\prime}$ can be found. When nonuniform flow cases are to be examined, it becomes necessary to extend strip theory to sectors of an annulus. Here it is assumed that the forces developed on the blades as they sweep through a sector of an annulus are equal to the change in momentum of the flow as it passes through the same area. Each sector and 
annulus is assumed to be independent of all others. Thus, the performance of the entire rotor can be found by analyzing its performance at several different radial and circumferential stations and integrating to obtain the final result.

\subsection{AXIAL FORCE EQUATION}

The axial force equation is used to find the axial interference factor, $a$. The flow approaching the turbine decelerates, passes through the turbine, and decelerates further. In classical momentum theory the theoretical results indicate that the total amount of deceleration the flow experiences in the far wake is twice the deceleration seen at the rotor disk.

The axial component of thrust produced by a blade element of length dr is:

$$
d T=\frac{1}{2} \rho w^{2} C_{L} C B \cos \phi \cos \psi d r
$$

The blade contributes only a portion of this thrust to a given sector of width d $\theta$. This defines the incremental thrust as:

$$
\mathrm{dT}=\frac{1}{2} \rho w^{2} \mathrm{C}_{\mathrm{L}} \mathrm{CB} \cos \phi \cos \psi \mathrm{dr} \frac{\mathrm{d} \theta}{2 \pi}
$$

The pressure drop across the rotor is:

$$
\Delta \mathrm{p}=\frac{1}{2} \rho \mathrm{v}_{\mathrm{x}}{ }^{2} \mathrm{C}_{\mathrm{H}}
$$

where $\mathrm{C}_{\mathrm{H}}$ is the head loss coefficient. It is the dimensionless measure of the amount of energy a fluid parcel loses as it passes through the rotor. Note that the normalizing velocity is $v_{x}$ instead of $v_{0}$. This is because $v_{x}$ is the axial component of the velocity, and the force produced by $p$ is in the axial direction. Only the axial components of both force and velocity are under consideration here. The incremental thrust due to this pressure drop is:

$$
d T=\Delta p r \cos ^{2} \psi d r d \theta
$$

The two equations for $\mathrm{dT}$ can now be equated:

$$
\frac{1}{2} \rho w^{2} C_{L} C B \cos \phi \cos \psi d r \frac{d \theta}{2 \pi}=\frac{1}{2} v_{x}^{2} C_{H} r \cos ^{2} \psi d r d \theta
$$


Canceling like terms we get:

$$
w^{2} C_{L} \cos \phi c B=2 \pi v_{x}^{2} C_{H} r \cos \psi \text {. }
$$

Normalizing by $V_{0}$ and $R_{T}$, and using the relation for the rotor solidity, we have:

$$
\sigma \frac{W^{2}}{V_{x}{ }^{2}} C_{L} \cos \phi=C_{H}
$$

The head loss coefficient is a function of a. Since it is a measure of the energy lost by the flow, it can be found by taking the difference in the energy of the flow far ahead of the rotor and far behind it. Sufficiently far away from the rotor the pressure perturbation of the rotor will be insignificant and all of the energy perturbation will be kinetic. The normalized velocity far upwind is 1.0; far downwind it is $1-2 a$. Thus, for $C_{H}$ we have:

$$
C_{H}=1-(1-2 a)^{2}=4 a(1-a) \text {. }
$$

This is the classical result. Note that according to the above equation, values of $C_{H}$ cannot exceed 1.0. To do so would imply that more energy is being removed from the flow than it possesses. In practice, however, values of $\mathrm{C}_{\mathrm{H}}$ greater than one are observed as shown in Figure 3-3 (Hibbs and Radkey 1983). The extra energy comes from turbulent mixing of the wake with the outer flow. An approximate relation between $C_{H}$ and a for a greater than 0.9 is:

$$
C_{H}=0.889-0.444 a+1.55 a^{2} .
$$

The variables $W$ and $\phi$ are functions of a along with $C_{H}$. In addition, $C_{L}$ is a function of the section angle of attack, which is a function of $\phi$, and hence a. The variable a thus appears on both sides of the equation for $\mathrm{C}_{\mathrm{H}}$. To solve for a this equation must be solved iteratively.

\subsection{CIRCUMFERENTIAL FORCE EQUATION}

The circumferential interference factor $a^{\prime}$ is found by equating the blade torque to the angular momentum added to the air. The torque produced by a blade element must equal the angular momentum. The torque generated by a blade element of length $d r$ sweeping out a sector of width $d \theta$ is:

blade incremental torque $=\frac{1}{2} \rho w^{2} B$ c $r C_{L} \sin \phi \cos \psi d r \frac{d \theta}{2 \pi}$. 


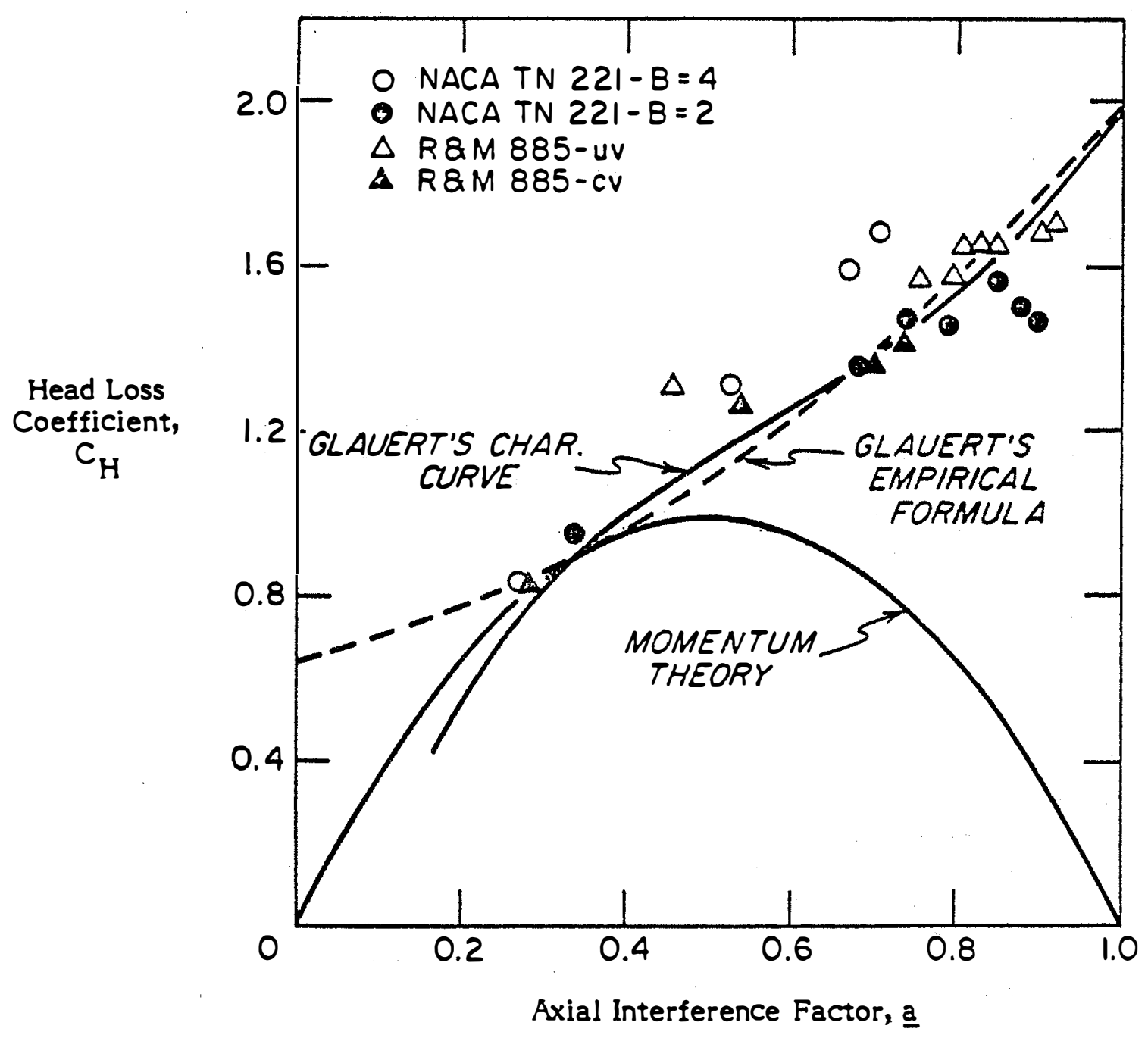

Figure 3-3. Relationships between $\underline{a}$ and $C_{H}$, Theory and Experiment 
The mass flow through the section of the rotor swept by the blade is:

$$
\text { mass flow }=\rho v_{i} r \cos \psi d r d \theta \text {. }
$$

The increment in cross velocity is:

$$
\text { cross velocity increment }=2 a^{\prime} \Omega r \cos \psi \text {. }
$$

Multiplying these two terms together and by the radius of the element, we get the amount of angular momentum added to the fluid:

$$
\text { angular momentum }=2 a^{1} \Omega r^{3} \cos ^{3} \psi v_{i} \rho d r d \theta
$$

Equating this to the torque given above, we have:

$$
2 a^{1} \Omega r^{3} \cos ^{3} \psi v_{i} \rho d r d \theta=\frac{1}{2} \rho w^{2} B c r C_{L} \sin \phi \cos \psi d r \frac{d \theta}{2 \pi} .
$$

Canceling out 1 ike terms:

$$
4 \pi a^{\prime} \Omega r^{2} \cos ^{2} \psi v_{i}=\frac{1}{2} w^{2} B c C_{L} \sin \phi .
$$

Normalizing by $R_{T}$ and $V_{0}$, and using the relation for $x$ :

$$
4 \pi a^{\prime} R^{2} \times V_{i}=\frac{1}{2} W^{2} B C C_{L} \sin \phi .
$$

The solidity $\sigma$ can now be included, as well as the relation $\sin \phi=V_{i} / W$ :

$$
a^{\prime}=\frac{W \sigma C_{L}}{4 \times R}
$$

Again, this equation must be solved iteratively and the iterations must be done in conjunction with the equation for a.

\subsection{TIP LOSS CORRECTION}

The basic analysis presented above does not take into account the aerodynamic losses caused by vortices shed from the tips of finite blades. A tip loss correction is required because there is a finite number of blades of finite 
tip chord, while blade element theory implies an infinite number of vanishingly small blades. Tip loss correction is important because tip losses can cause a decrease in torque and, hence, power output from the blade. Thus, it is necessary to examine the properties of tip loss and how it can be modeled.

The standard strip theory, as described, assumes that the flow through each annulus is uniform. In fact, each blade sheds a discrete vortex near the tip. The effect of this helical vortex is to produce an induced flow field that is not uniform, but varies around the annulus, with a period related to the number of blades. This causes an increase in both the axial and circumferential interference factors in the vicinity of the blade tip. This causes a decrease in section angle of attack, as well as a decrease in the circumferential component of the lift force, resulting in decreased torque. The effect is greatest for blade elements near the tip, and decreases for inner elements. The effect is also smaller if the helical wake formed by the vortices is tighter, which occurs when the tip speed ratio is increased. This would also be the case if the number of blades, is increased, causing the flow more nearly to approach blade annulus theory.

A good approximation to the tip loss is given by the Prandt model (Glauert 1935). This model is a close approximation to the actual loss factor. The formulas used are simple and have been used with good success. The Prandtl tip loss factor, $F_{T}$, is:

$$
F_{T}=\frac{2}{\pi} \operatorname{arc} \cos \left(e^{-f}\right),
$$

where

$$
f=\frac{B}{2} \frac{R_{T}-R}{R_{T} \sin \phi_{T}},
$$

and $R_{T}$ is the radius of the tip while $B$ is the number of blades.

In the expression for $f$, the factor, $R_{T}$ sin $\phi_{T}$, can be approximated by $R$ $\sin / \phi$, which is more easily computed.

If the blade terminates before reaching the axis, then there will be a hub loss factor, $F_{H}$, similar to the tip loss factor. The equation for $F_{H}$ will be the same as for $F_{T}$, but $f$ is now:

$$
f=\frac{B}{2} \frac{R-R_{H}}{R_{H} \sin \phi},
$$

where $R_{H}$ is the radius of the hub. The total loss factor, $F$, is simply the product of $F_{T}$ and $F_{H}$, or

$$
\mathbf{F}=\mathrm{F}_{\mathrm{T}} \mathrm{F}_{\mathrm{H}} \text {. }
$$


The loss factor can now be applied to the equations for a and $a^{\prime}$. The flow velocity components through the annulus averaged around the annulus are less by the factor $F$. An examination of the equation for $F$ reveals that $F$ has a value approaching 1.0 far from the tip, decreasing to zero at the tip. Because the average flow velocity (again, averaged around the annulus) determines the rate of momentum transfer to the air, the equations for a and $a^{\prime}$ should be modified by using $a F$ and $a^{\prime} F$ in place of $\underline{a}$ and $\underline{a}^{\prime}$.

The tip loss factor is also useful in the post-stall data synthesization routine given above. In that routine the blade lift and drag coefficients are functions of the aspect ratio. The aspect ratio determines how flow around the blade tips affects the overall blade characteristcs. However, on a wind turbine the flow around the tips is a function of the number of blades and the tip speed ratio. The actual aspect ratio of the blade is not used to find tip 1oss. The tip loss factor gives the mangnitude of the flow about the tip. It can be related to the aspect ratio as follows.

One interpretation of the tip loss factor is that it is the amount of lift lost; that is:

$$
F=\frac{\mathrm{C}_{\mathrm{L}}}{\mathrm{C}_{\mathrm{L}_{0}}} \text {, }
$$

where $C_{L}$ is the actual lift coefficient, and $C_{L}$ is the 1 ift coefficient that would be obtained if there were no tip loss. A 8 imilar relationship holds for finite aspect ratio wings as given by the well-known result from wind theory for wings of moderate-to-high aspect ratio ( $A R>2)$ :

$$
\frac{1}{1+2 / A R}=\frac{C_{L}}{C_{L_{0}}} \text {. }
$$

Equating these two relationships,

$$
F=\frac{1}{1+2 / A R}
$$

and solving for the aspect ratio

$$
\mathrm{AR}=\frac{2 F}{1-F}
$$

gives an equation for an apparent aspect ratio as a function of $F$.

This apparent aspect ratio is used directly in the post-stall data synthesization routines. 
Once the values of $a$ and $a^{\prime}$ have been found, the local thrust and torque coefficients can be calculated. After algebraic manipulation, the local thrust coefficient $C_{T 1}$ is

$$
C_{T 1}=W^{2} \sigma\left(C_{L} \cos \phi+C_{D} \sin \phi\right),
$$

and the local torque coefficient $\mathrm{C}_{\mathrm{ql}}$ is:

$$
C_{q 1}=W^{2} \sigma R\left(C_{L} \sin \phi=C_{D} \cos \phi\right) / \cos \psi \text {. }
$$

The local power coefficient is equal to the local torque coefficient times the tip speed ratio.

The total thrust, torque, and power coefficients are then found by integrating the local values over all stations. Note that all coefficients are normalized by the hub height mean velocity and the projected area. The projected area of the entire rotor is equal to $\pi \mathrm{R}_{\mathrm{T}}{ }^{2} \cos ^{2}$. 


\section{SECTION 4.0}

\section{TEST CASES}

The effect of the nonuniform flows and dynamic stall was tested on several test cases using the new code. These test cases cover the four types of nonuniform flows, as well as combination of those flows. Eight cases were considered. They are

- Uniform flow

- Wind shear, one seventh power law

- Tower shadow

- Wind shear and tower shadow combined

- Yaw error, $20^{\circ}$

- Wind shear, tower shadow, and yaw error combined

- Turbulence, intensity of $20 \%$ and a frequency of two cycles per revolution

- Turbulence, intensity of $20 \%$ and a frequency of three cycles per revolution.

Each of these cases was run both with and without the effects of dynamic stall (except, of course, the uniform flow case).

It was desirable to subject two different turbines to these cases. In selecting which two turbines to consider, several factors had to be examined. First, test data should be available on the turbine power output. Sufficient information should be available so that the shaft power output can be determined, as normally only the electrical power output is measured. The computer code predicts shaft power. The turbines considered should have a downwind rotor so that tower shadow will have an effect on the turbine. Finally, there should be some configurational difference between the two turbines considered.

The two turbines selected are the Mod 0 in the aileron control configuration, and the Enertech 44/25. For the Mod 0, data of direct shaft power measurements are available for direct comparison with the computer predictions. It operates in the downwind configuration and is thus subject to tower shadow. In addition, it has a tower height that is small with respect to the rotor diameter, thus making it subject to a larger wind variation over the rotor due to wind shear. The Mod 0 uses an untwisted, tapered blade with a NACA 23024 airfoil. The rotor is teetered for load relief. PROP does not take teeter into consideration, thus resulting in some inaccuracies. It was hoped that the analysis of this turbine would help evaluate the magnitude of those inaccuracies. 
The second turbine considered, the Enertech 44/25, has three blades and a rigid hub. The rigid hub of this turbine allows for direct comparison between the computer prediction and the measured power curve without the effects of teeter. The Enertech rotor operates downwind and in the tower shadow. The hub is quite high in comparison to the rotor diameter, so the effects of wind shear should not be very apparent.

The blades of the Enertech have a small amount of twist and taper. The airfoil is a 44 series NACA section, with a thickness of $24 \%$ near the root, tapering to $12 \%$ at the tip. At the three-quarter radius station the blade thickness is $18 \%$. When the rotor was analyzed, the airfoil section thickness change was not accounted for, and the data for the $18 \%$-thick airfoil were used in order to have the results of the prediction comparable to previous work (Tangler 1983). Test data on the Enertech have been taken at Rocky Flats. These data give the electrical power output of the turbine as a function of wind speed. Data on the efficiency of the power train allow for the determination of the shaft power developed by the rotor. Table 4-1 gives the power curve for the Enertech with the blades set at a pitch setting of $0^{\circ}$ at the tip.

\subsection{TEST CASE RESULTS}

A few remarks can be made that generally cover all the test cases considered. First, the nonuniform flows made almost no difference in the turbine performance. Peak power output was almost always decreased by the presence of nonuniform flow, but only by a few percent. Dynamic stall had an even smaller effect. In many cases the dynamic stall results are virtually indistinguishable from the nonuniform flow results. What effect dynamic stall had was almost always negative: rotor power was reduced.

\subsection{MOD 0 TEST CASES}

The first test case for the Mod 0 is the uniform flow case. Figure 4-1 shows the results for this case at the design pitch angle and design $\pm 2^{\circ}$. Also shown are the experimental data. Agreement between the experimental data and theory is good up to $9 \mathrm{~m} / \mathrm{s}$. Between 9 and $13 \mathrm{~m} / \mathrm{s}$, the theoretical curve lies slightly above the experimental curve by a maximum of $5 \mathrm{~kW}$. Above that speed the experimental data begin to diverge to higher power levels than predicted. Overall, agreement is good, the differences being equivalent to less than $1^{0}$ of pitch at any given wind speed.

It should be mentioned that the closeness of the agreement is, in part, due to the maximum lift coefficient used in the input data. The 23024 airfoil has a maximum $C_{L}$ of 1.2 at the Reynolds number of the Mod 0 blade. However, observation of the actual blade used in these tests by the author indicated that there was a small amount of aft camber on the aileron section of the blade. Thus, it was felt that increasing $C_{L} \max$ to 1.4 was justified. If a value of 1.2 is used, PROP will underpredict the experimental data by about $15 \mathrm{~kW}$. 
Table 4-1. Power Curve for the

Enertech 44/25

\begin{tabular}{cccc}
\hline $\begin{array}{c}\text { Wind } \\
\text { Speed } \\
(\mathrm{m} / \mathrm{s})\end{array}$ & $\begin{array}{c}\text { Electrical } \\
\text { Power } \\
(\mathrm{kW})\end{array}$ & $\begin{array}{c}\text { Power } \\
\text { Train } \\
\text { Efficiency }\end{array}$ & $\begin{array}{c}\text { Shaft } \\
\text { Power } \\
(\mathrm{kW})\end{array}$ \\
\hline 5 & 1.25 & 0.30 & 4.2 \\
6 & 3.5 & 0.64 & 5.5 \\
7 & 8.8 & 0.79 & 11.1 \\
8 & 13.0 & 0.79 & 16.5 \\
9 & 17.5 & 0.77 & 22.7 \\
10 & 20.5 & 0.72 & 28.5 \\
11 & 22.3 & 0.68 & 32.8 \\
12 & 24 & 0.65 & 36.9 \\
13 & 25 & 0.64 & 39.1 \\
14 & 25.5 & 0.63 & 40.5 \\
15 & 26 & 0.62 & 41.9 \\
\hline
\end{tabular}

A second consideration is the rotor rate of rotation used in finding power output from the coefficient data found by PROP. In the stall region the power is approximately proportional to the cube of the rotor rotation rate. Thus, prediction accuracy is increased if the rotation rate at full power is used; that is, the slip of the induction generator is accounted for. For the Mod 0 , the slip at full power is $3 \%$.

A full listing of the input data used for the Mod 0 and Enertech turbines is given in the example runs shown in Appendix C.

The next case is the Mod 0 in wind shear. The results for this case are shown in Figure 4-2. The uniform flow case is shown along with the nonuniform flow case and the dynamic stall case. The three curves are essentially identical. Neither nonuniform flow nor dynamic stall have much of an effect on the turbine performance. It is instructive to examine this case more closely to see why these results are obtained.

Figure 4-3 shows the time history of 1 ift and drag coefficients of a blade element located at 0.75 radius. The rotor was operating at a tip speed of 4.2, which results in this element moving in and out of stall. The figure shows the time history of the nonuniform flow case with and without dynamic stall. For most of the cycle, the curves are identical. They separate as 


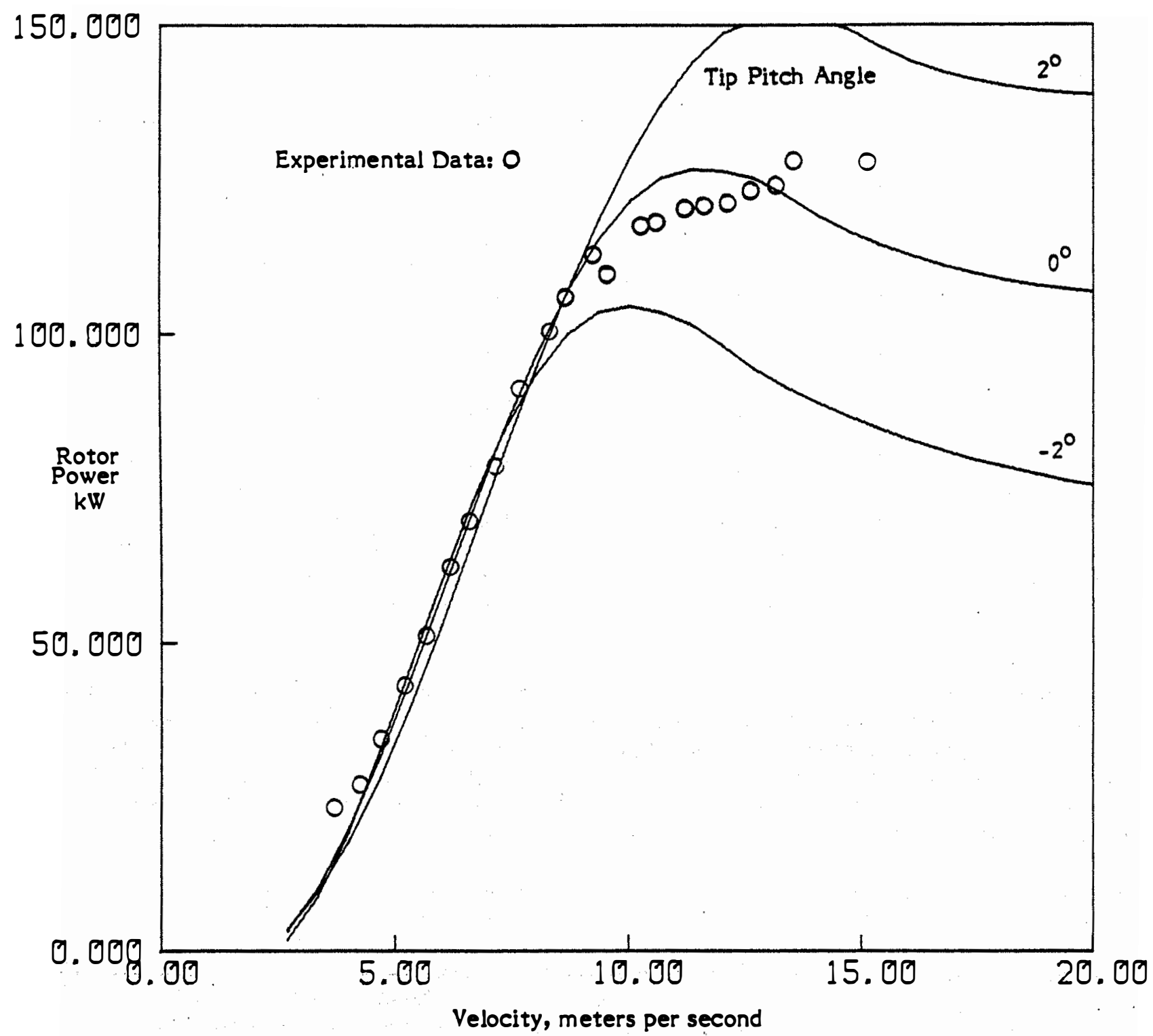

Figure 4-1. Mod 0 Performance in Uniform Flow, Comparison to Experimental Data 
150.000

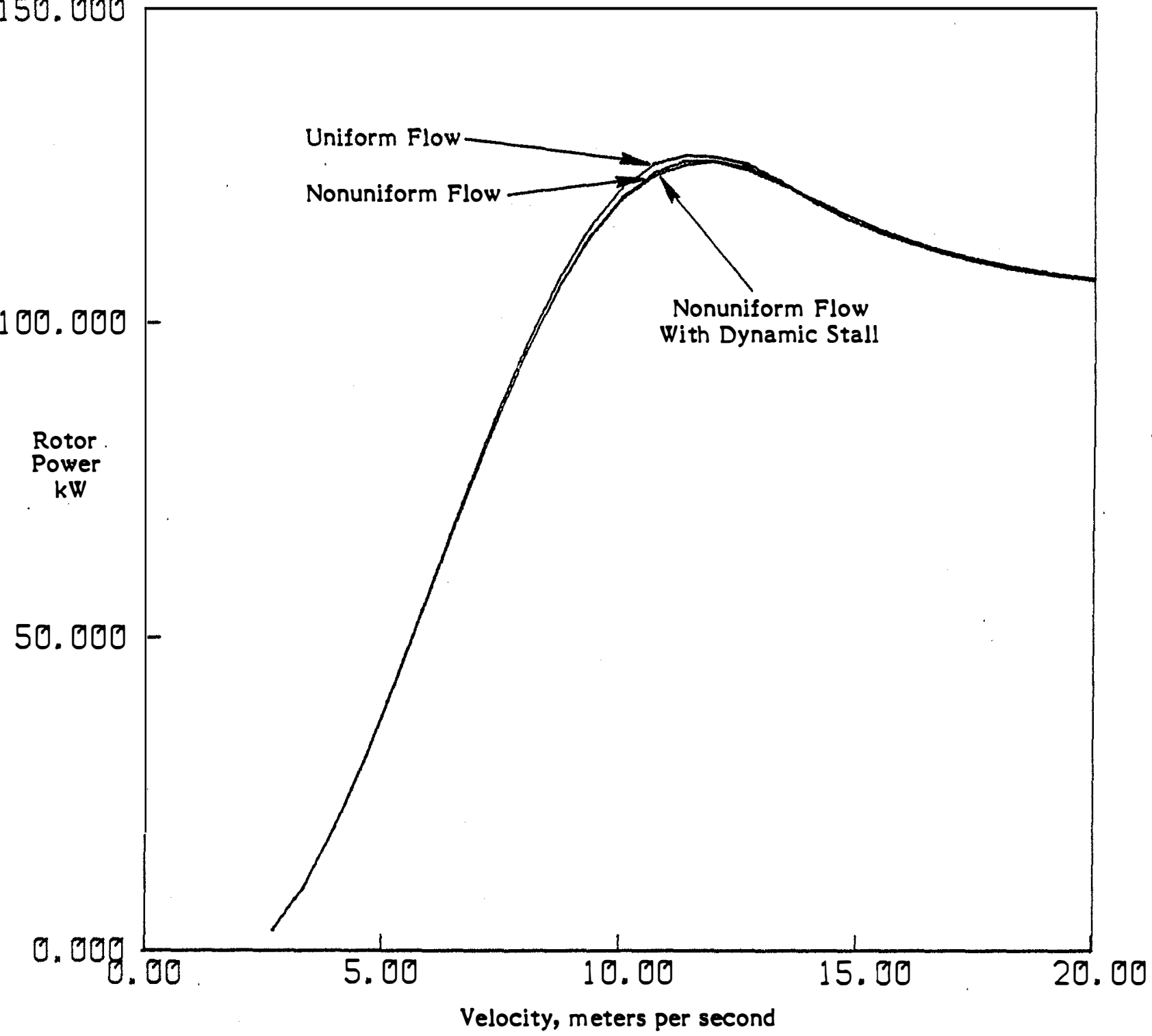

Figure 4-2. Mod 0 Performance with Wind Shear 


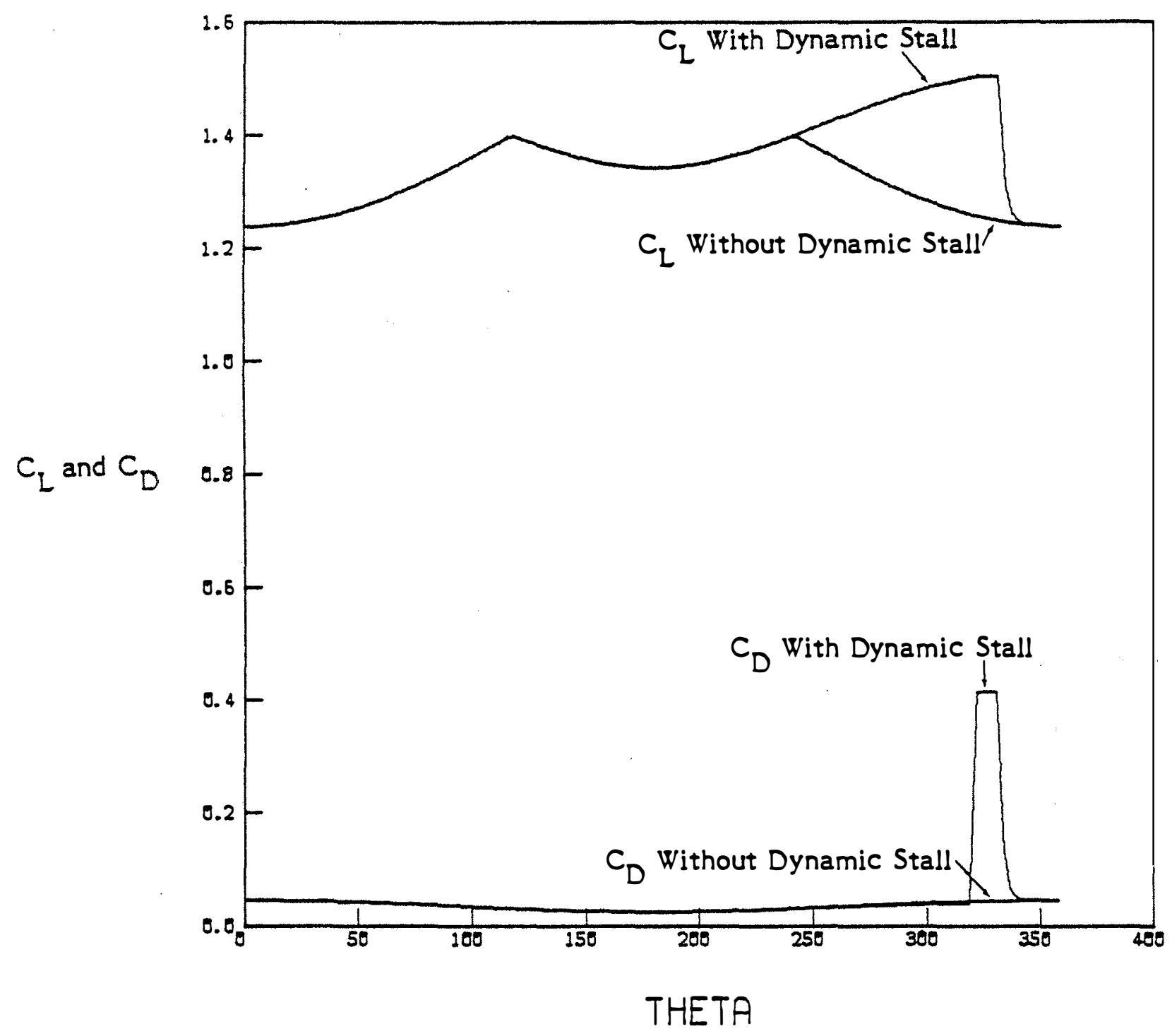

Figure 4-3. Lift and Drag Coefficent Time Histories for the Mod 0 Turbine Blade at $R / R=0.75$ and a Tip Speed Ratio of 4.2, both with and without the Effects of Dynamic Stall 
the blade enters the stall region at about a $\theta$ angle of $15^{\circ}$. Note that the dynamic stall lift coefficient curve does indeed show some increase in 1 ift, which should generate extra power. The drag coefficient also shows an increase, decreasing the power output. These two effects tend to cancel each other, resulting in almost no net change in the power output. The hysteresis loop for this case is shown in Figure 4-4.

It would appear from these results tha a small change in the dynamic stall model may cause a large change in the results. The effects of the lift coefficient increase would no longer balance the effects of the drag coefficient increase. To test this idea, a sensitivity run was made in which the increase in the drag coefficient was eliminated. This shows the sensitivity of major changes in the model.

Figure 4-5 shows the power curve prediction with the modifed model. Also shown is the uniform flow results and the nonuniform flow without dynamic stall results. The effect of dynamic stall is still small, adding only $5 \mathrm{~kW}$ to the peak power.

Although dynamic stall results in little change in performance, it does result in significant changes in the cyclic loads as seen by the blade. The peak-to-peak variation in the 1 ift coefficient is nearly doubled. The peakto-peak variation in the drag coefficient is increased by a large factor. It would appear that dynamic stall has an impact on both the flatwise and edgewise cyclic fatigue loads.

Figure 4-6 shows the results for the tower shadow case with the Mod 0 . The tower shadow was assumed to have a total width of 0.114 times the rotor radius, and a deficit of 0.4 times the undisturbed flow velocity. Again, the effects of the nonuniform flow as dynamic stall are very small. When wind shear and tower shadow are combined, the turbine performs as shown in Figure 4-7. The decrease in peak power caused by the two nonuniform flows combined is larger than either shown. In fact, the deficit appears to be approximately equal to the deficit caused by each of the nonuniform flows added together.

The case with a $20^{\circ}$ yaw error is shown in Figure 4-8. The results show that yaw error does not reduce peak power output, but shifts it to a higher wind speed. In fact, the entire power curve has been stretched to higher wind speeds. Again, dynamic stall has almost no effect. Figure 4-9 shows the results of shear, shadow, and yaw error combined. The same stretching of the power curve to higher wind speeds is apparent. However, the effects of the other nonuniform flows do not appear to be very great. The effects of each nonuniform flow are not adding in a linear fashion.

Figures 4-10 and 4-11 show the effects of two cycles per revolution and three cycles per revolution turbulence. Turbulence has the largest effect on peak power of all the nonuniform flows. At high wind speeds, turbulence increases the power output. The result is that the curve is flattened. Figure 4-8, showing the yaw error case, shows a similar result. The power curve with the nonuniform flow is somewhat flattened. As operation off axis is a likely result of operation in turbulence, it would appear that turbulence can flatten the power curve through several means. 


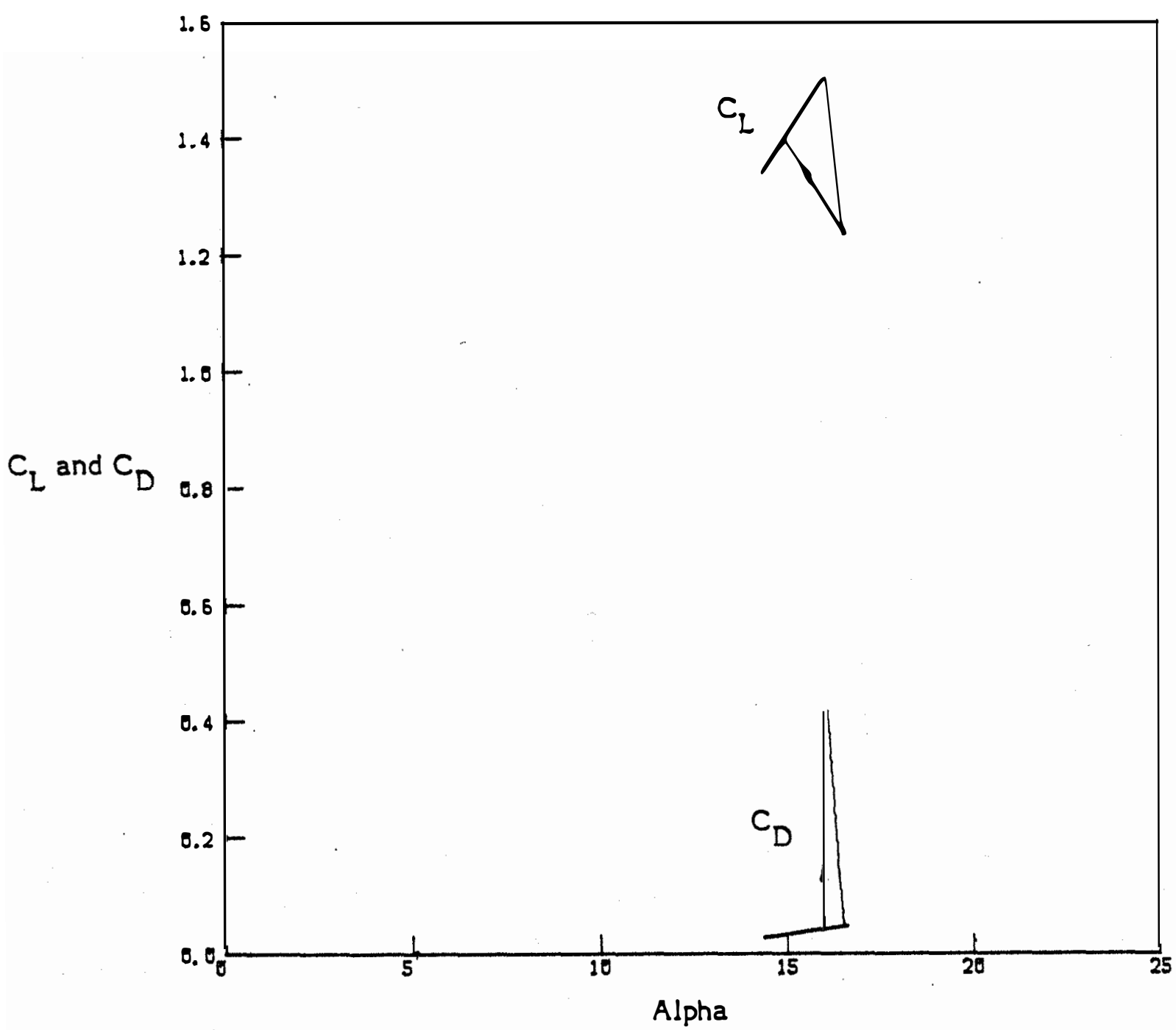

Figure 4-4. Lift and Drag Coefficient Hysteresis Loops for the Mod 0 Turbine Blade at $R / R_{0}=0.75$ and a Tip Speed Ratio of 4.2 


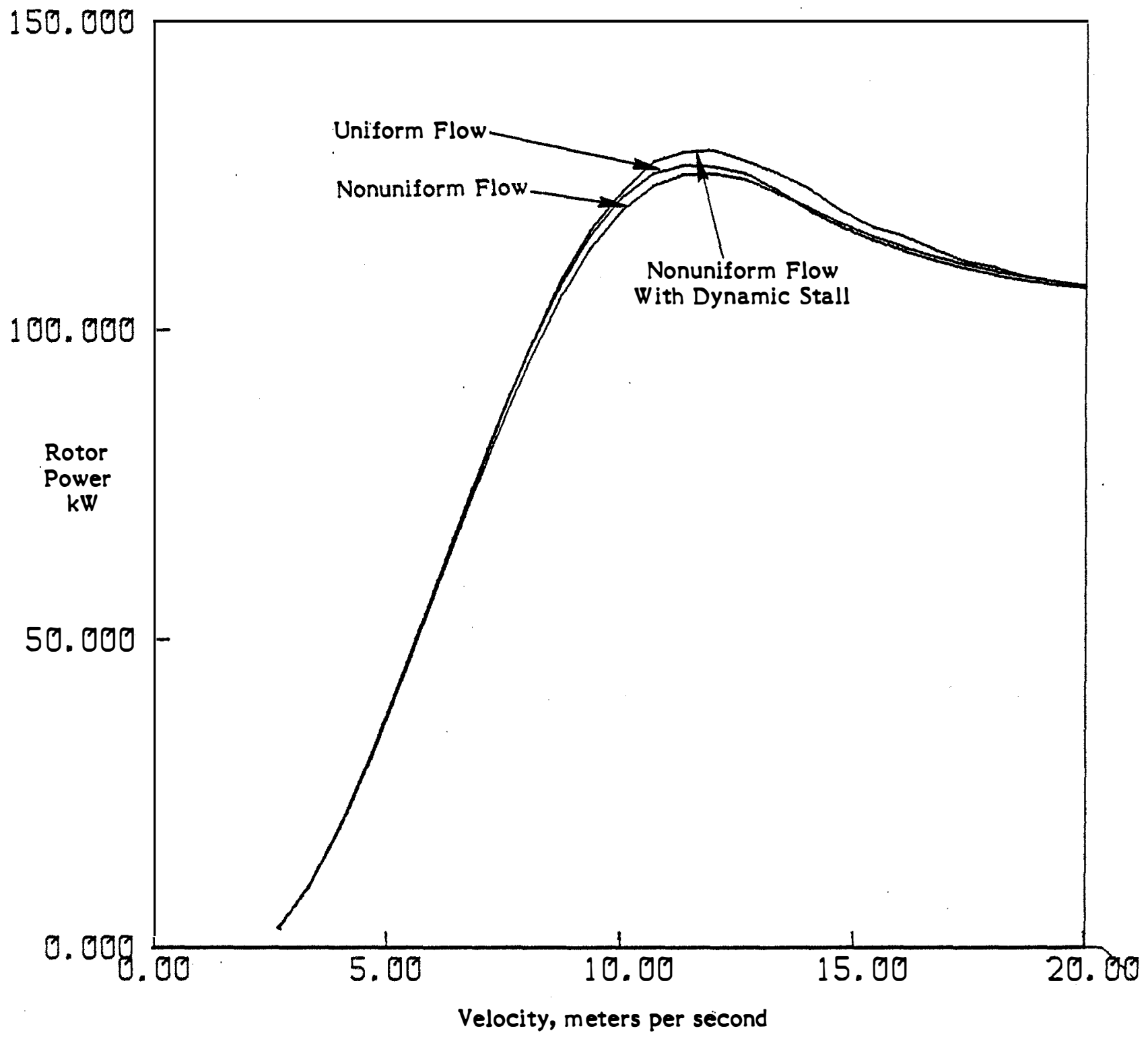

Figure 4-5. Mod 0 Performance with Wind Shear and Tower Shadow, Drag Rise during Dynamic Stall not Included 


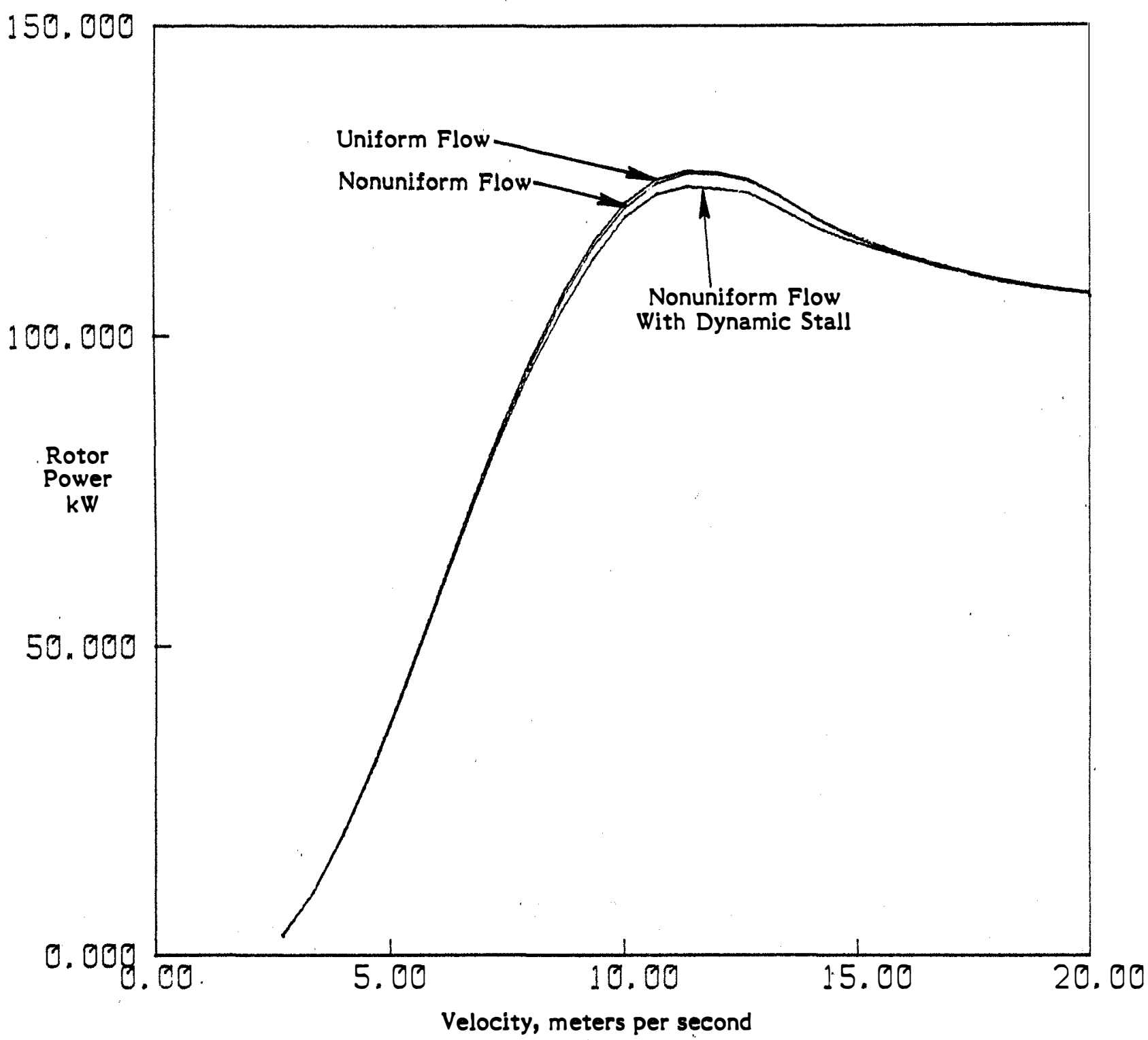

Figure 4-6. Mod 0 Performance with Tower Shadow 


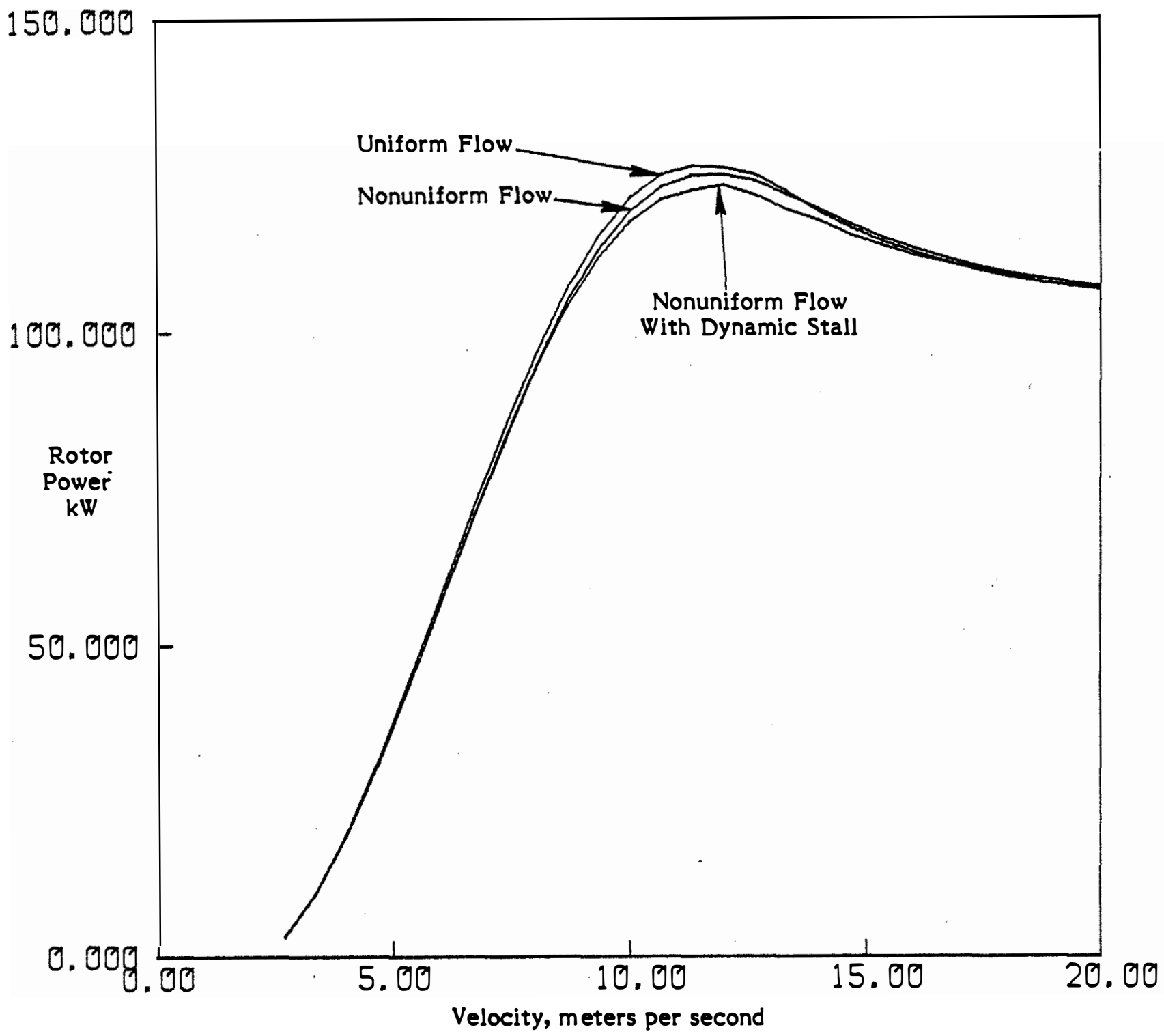

Figure 4-7. Mod 0 Performance with Wind Shear and Tower Shadow 


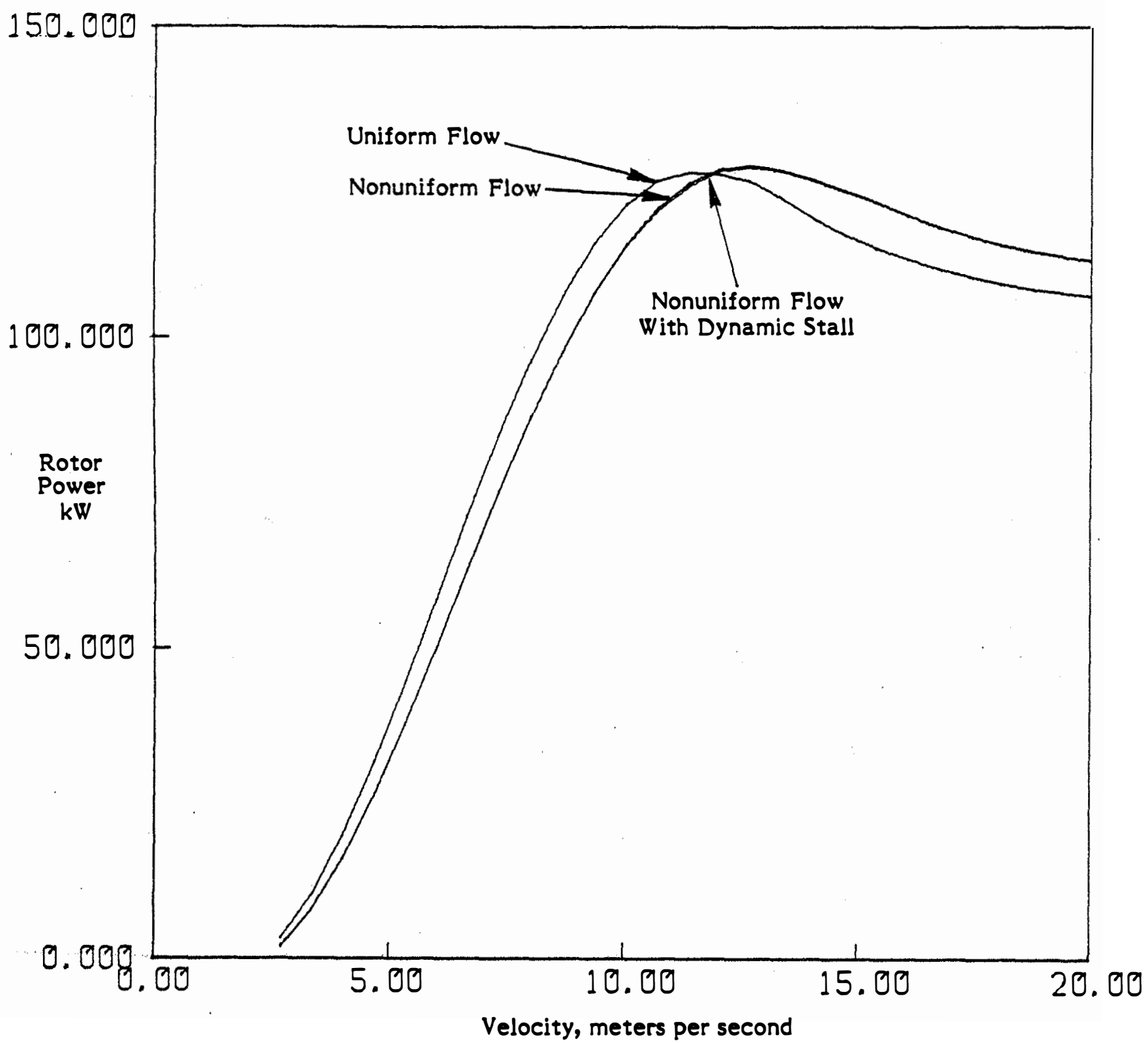

Figure 4-8. Mod 0 Performance with $20^{\circ}$ Yaw Error 


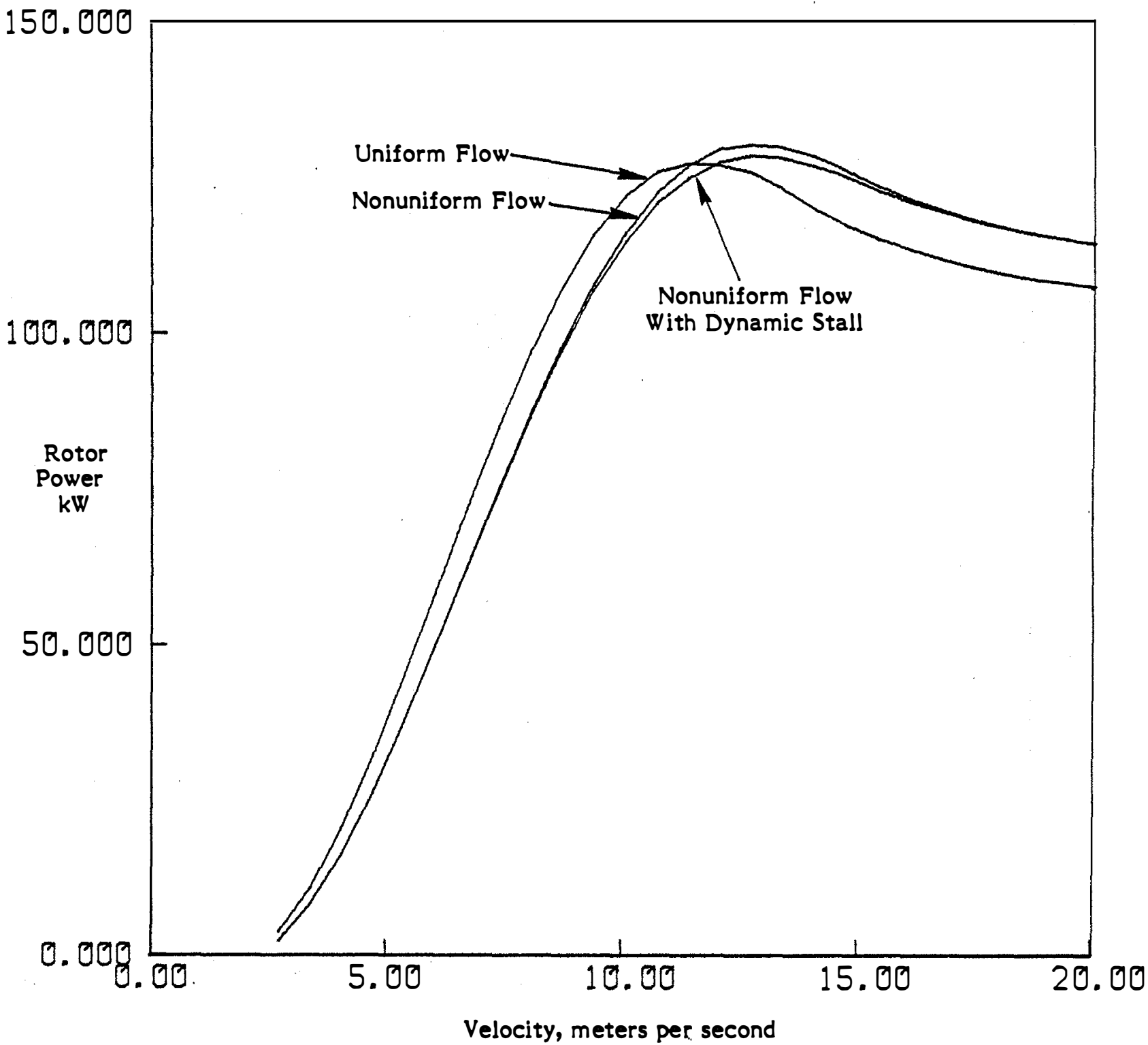

Figure 4-9. Mod 0 Performance with Wind Shear, Tower Shadow, and Yaw Error 


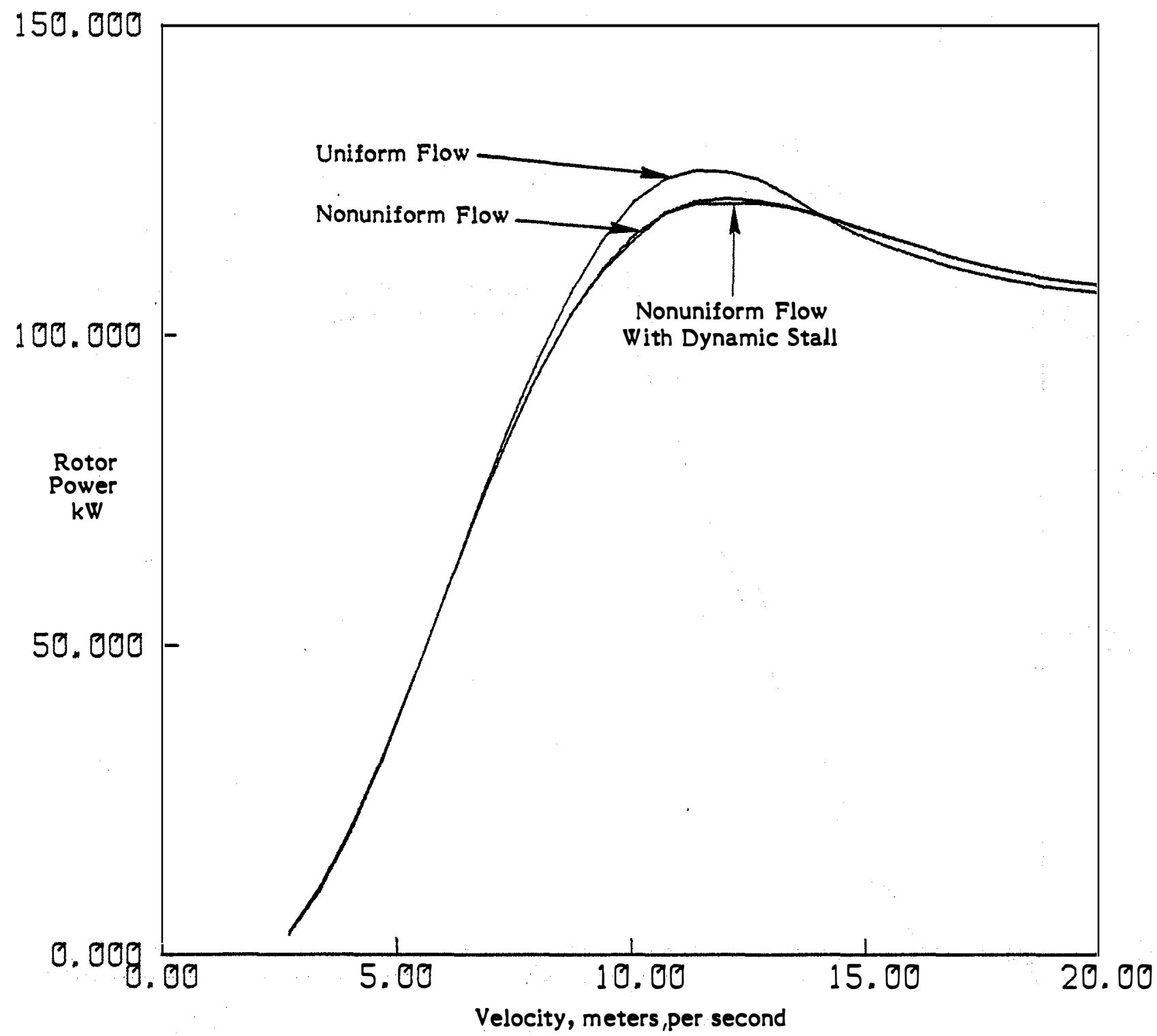

Figure 4-10. Mod 0 Performance with Two Cycles per Revolution Turbulence 
150.000

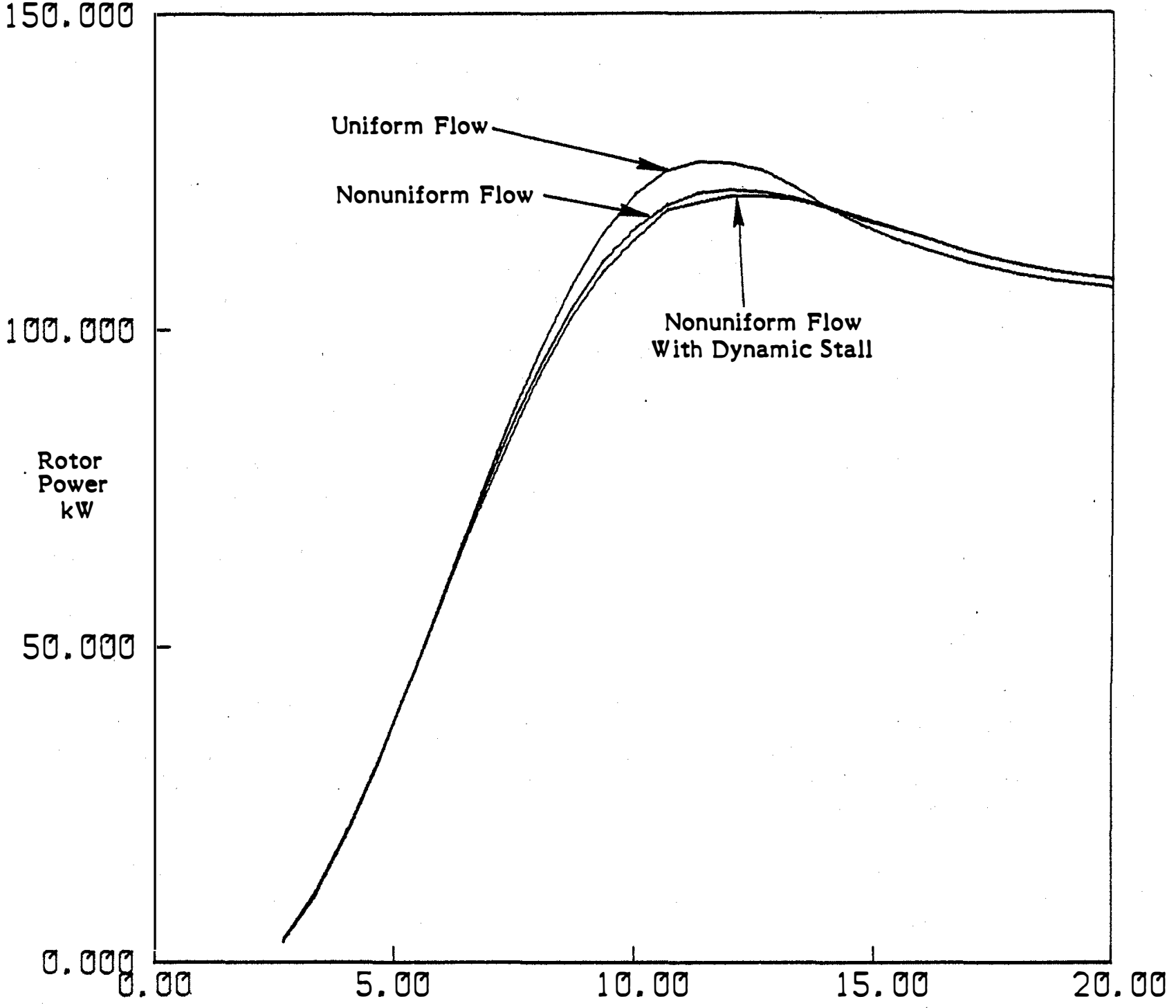

Velocity, meters per second

Figure 4-11. Mod 0 Performance with Three Cycles per Revolution Turbulence 


\subsection{ENERTECH TEST CASES}

The uniform flow case is shown in Figure 4-12, along with the test data. The test data lie very close to the prediction at $2^{\circ}$ tip pitch angle. It is possible that this difference may be due to the airfoil used by Enertech, which has a dropped leading edge and is thus not a true NACA 44XX series airfoil. This modification can be expected to result in an increase in the maximum lift coefficient. The effect of this increase in lift coefficient is similar to the effect of an increase in the pitch angle; more power in high winds. However, this does show quite graphically the difficulty in predicting peak power.

The case with wind shear showed no difference in performance from the uniform flow case. This case is not shown. The case with tower shadow is shown in Figure 4-13. For the Enertech, the tower wake was assumed to have a total width of 0.173 rotor radii, and a maximum deficit of 0.83 times the local undisturbed flow. Again, the effects of nonuniform flow or dynamic stall are minor. These effects are mainly seen at wind speeds below peak power, in contrast to the Mod 0 where the effects were greatest near peak power. This is most likely due to the lower tip speed ratios of the Enertech at peak power ( 2.7 for the Enertech versus 3.7 for the Mod 0 ).

The case with both wind shear and tower shadow has almost the same performance as the case with tower shadow alone, and hence is not shown.

Figure 4-14 shows the performance prediction for the Enertech with a $20^{\circ}$ yaw error. The same trend of the curve being "stretched" to higher wind speeds is seen, as it was with the Mod 0 . In addition, the tendency for the power curve to flatten out at high wind speeds is quite apparent.

Figures 4-15 and 4-16 show the two turbulence cases: two cycles per revolution and three cycles per revolution. The turbulence tends to reduce the peak power and flatten the power curve, as was seen before. Dynamic stall has a somewhat more than negligible effect on performance at wind speeds just below the rated wind speed.

The last case, wind shear, tower shadow, and yaw error, is shown in Figure 4-17. This case bears a strong resemblance to the case with yaw error only. The only notable aspect is that the peak power seems to be increased slightly by the nonuniform flows. 


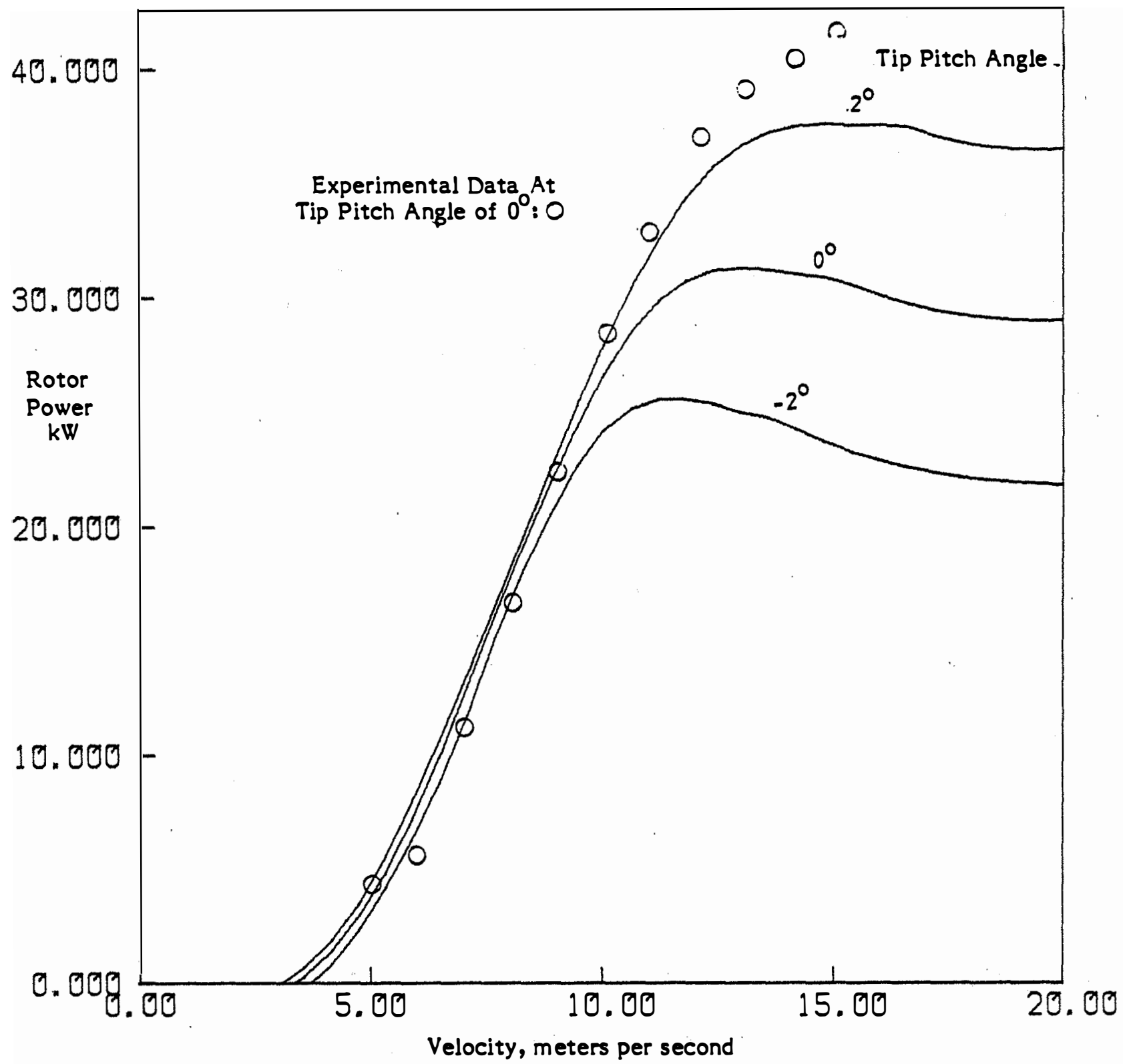

Figure 4-12. Enertech 44/25 Performance, Uniform Flow 


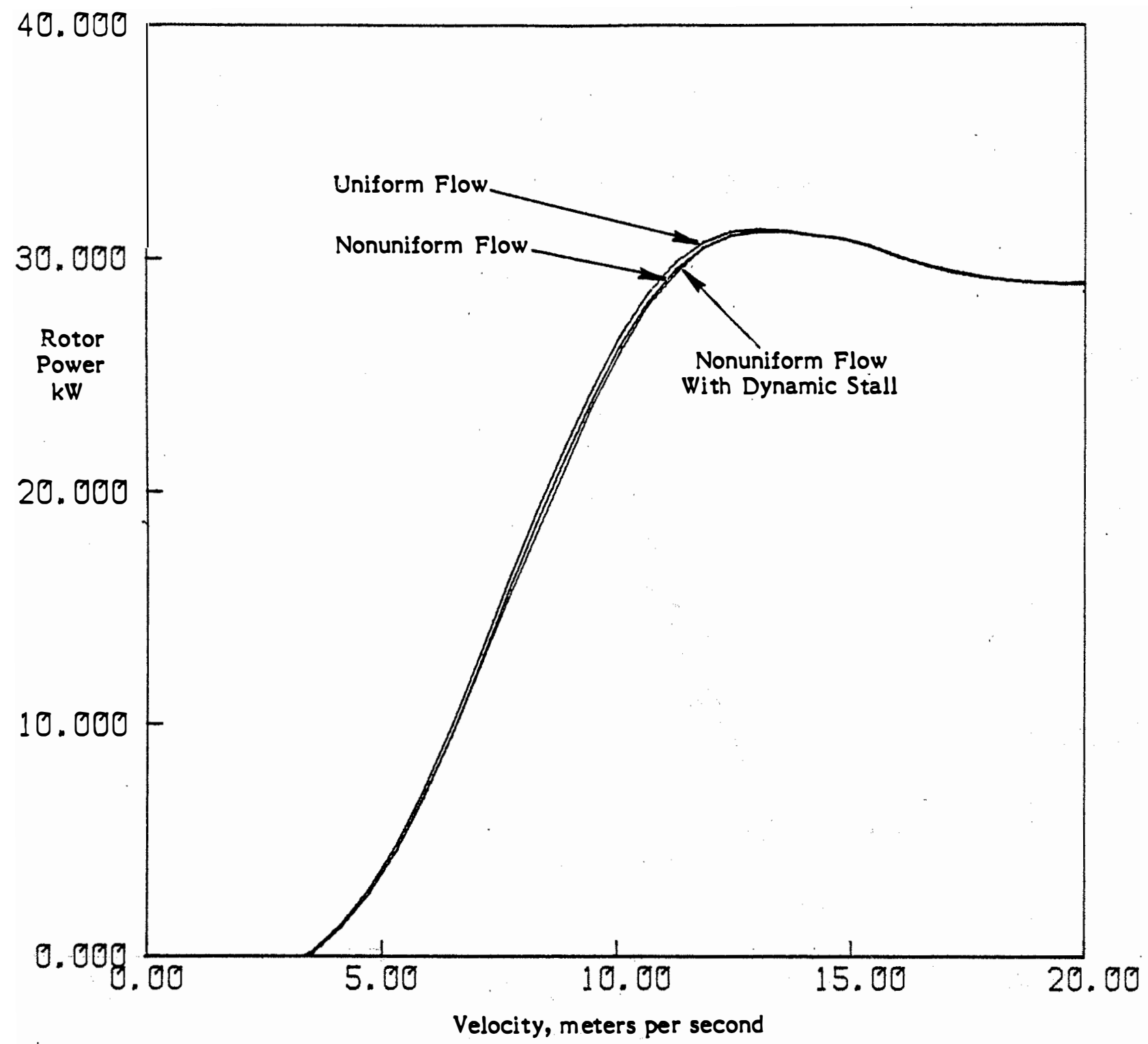

Figure 4-13. Enertech 44/25 Performance with Tower Shadow 


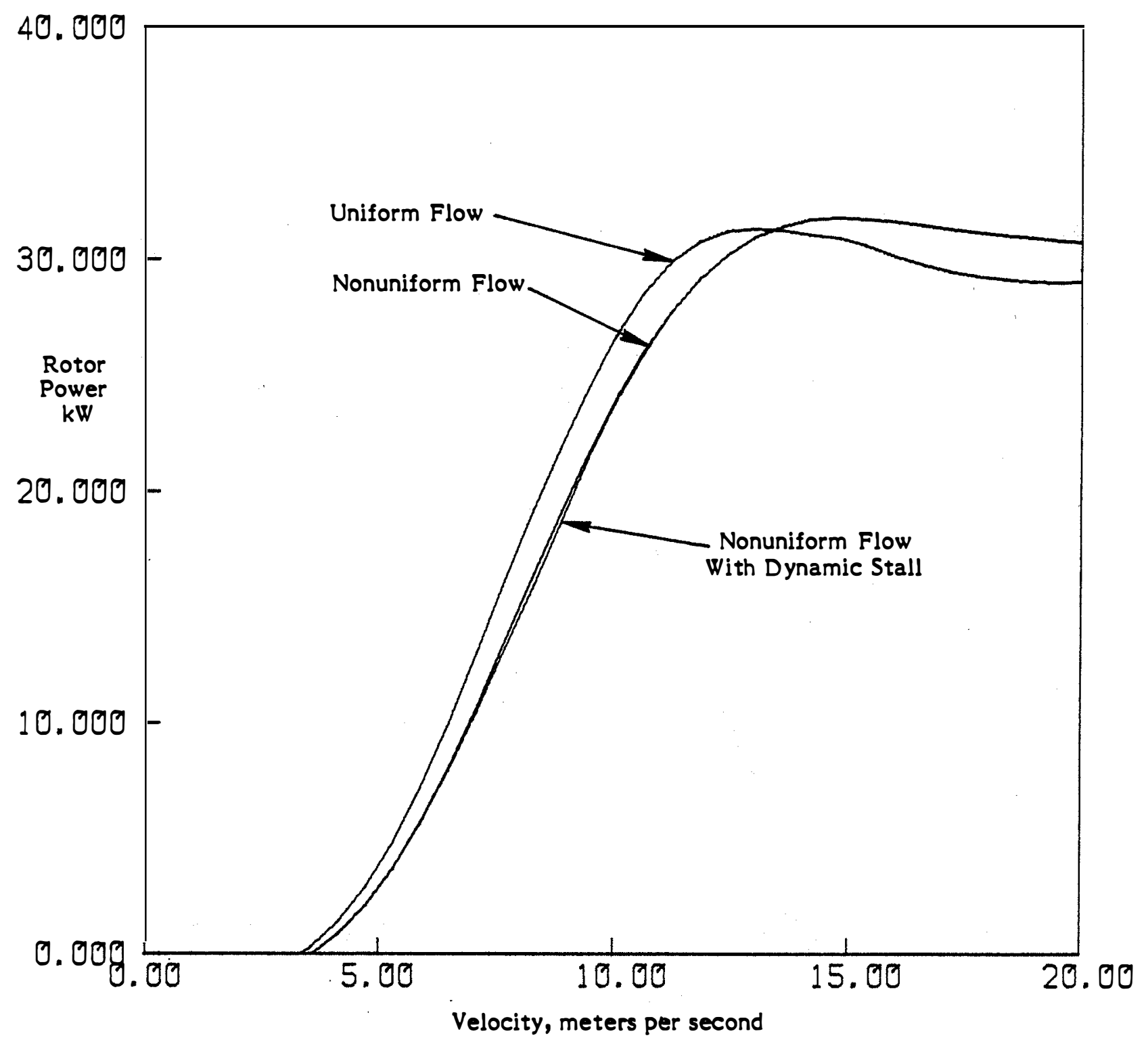

Figure 4-14. Enertech 44/25 Performance with $20^{\circ}$ Yaw Error 


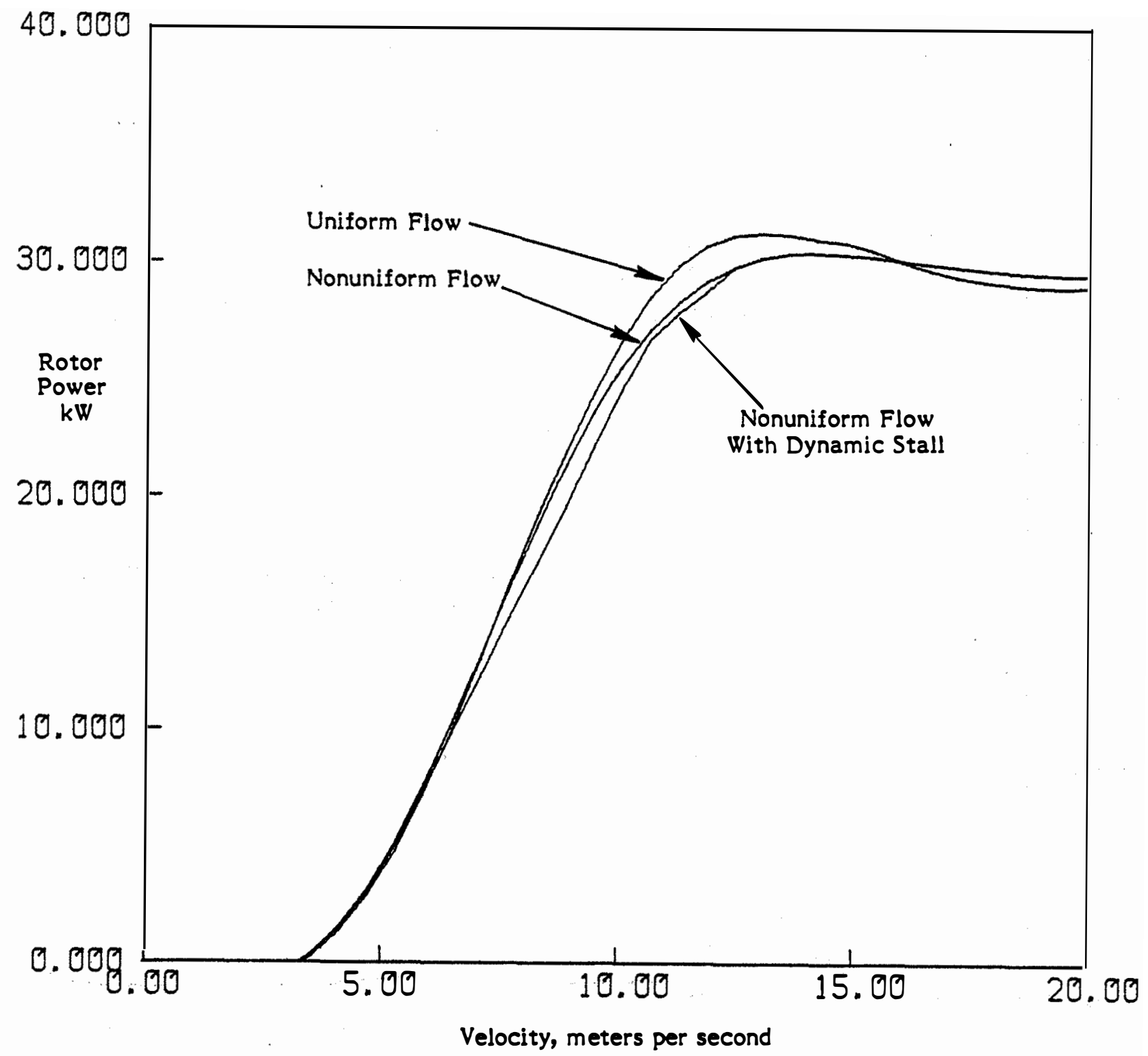

Figure 4-15. Enertech 44/25 Performance in Two Cycles per Revolution Turbulence 


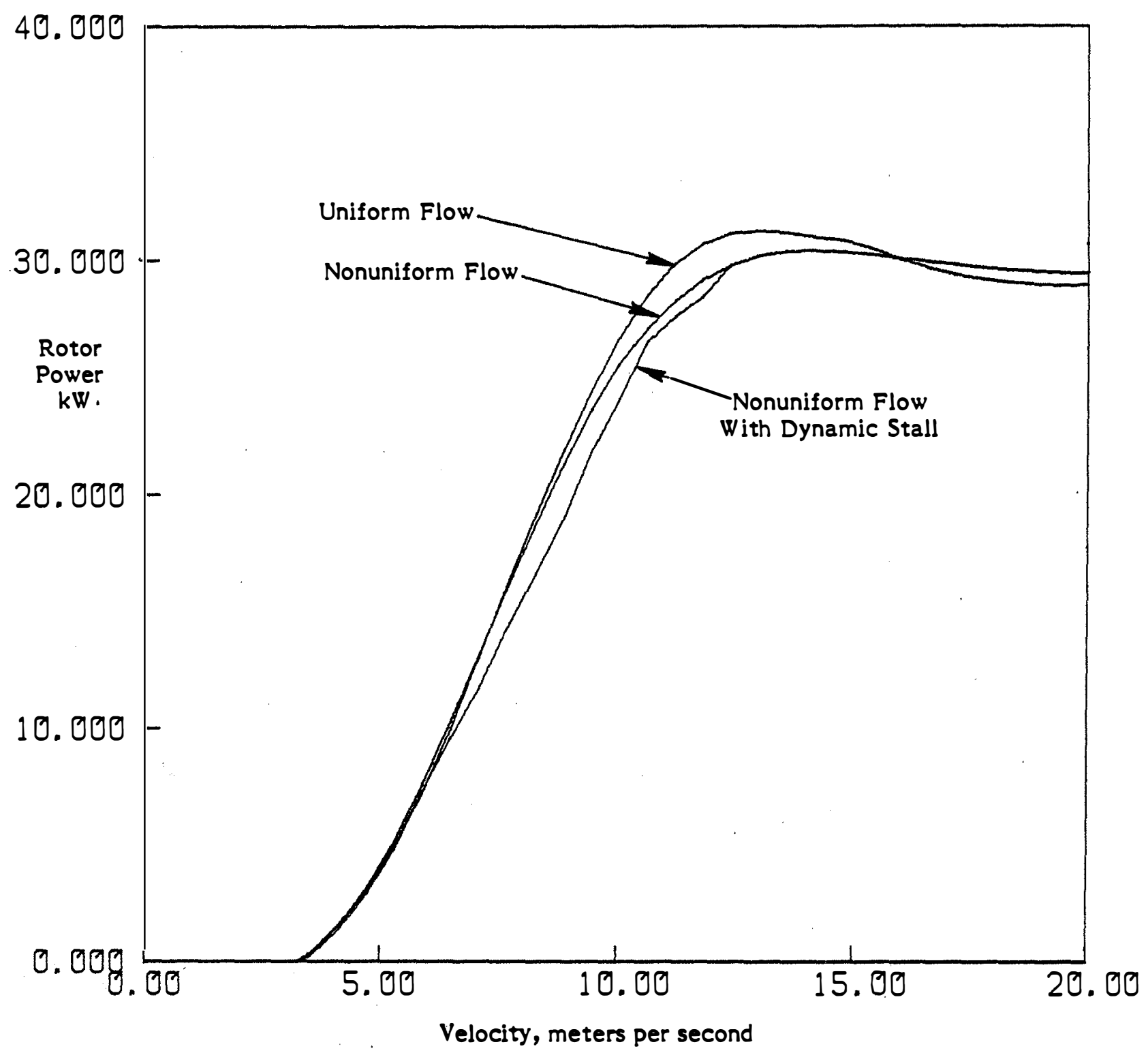

Figure 4-16. Enertech 44/25 Performance in Three Cycles per Revolution Turbulence 


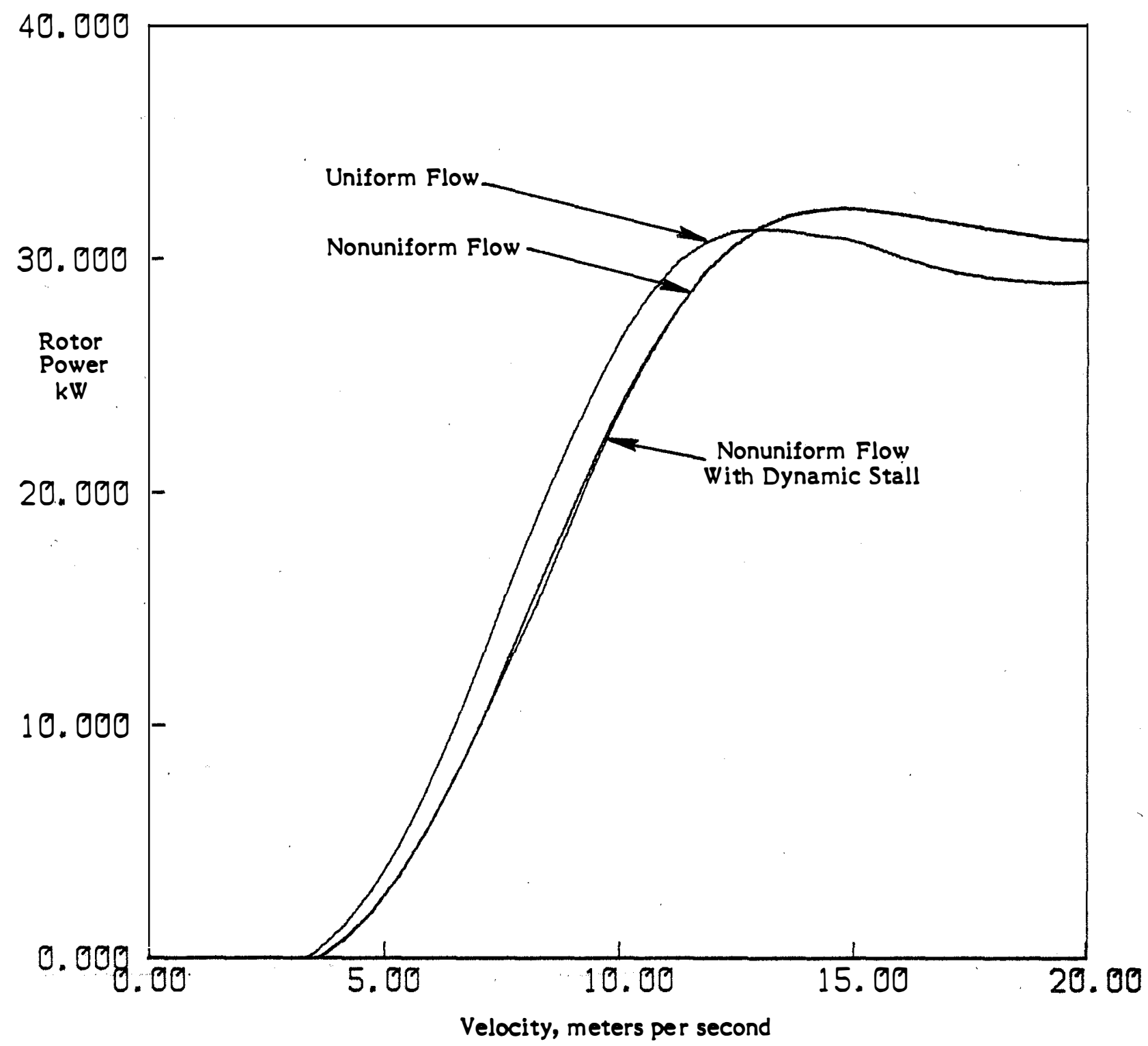

Figure 4-17. Enertech 44/25 Performance with Wind Shear, Tower Shadow, and $20^{\circ}$ Yaw Error 
SECTION 5.0

\section{CONCLUSIONS}

A modified version of the rotor analysis program PROP has been developed. This new code incorporates several improvements. The rotor geometry can be described at arbitrary radial points, instead of at 10 equally spaced points. The rotor disc can be divided into an arbitrary number of radial and circumferential stations for analysis purposes. The turbine performance can be analyzed under the influence of four differnt types of nonuniform flow: wind shear, tower shadow, turbulence, and off-axis flow. The effects of dynamic stall, as determined by the MIT model, can be included. The program outputs the dimensionless turbine performance as well as dimensional values.

The new computer code was exercised on two turbines, the Mod 0 with aileroncontrolled blades and the Enertech 44/25. Each of these turbines was examined under seven conditions of nonuniform flow involving various combinations of the four basic nonuniformities both with and without the effects of dynamic stall included.

The results showed that the nonuniform flows caused about a $2 \%$ change in the peak power prediction in most cases. Both increases and decreases in peak powers were predicted for different cases. Dynamic stall caused even less of a change in performance, and generally that change was toward lower performance. Detailed analysis of the results showed that the 1 ift rise associated with dynamic stall caused a performance increase, but the drag rise caused a performance loss. These two effects tend to cancel. A sensitivity run was conducted in which the drag rise was eliminated. This gave a performance increase of about $5 \%$. This is a first order change to the dynamic stall method and thus a significant perturbation, consequently it indicates the maximum theoretical performance change expected from dynamic stall.

The nonuniform flow cases that caused the greatest changes were the turbulence and yaw error cases. For both these nonuniform flows the power output is reduced for wind speeds below rated, peak power is either reduced or unchanged, and power output in high winds is increased. The net result is that the power curve is shifted in a way that makes it resemble the experimental curves more closely, although the peak power output prediction is still low; that is, below that experimentally measured.

It is concluded that dynamic stall has little significant effect on the performance of horizontal axis wind turbines. Most strip theory models underpredict the peak power output of turbines, but this discrepancy does not appear to be due to not taking dynamic stall into account. It now appears that the discrepancy betwen theory and experiment may be due to other effects that have not been incorporated in the PROP model. Some likely effects are: radial flow causing delay in blade stall and creating aerodynamic performance different from dynamic stall; aeroelastic twist of the blades due to aerodynamic loads causing the rotor twist geometry to vary from the nominal settings; and improperly modeled airfoil characteristics in the stall region. Other poststall routines, like those given by Viterna and Corrigan (1981), may be an improvement in this area. 
An additional conclusion is that dynamic stall increases the cyclic loads, both flatwise and edgewise seen by the blades. This may be an important consideration in the fatigue analysis of the blade. 


\section{SECTION 6.0}

\section{REFERENCES}

Gangwani, S.T., 1981, "Prediction of Dynamic Stall and Unsteady Airloads for Rotor Blades," Proceedings of the 37th American Helicopter Society Annual Forum.

Glauert, H., 1935, "Airplane Propellers," in Aerodynamic Theory, W.F. Durand, ed., Vol., IV, Division L, Chapter VII, Section 4, Berlin: Julius Springer, pp. 169-360.

Hibbs, B., and R. L. Radkey, 1983, Calculating Rotor Performance with the Revised "PROP" Code, RFP-3508, UC-60, February.

McCroskey, W. J., 1981, "Dynamic Stall on Advanced Airfoils Sections," Journal of the American Helicopter Society, Vol. 26, July.

McCroskey, W. J., 1982, "Unsteady Airfoils," Annual Review of Fluid Mechanics, Vol. 14.

McCroskey, W. J., 1983, An Experimental Study of Dynamic Stall on Advanced Airfoil Sections, Volume 2: Pressure and Force Data, NASA-TM-84245-Vo1-2.

Nol1, R. B., and N. D. Ham, 1983, Study of Dynamic Stall as it Affects Smal1 Wind Energy System Design, Aerospace Systems, Inc. report prepared for Rockwell International Corporation.

Rogers, J. P., 1984, "Application of an Analytic Stall Model to Time History and Eigenvalue Analysis of Rotor Blades," Journal of the American Helicopter Society, January.

Tangler, J. L., 1983, "Assessment of Blade-Element/Momentum Analysis for Horizontal Axis Wind Turbines," presented at Wind Workshop VI.

Tangler, J. L., and C. Ostowari, 1984, "Horizontal Axis Wind Turbine PostStall Airfoil Characteristics Synthesization," DOE/NASA HAWT Workshop, May.

Viterna, L. A., and R. D. Corrigan, 1981, "Fixed Pitch Rotor Performance of Large Horizontal Axis Wind Turbines," presented at the DOE/NASA Workshop on Large Horizontal Axis Wind Turbines, Cleveland, Ohio, July. 


\section{APPENDIX A}

\section{NOTES ON NOMENCLATURE}

The NUPROP computer program is designed to handle both wind turbines and propeller rotors. It should be noted that the standard definition of power coefficient for propellers is not the same as the one used for wind turbines. For propellers, the power coefficient is found by normalizing power by $\rho n^{3} \mathrm{D}^{3}$, where $\rho$ is the density, $n$ is the rate of rotation in cycles per sef̧ond, and $D$ is the diameter. For wind turbines, the normalizing factor is $\rho V_{0}^{3} \pi R^{2}$.

In propeller nomenclature, both power coefficient definitions are used, and both are loosely called the power coefficient. However, the wind turbine definition is normallyy given the variable name $P_{C}$, and the propeller definition is given the variable name $C_{p}$. These are the conventions used in the NUPROP code, and we distinguish between them by calling $P_{C}$ the power coefficient and $C_{p}$ the coefficient of power.

Below is a list of the definitions used in the NUPROP code.

Coefficient of power:

Coefficient of torque:

Coefficient of thrust:

Diameter:

Advance ratio:

Rotation rate, cycles per second:

Power:

Power coefficient:

Torque:

Torque coefficient:

Radius :

Thrust:

Thrust coefficient:

Free stream velocity:

Tip speed ratio:

Density:

Rotation rate, medians (second):

$$
\begin{aligned}
& C_{P}=P /\left(\rho n^{3} D^{5}\right)=2 \pi C_{Q} \\
& C_{Q}=Q /\left(\rho n^{3} D^{5}\right) \\
& C_{T}=T /\left(\rho n^{2} D^{4}\right) \\
& D=2 R \\
& J=V / n D=\pi / X
\end{aligned}
$$

n

$$
\begin{aligned}
& \mathrm{P}=\frac{1}{2} \rho \mathrm{V}_{0}^{3} \pi \mathrm{R}^{2} \mathrm{P}_{\mathrm{C}}=\rho \mathrm{n}^{3} \mathrm{D}^{5} \mathrm{C}_{\mathrm{P}} \\
& \mathrm{P}_{\mathrm{C}}=\mathrm{P} /\left(1 / 2 \rho \mathrm{V}_{0}^{3} \pi \mathrm{R}^{2}\right)=8 \mathrm{C}_{\mathrm{p}} /\left(\pi \mathrm{J}^{3}\right) \\
& \mathrm{Q}=\frac{1}{2} \rho \mathrm{V}_{0}^{2} \pi \mathrm{R}^{3} \mathrm{Q}_{\mathrm{C}}=\rho \mathrm{n}^{2} \mathrm{D}^{5} \mathrm{C}_{\mathrm{Q}} \\
& \mathrm{Q}_{\mathrm{C}}=\mathrm{Q} /\left(1 / 2 \rho \mathrm{V}_{0}^{2} \pi \mathrm{R}^{3}\right)
\end{aligned}
$$

$\mathbf{R}$

$$
\begin{aligned}
& T=\frac{1}{2} \rho V_{0}^{2} \pi R^{2} T_{C}=n^{2} D^{4} C_{T} \\
& T_{C}=T /\left(1 / 2 \rho V_{0}^{2} \pi R^{2}\right)=8 C_{T} /\left(\pi J^{2}\right)
\end{aligned}
$$

vo

$X=\Omega R / V=\pi / J$

o

$\Omega=2 \pi n$ 


\section{APPENDIX B}

\section{USER'S GUIDE FOR THE PROGRAM PROP}

The modified version of the PROP computer code, called NUPROP, is written as an interactive program. The programming language is FORTRAN. When run, NUPROP displays a menu of 12 commands. After each command is completed, the menu is again displayed. Each of the menu commands is explained below.

\section{- Command 1 -- Radius of Each Station}

In NUPROP, the blade chord, twist, and airfoil section data can be defined at arbitrary radial stations. Values at intermediate points are formed as required. This command is used to define the raidal position of each station. The program asks for the number of stations, and then the normalized radius of each staion. The number of staions should be between 2 and 20 . The radial values should be in the range zero to one, with the first value being near the hub (and usually at the inner end of the blade), and the last point near the tip (usually with a value of one).

\section{- Command 2 -- Airfoil Section Data Input}

This command allows the airfoil 1 ift and drag characteristics to be defined at each station. At each staion the user is asked which input mode is to be used to define the data. The possible modes are:

Mode -1: Input the data from a disc file. The user will be asked for the file name.

Mode 0: Keyboard input.

Mode 1 to 20: Copy the airfoil section data from Station 1 to 20. This mode is useful when the blade has the same airfoil along its entire span. The first station is input using either Mode -1 or Mode 0 , and then the Station 1 data are duplicated at all other stations by using Mode 1.

The input format for the section data used for Modes -1 and 0 is as follows:

The first value input is the number of points used to define the lift coefficient curve. This is followed by angle of attack and 1 ift coefficient values, one set per line. The lowest angle should be entered first. After the appropriate number of data points have been entered, the number of points used to define the drag coefficient curve is entered. The angle of attack and drag coefficient values are then entered in a manner similar to the lift coefficient values. After the appropriate number of data elements have been input, the program will move on to the next station.

For Mode -1 the above data are contained in a disc file. For Mode 0 they are entered from the keyboard in response to queries. 


\section{- Command 3 -- Rotor Characteristics}

The user is queried for the following information: Number of blades, cone angle, and hub radius.

The cone angle is in degrees, and the hub radius is normalized and usually set to the radius of station 1 , as defined by Command 1 .

The tip and hub loss models to be used are asked for. Currently only the Prandt model or no loss model are available.

- Command 4 -- Blade Chord and Twist

The user is queried for the chord and twist at each station as defined by Command 1. The chord is normalized by the blade length and the twist is in degrees, positive being leading edge into the wind.

\section{- Command 5 -- Real Rotor Data}

This command provides output giving dimensional values for the rotor performance. The rotor radius (in meters), rate of rotation (in RPM), and fluid density (in kilograms per cubic meter) must be input.

\section{- Command 6 -- Analysis Parameters}

This command allows the user to define the number of radial and circumferential elements to be analyzed, and some other analysis parameters.

The user is first queried for the radius range over which to analyze and the number of radial elements to analyze. Normally the radius range should be from the hub to the tip. Other values are also useful, for isolating a portion of the rotor for detailed analysis, or rotor design work. The number of radial elements can have any value, but experience has shown that 10 to 20 elements work best. Note that the number and position of the analysis elements need not have any relationship to the number and position of the radial station as defined by Command 1 .

Next the user is queried for the number of blade rotations to analyze over and the number of circumferential elements to consider. The values to use for these two parameters are highly dependent on the nonuniform flows that are 
being included in the analysis (see Command 7). The table below covers most of the cases.

\begin{tabular}{lcc}
\hline \multicolumn{1}{c}{ Case } & $\begin{array}{c}\text { Number } \\
\text { of Rotations }\end{array}$ & $\begin{array}{c}\text { Number of Circum- } \\
\text { ferential Elements }\end{array}$ \\
\hline Uniform flow & 1 & 1 \\
Wind shear & 0.5 & 5 \\
Tower shadow & 0.5 & 50 \\
Yaw error & 1 & 10 \\
Turbulence & $1 / 2$ cycle* & 10 \\
Dynamic stall & 1 or more & 100 or more
\end{tabular}

rExample: for turbulence with a frequency of three cycles per revolution, it would only be necessary to analyze over $1 / 6$ of a revolution.

Next the user is prompted for whether or not to suppress the swirl term. This should be answered with a " $Y$ " or " $N$ ". The swirl term is suppressed when a system that includes stator vanes or counter-rotating rotors is analyzed.

The user is then prompted for whether or not to analyze the rotor as a propeller, requiring answer " $\mathrm{Y}$ " or "N". Analyzing the rotor as a propeller changes the sign of the angle of attack, the interference factors, the torque, power, and thrust.

Lastly, the user is asked whether or not to include the effects of dynamic stall. Answer "Y" or "N" is required.

\section{- Command 7 -- Nonuniform Flow Input}

With this command the user may define the parameters of the four nonuniform flows considered by NUPROP. For wind shear, the user is prompted for the shear exponent and the hub height divided by the rotor radius. For tower shadow, the user is queried for the wake width and deficit. The width is defined as full width divided by the rotor radius. For turbulence, the user is asked for the turbulence frequency divided by the rotor rotation frequency, and the turbulence intensity as the peak variation of the wind speed divided by the free stream flow speed. For yaw error, the user is queried for the yaw error of the rotor in degrees. 
- Command 8 -- Rotor Analysis

This command results in the rotor, as defined by the above commands, to be analyzed.

The user is first queried for the collective pitch angles (delta beta) over which to analyze. Then the program asks whether or not to display the analysis results for each blade element. Answer " $Y$ " or " $N$ ". Answering " $Y$ " can result in an enormous amount of output. Next the user is asked whether to increment the variable $\mathrm{X}$, the tip speed ratio, or $\mathrm{J}$, the advance ratio for each analysis point. An answer of " $\mathrm{X}$ " or " $\mathrm{J}$ " is required. Then the user is asked for the range of $X$ (or $\mathrm{J}$ ) values over which to analyze.

Finally, the user will be asked where the output should go. Usually this will be a disc file. However, the output can be sent to the terminal or printer if the proper device name is given. These names are, of course, system dependent.

The analysis output first consists of a listing of all the input parameters. Then the analysis starts with the first collective pitch angle and the first $X$ or $J$ value specified. The $X$ or $J$ value is then incremented between each analysis until the maximum specified value is reached. The collective pitch angle is then incremented and the required $\mathrm{X}$ or $\mathrm{J}$ values are again analyzed. This continues until all of the collective pitch angles are examined.

\section{- Command 9 -- Change Blade Chord or Twist at One Station}

This command allows the blade chord and/or twist angle to be changed at any one station. Generally this command is used for rotor design studies.

\section{- Command 10 -- Augmentation Input}

With this command, the effects of a duct or shroud on rotor performance can be included. The flow velocity through the rotor is

$$
V_{x}=C_{m_{0}}-a M_{a}
$$


Normally for free rotors $C_{m}$ and $M_{a}$ have a value of 1.0 . For these cases, this command need not be used. Some values for $C_{m_{0}}$ and $M_{a}$ in various cases are given below.

\begin{tabular}{lcc}
\hline \multicolumn{1}{c}{ Case } & $\mathrm{C}_{\mathrm{m}_{\mathrm{o}}}$ & $\mathrm{M}_{\mathrm{a}}$ \\
\hline Free rotor (default) & 1 & 1 \\
Rotor in cylindrical duct & 1 & 2 \\
Rotor in a pipe & 1 & 0 \\
Free rotor with a large center body & $*$ & 1 \\
Rotor in a noncylindrical duct & $*$ & $*$ \\
\hline
\end{tabular}

*These values must be determined from potential flow theory based on the specific geometry.

- Command 11 -- Header Input

This command allows the user to input a run header. This header is printed out when the rotor is analyzed.

- Command 12 -- Exit; Terminates NUPROP

- Output

If blade element data are requested, then the program will output the following information:

For each collective pitch angle, advance ratio, blade element, and circumferential station, the values of the axial velocity component, $\underline{a}$, $\underline{a^{\prime}}, \phi, \alpha, C_{L}, C_{D}, P_{C 1}, Q_{C 1}, C_{P 1}, C_{T 1}$ and $n$ are output. 
For a complete rotor:

For each feather angle and advance ratio, the values of $x,{ }_{C}, T_{C}, Q_{C}$, ${ }_{C w}, J, C_{p}, C_{T}, n, F_{m}, V_{0}, P, T$ are output. Note that the last three values are dimensional. $T_{C_{w}}$ is the thrust coefficient based on integration of the inviscid portion of the wake. Generally, it is only useful for ducted props. $F_{m}$ is the propeller figure of merit.

- Program Listing

A listing of the NUPROP program follows. 
APPENDIX C

EXAMPLE OF RUN OF THE PROP CODE

This appendix contains two sample runs of the PROP code. One run is for the Mod 0 turbine operating in wind shear. The second is for the Enertech operating in uniform flow. The runs show typical output from the program, as well as the input data used to analyze the two turbines. 
FPODAAM NUPGOP

G AY PFOF PROQRAM, NON PLOTTING VERSION

DIMENSION AL, (50,20), CL, $(50,20), A D(50,20), 0 D(50,20)$

DIMENSION CH(20), TW(20), PV(12),CMO(20), OMA(20:

DIMENGION NFL ZOU, NFD(ZO), RSTAT ZOO

INTECER VAR, PUE(13), VACZ)

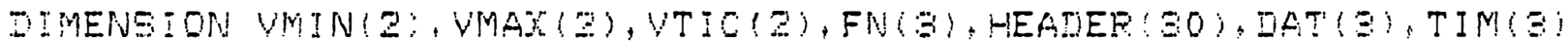

COMMON $x$, PC, TC, OC. TCW, A, OF, ET, ETA, FM, VELO, WWF, THF

OCMMON /ES/ERCODE

COMMON /DUNAMMMOEDT IOTLC

EOUIVALEOE $(F V ! 1), X$ )

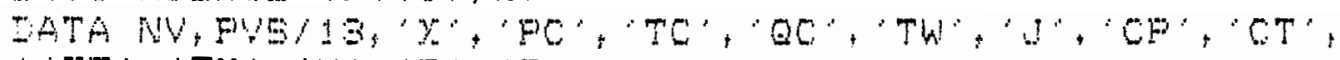

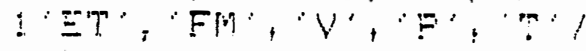

ZSTA CMO, CMA, COF, USEMF, HH, WEXF, YAW/4Z*1,0,2\%0,/

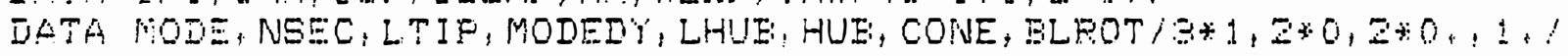

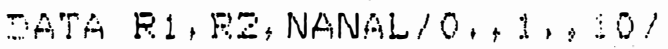

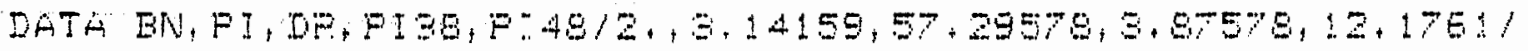

DATA FADIUE, RPM, FHO/1, 60, 1.1

DATA NETAT, ESTAT/10, 05, 15, 25, 35, 45, 55, 65, 75, 85, 95, 10*1,

IATA EFCODE / - $95999 . /$

- COMMEND INEUT

5 TTEE 1000

IOOS FORMAT! 1 FADIUS OF EACH STATION:'

+ - AIFEOIL, SECT:ON IIATA INFUT"

+3 DOTOF CHARAETERISTICS"

t 4 ELADE CHDED AND TWIST'/

+5 EEAL ROTOR STZE, SPEED'/

+ + 6 ANALYSIS PAPAMETEFS"

+7 NON UNIFORM FLOW INPUT'

* 8 ANALIZE THE YOTOS';

+ G CHANCE CHORI OF TWIST AT ONE STATION"

+ 10 AUGMENTATION :JFTA INPUT'?

+11 HEADER INIEUT"!

+12 EXIT:/1

+ \$COMMAND?" ")

ACCEPT *, II

COTO(50,100,200, $300,500,320,340,500,400,410,430,990), 12$

5

CTTATIEN RADIUS INFUT

D) TIPE 1001

1 UOL FORMAT ('FNUMEEP OF ETATIONS? ')

ACCEFT * NSTAT

DO $60 \quad I=1$, NSTAT

TIPE 1002 , I

JOG2 FORMATl"\$FOF STATIGN \# I3: RADIUS?"'

EO ACCEPT * RSTATIJ)

GOTOS

c

C ELEMENT CHARACTEFISTIC INEUT (CL,CD)

100 TIPE 1003

IOGG FORMATI" SECTION DATA INPUT SOURCES: " $i$

$1 \cdot-1$ DISC FILE INPUT' $;$

$1: 0$ TETBOAFD INPUT'

1. $1-10$ COPY FROM SECTION $1-10 \% 11$

DO $110 \quad I=1$, NSTAT

$\therefore 10$ GALIL SECTON:D, NFI. AL, CL, NFD, AD, CD)

COTOS

5

G POTOR CHARACTEFISTIC INFUT:

2DO TIFE 1004 


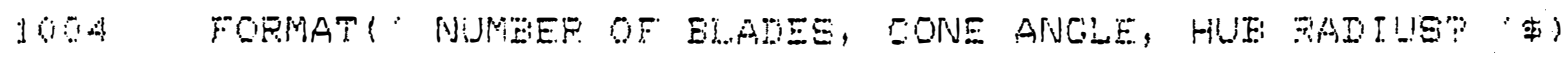
ACCEPT * IEN, CONE, HUE:

COP =OOS ICONE, IDP!

SIP=SIN, CONEIDK:

20 TIPE 1028

TYPE 1029

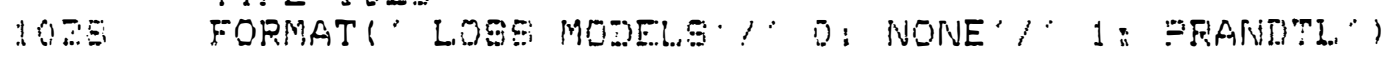

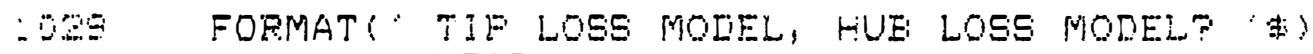

ACCEPT * LTIP, L.HUE:

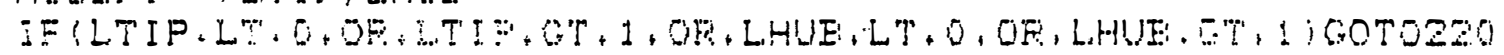

COTOS

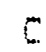

OINPUT STATION CHDFIS, TWIET

$200 \quad$ DO $: 10 \quad I=1, N S T A T$

TYPE $101:$ I I BSTAT" (I)

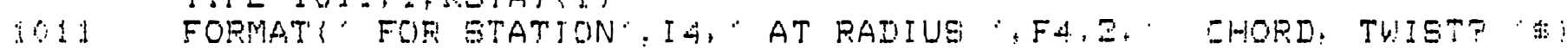
AOCEPT * CH(I), TWD

$T(W)=T W D i J P S$

::0 CON'TINUE

GOTO5

5

C ANALISES PARAMETERS

30 TYPE 1017

$101 \%$ FORMAT! 'WRAIUS BANGE TO ANALIZE: INNER, OUTER, \# OF EIEMENTE?:? ACCEPT *, P1, RE, NANAL

TYPE 1053

: 55 FORMAT! ELADE ROTAT:ONS TO AVERACE

$\therefore$ NUMEER OF ANNULAR STATIONS? "末

ACCEPT * BL,POT , NSEC

TYPE $102 E$

:026 FORMAT \{' SUPRPES SWIRL TEFM?' '\$)

ACCEPT 1023, MCM

DQZ FOPMAT $(A Z)$

USEAP $=1$.

IF (MCM . EQ + IH' USEAP $=0$.

$M O D E=1$

TYPE 1030

10.30 FORMAT! ANALYZE AS PROP? 's)

ACCEPT $1023, M C M$

IF (MCM, EQ, IHY) MOISE $=-1$

MODEDY $Y=0$

TYPE 1031

1031 FORMAT("WNCLUDE DYNAMIC STALL EFFECTS?"

ACCEPT 1023, MCM

IF (MCM, EQ, ' ' ' MODEYYY Y $=1$

COTOS

c

C VON UNIFORM FLOWS

310 TYPE 1052

$10 \%$ FORMAT!'

ACCEPT *, WEXP, HH

TYPE 1009

1005 FORMATl'\$OWER WAEE WIDTH, DEFICIT?" )

ACCEPT *, WWIDTH, WDEF

TYPE 1009

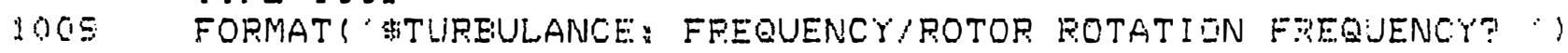
ACCEPT * FTURB

TYPE $101 E$

1016 FORMAT "\$TURBLLANCE INTENSIT'?")

ACCEPT * TLIRE I 


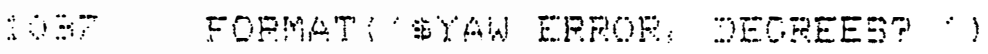

ACCEPT * TAW

GOTOS

5

CHAHE STATION WHOR, TWIST

SOO THE 0013

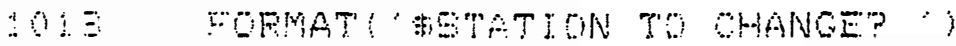

ACCEPT * :

TYPE $10:$ A, CHIS)

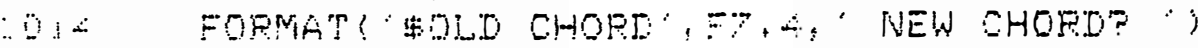

ACCEPT * OH!?

$T, D=?, 1, * 0 P$

TYPE 1015: TWW

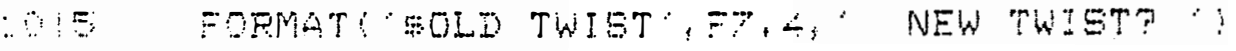

ACOEPT $*$ THE

TWIT:TWD $/ D F$

$\cot 05$

E

C AUGNENTATION INWU?

$40 \quad$ DO $4 \geq 0 \quad I=1$, NSTAT

TYFE $I 0 \pm B . I$

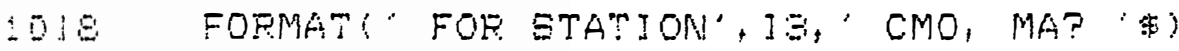

4 CO ACEEPT * CMO(J), CMAII)

GOTOS

(5

C MEATER INPUT

400 TYPE 1038

IOSE FOPMAT!'

ACCEPT 1OA1, HEFIDEF

$10 \therefore$ - FORMAT (30A4)

SOTOS

L

C PEAL OTOR DIMENSEONS

SOO TYPE 1007

1007 FOPMAT('\$ROTOF PADIUS (M), FATE OF POTATION (RPM)?') ACCEFT * RADIUS, RPM

TYOE 1010

:010 FORMAT("

ACCEFT *, RHO

COTOS

C

C ANALTEE FROF!!!

S SET RI IIF NEEDED\}, GE'T DELTA RADIUS

600 IFUPI.LT HUEIPI=HUE

DPAD $=(R 2-P I) / N A N A L$

TYPE 10.92

1052 FOPMAT!" DELTA BETA ANCLES: INITIAL, FINAL, INMEMENT? "\$) $A C C E P T *$ * FS, FF, FD

TYPE 1019

DIE FORMAT \{ SHOW ELEMENT DATA? "\$)

ACCEPT 1023 , IS

TYPE 1025

$10 \%$ FOPMAT! INGEEMENT $\approx$ OP I? "\$)

ACEEPT 1023 , INCV

TYPE 1020, INCW

SOE FORMATIA3, STAFT, ENJ, INCREMENT? "\$)

ACCEFT * XJS, XLE, DXU

TYPE 1005

1035 FORMAT! HOUTPUT TO ITT:, LE:, OR FILE NAME)?' ' 
ACCEPT IO:2, FN

1012 FOPMAT (BA.4)
OPEN(UNIT: 10 , NAME: $=$ FN:

5

OUTHTH WEADER

EOS CALL DATE(DAT)

CALL TIME (TIM)

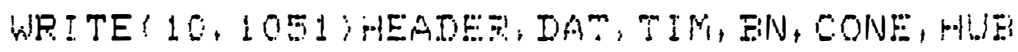

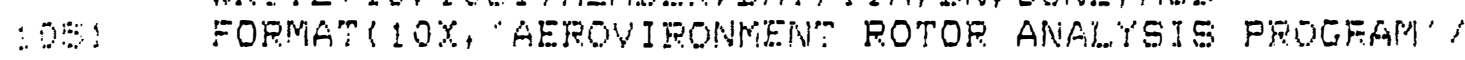

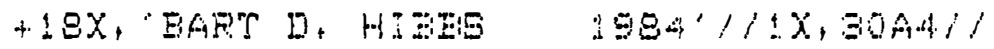

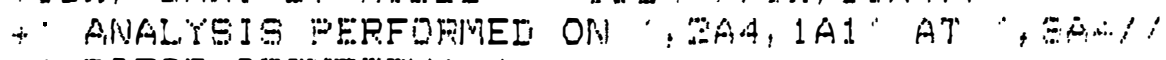

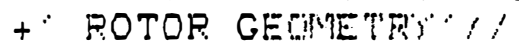

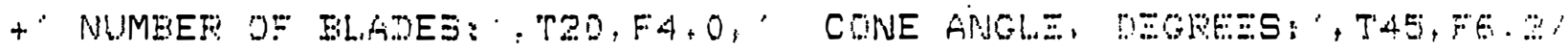

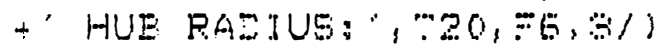

WHITE $(10,1029$ :

WFITE $10 ; 1040)$ IIT:F: L.HLE:

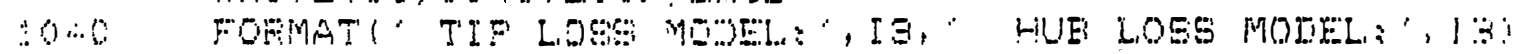

WFITE 10,1035 INSEE, E: FOT' RANAL, F1, RE

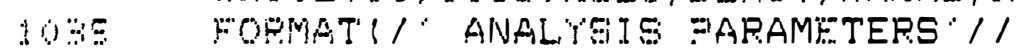

-I4, CIRCUMFERENTAL STATIONS ANALIZED OVER",F5.1. "ROTATIONS";

+ I3. ELEMENTS ANALIZED OVER A RADIUS RANGE FROM "F.5.

+1 TO,$F$, 3 )

IF (MODE, EQ, I)WRITE $(10,1033)$

IF (MODE, NE, 1) WPI I TE $(10,1034)$

1033 FORMAT! POTOR ANALYZED AS WINDTUREINE')

:OSL FORMAT ' ROTOR ANALYZED AS PROPELLER')

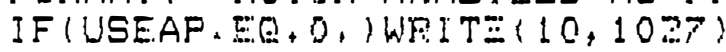

:OY FORMAT? SWIRL TEPM SUPPPESSED')

IF (MODE,NE. I) YOTO615

IF(MOLEDY EQ, 1) WSITE (10, (042)

$10 \therefore 2$ FORMAT! D'NAMIS STAl.L. EFFECTS INCLUDED';

WRI TE $(10,1054)$ WEXP, HH: WWIDTH, WDEF, TURE I, $\because A W$, FTUIFE

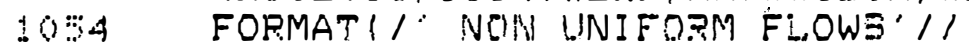

+'WIND EXFONENT:', T25,FE, 3,' HUE HEICHT/RADIUS:', T55,FE, 3/

+ TOWER WAKE WIDT:H: 'T25,FE, 3, 'WAKE DEFIEIT:', T'55, FE, 31

+ TUREULANCE IN:ENSITY: T25, FE, 3,

+" YAW ERROR, IIEGREES:' T55, FE , 31

EIE L WRITE(10,1005)RADIUS, RPM, RHO

$\therefore 005$ FORMAT $/ 1$ DIMENSIONAL VALLES' $/ 1$

+ POTOR RADIUS: " TZS.F9.1," M'/

+ ' ROTOR RATE OF ROTATION:' T25,F9, Z, 'RPM'

+ DENSIT': ', TZS,FI,, , KG/M**3')

WRI IE $(10,10.43)$

$10<3$

FOPMAT ( / ELADE

1, CIMO "MA')

DO EZO I=I, NSTAT

$T W D=T W(I) * D P$

520

$: 0.47$

WRITE $(10,1047) I, \operatorname{PSTAT}(I), \mathrm{CH}(I), \mathrm{TWD}, \mathrm{CMO}(I), \mathrm{CMA}(I)$

FORMAT (IE, 5F9, 4)

DO E.3O $I=1$, NSTAT

WP I TE $(10,1048)$ I

1048

FORMAT $/{ }^{\circ}$ AIRFOI

1. ALPHA CD')

$N=M A X O(N F L(I), N P D(I))$

DO $E 30 \mathrm{~J}=1, N$

10.49 FORMAT (2F9.4,5X, 2F9.4)

630

WRITE $(10,1049)$ AL (J, I), CL(J,I), AD (J,I), CDiJ,I)

C

CONTINUE 
C EMART WITH FERST FEATHER ANOLE

$F L=F E$

ON: $\quad E I P=F L I D S$

$\mathrm{C}$

CIPST X (OF U) VALUE

$X_{U}=X_{15}$

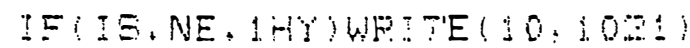

- PESET INTEQFATEN VALUES

TIO TS TO

$\mathrm{ge}=\mathrm{C}$

$T C b=0$.

- MHE TIPET $X$ OE I VALUE

$x=x !$

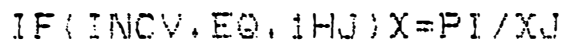

FEIIE,EO, IHY) WFITE(10,103E)FL, $x$

IOSE EOFMAT!' BLADE ELEMENT IATA FOR DELTA EETA=" FE. ${ }^{\prime}$ " $x={ }^{*}$,

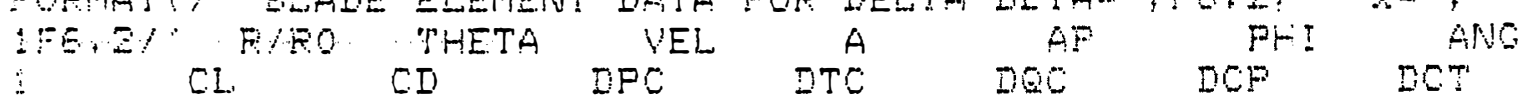
ETA:

- Lop thel all pajial elements

$7:$ DO 780 I $=1$, NANAL

C RADILS OF THIS SECTION

$F=D E A D *(I-.5)+P 1$

6 BHOFD, TWIET, AUGMENTAT:ON OF THIS SECTION

CHU =ALOOY (CH, RSTAT, R, NSTAT)

IF ICHU, EQ, ERCODEIGOTO990

TWU=ALOOE! TW, RSTAT, R, NSTAT ?

CMOU = ALOOK (CMO, PSTAT, R, NSTAT)

CMAU=ALOOK (CMA, RSTAT, R, NSTAT)

C PESET: GECTION DATA SUEROUTINE

I DFLC= 1

CALL SECIAT (CHU) R, PETAT, NSTAT, ANG, O , F;

1NPL, AL, CL, NPI, AI) CI, CLU, CII)

C FIRST GUUES FOF $A$, A PRIME

$A 1=0$.

$A P I=0$.

C SOLIIITY

$S L=E N * C H U 1\{P I * C O P * P * 2$,

C LOOP THPU ALL ANIULAR ELEMENTE

I) $790 \mathrm{NS}=1$, NSEC

THETA $=360 * * E L H O T *(N S-.5) / N S E C$

IDFLS $=2$

C NON UNIFOPM FLOW

CALL NUFL ( $V X, V C$, VR, $X, F$, THETA, HH, WEXP, WWI ITH, WDEE, FTUPE, TUREI, YAW)

C REEET A. A PRIME STEP VALUES

$A \mathrm{~K}=0.0$

$A B \mathrm{~K}=0.0$

C DTART OF I TERATION LOOP

C LOCAL AUGMENTATION

$730 \quad C M=C M O U-C M A U * A 1$

C LOCAL FLOW VELOCITIES

$V I=V X * C M * C O P+V P * S I P$

$V J=(1++A P 1) * P * 3 n+V C$

C INFLOW ANGLE

$\left.W=\operatorname{SQRT}\left(V I * * Z+V_{\downarrow}\right) * Z * 2\right\}$

$P=1.5 \%$

IF (VI, NE, O, ) P=ATAINZ (WI, VJ)

$I F(A E S(F), L T, I E-5) P=\lfloor E-5$

$\operatorname{CO}=\cos (P)$

$S I=S I N\{F\}$ 
C ANOLE OF ATTACK

$A=F-T W U-F L F$

$A N G=A * D P * M O D E$

C TIP AND HUE LOSSES

$F T=1$,

IF (LT IP, EQ, I) FT =PFAND (EN, 1, R, EI)

$F H=1$.

IF (LHUE, EQ, 1, AND, HUE, NE, O ) FH=PRAND (EN, R, HLIE, SI)

$C$ CLA AND CD

$F=F T * F H$

CALL SECDAT (CHU), R, RETAT, NSTAT, ANG, THETA, F,

INPL, AL, CL, NPD, AD, CD, CLU, CDD )

C FIND AZ

$C L L=C L U * M O D E$

ICH $=S L * W * W * G L L * C O /(V X * 2)$

IF $(D C H+L T,, 9 E) A Z=(, 5-, 5 * S Q R T(1,-D C H)) / F$

IF (ICH, GE, , 9E) AZ $=(, 143+5 Q R T(.0230-, 64 Z *(, 859-D C H)))^{\prime} / F$

C. FIND A PRIME 2

APZ $=\Xi L * C L L * W * U S E A P /(4, * F * X * R)$

C FINS NEW AI, API FOR. NEXT ITERATION

CALL AITER (AI, AZ, AK')

CALL AITER (API, APZ, APK)

790 IF(AES(AK), GT. .0001.0R.AES(APK),CT,.0001)60 T0730

C LOOP OVER, COMPUTE STUFF

C LOCAL VALUES

$P H I=P * D R$

$T C L=S L * W * W *(C I . L * C O+C D D * S I) * M O D E$

$Q C L=S L * W * W * R * M O D E *\{C: L * S I-C D D * C O\} / C O P$

$P C L=X * Q C L$

$T C L W=4, * A 1 * C M * F * M O D E$

$A 1=A 1 * M O D E$

AP. $1=A P I * M O D E$

$C T L=T C L * P I 3 B /(X * X)$

$C P L=P C L * P] 48 /(x * x * X)$

$\mathrm{ETA}=0$,

IF (PCL , NE , O, ) ETA $=A B S(T C L / P C L)$

IF (ETA , GT +1, ) ETA $=1$, /ETA

C. INTEGRATED VALUES

$T C W=T C W+T C L W * D R A D * 2$, *R/NSEC

$T C=T C+T C L * D R A D * Z, * R / N S E C$

$Q C=Q C+Q C L * D P A D * 2, * R / N S E C$

IF (IS, EQ , IHY) WRITE (1 , 1024)R, THETA, VX, A 1, AP 1, PHI, ANG, CLU, $1 C D D, P C L, T C L, Q C L, C P L, C T L, E T A$

1024 FORMAT (F⿻, 4,F $, 2,3 F 8,4,2 F 8,2,8 F 8,4)$

C TELL SECTION DATA ROUTINE TO ADVANCE TO NEW STATION

I DFLG $=3$

CALL SECDAT (CHU, R, RSTAT, NSTAT, ANG, THETA, F,

780 CONTINUE

C DONE WITH ALL STATIONS

$P C=Q C * X$

$C T=T C * P I 3 Q /(X * X)$

$C P=P C * F 148 /(X * X * X)$

$A J=P I / X$

C DIMENSIONAL STUFF

$P W R=C P * R H O * R P M * * 3 * R A D I U S * 5 * 1,48148 E-7$

$T H P=C T * R H O * R P M * 2 * R A D I U S * 4 * 4,444444 E-6$

$\checkmark E L O=A J * R P M * R A[I \cup S / 30$,

$E T A=0$.

IF $(P C, N E, 0) E T A=,A E S(T C / P C)$ 
IFUETA, GH, IIETA=,$+ I E T A$

$F T v_{i}=0$.

IF (CF,NE+0, IFW: $75798 * 49 S(C T) *+1,5 / \mathrm{CF}$

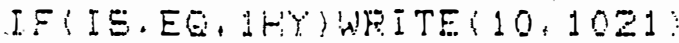

SIE FORMATII B EETA $X$ PC

$\therefore$ CF CT ETA FM VEL M S PWF, IW

$2 \quad$ THR, WNT'?

WPITE!1D, 102EIFL, X, FC, TC, QC, TCW, AU, CF, CT, ETA, FM, VELO, PWE, THE

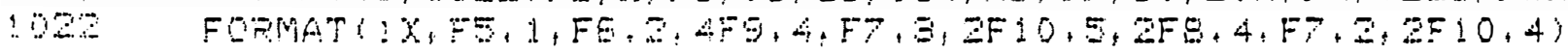

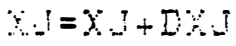

IFUX, IE,XUE) SO TO T:O

$F i=F L+F J$

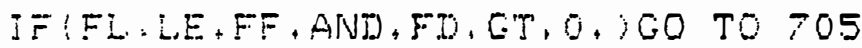

CLOSE!UNJT::10)

CO TO 5

$\because 0$ THE * ANALTSE OUTSIDE STATION DATA ATTEMPTED.

ES END

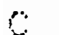

SUEROUTINE SECTON?I, NPL, AL, CL, NPD, AD, CD)

C READ IN SECTION DATA

IIMENEION A1. $(50,20), \operatorname{CL}(50,20), A D(50,20), C D(50,20)$

DIMENSION NE! $(20), N E D(20), F N(3)$

C DEE WHEFE TO GET THE DATA

105 TIPE $1002, ?$

$\$ 002$ FOBMAT: FOP STATION", I 4" IATA SOURCE?'\$)

ACCEPT *, I

IF,,+ OT, O) COTO120

I.F $[, E Q, \cdots 1)$ COTO200

OKET INPUT, GET \# OF CL FOINTS

160 TIPE 1003

1003 .FOFMAT!" NUMEER OF POINTS IN CL CUPVE?' ")

ACCEPT *, NPL (I)

C CET THE ALPHA, CL POINTE

DO $130 \mathrm{~J}=1$, NPL $\{$ I

TYPE $1004, \mathrm{~J}$

1004 FORMAT!' POINT', I 4,' ALPHA, CL? '\$1

130 ACCEPT *,AL $(J, I), C L(J, I)$

1005 FORMAT $\{3$ S 15.0$\}$

TYPE 1007

C THE CD CUPVE

1007 FORMAT!' NUMEEF OF POINTS IN CI CURVE?' $\$$

ACCEPT *,NPD(I)

DO $140 \mathrm{~J}=1, \mathrm{NED}(\mathrm{I})$

TYPE $100 \mathrm{~S}, \mathrm{~J}$

:OOE FOPMAT\{ POINT"I4,'ALPHA, CD? "\$!

140 ACCEPT *,AD $(J, I), C D(J, I)$

C CO AND SET THE REST TO ZERO

COTOZ30

$\mathrm{C}$

C IUPLICATE FEOM ANOTHEP STATION

120 DO $150 \quad N=1,50$

$A L(N, I)=A L(N, J)$

$C L(N, I)=\operatorname{CL}(N, J)$

$A D(N, I)=A D(N, J)$

$150 \quad C D(N, I)=C D(N, J)$

NPL (I) $=\operatorname{NPL}(\mathrm{N})$

$N P D(I)=N P D(J)$

RETURN 


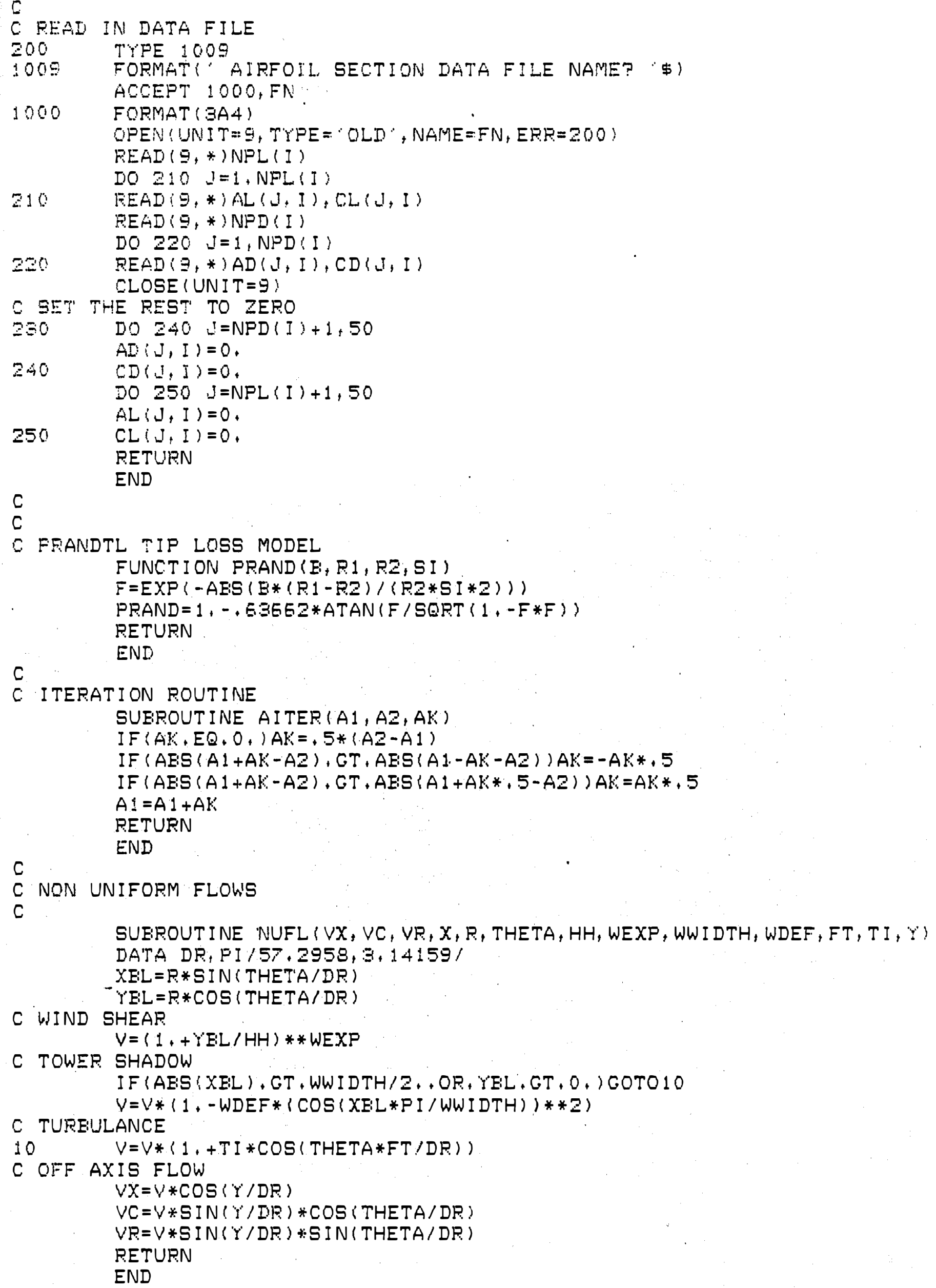


E SECTION DATA: DUNAM:S STALL.

SUEFOUTINE SECDAT!C, P, RE, NS, AING, TH, F, NFL, AL, CL, NPD,

IAI, CD, CLU, CDU!

DIMENSION AL $(50,20), C L(50,20), A D(50,20), C D(50,20)$

DIMENSION NEL $(20), N P I)(20)$, PS $(20)$

COMMON /ER/ERCODE

COMMON /DYNAM/MODEDY, IDFLO

IATA GAMMA, IRIEO , 57, 2858/

C PEEET THE ROUTINE

COTO 5, 100, 510)IDFLO

5 MODESV $=5$

C FIND BTATIC STALL ANCLE

ANS: $=0$,

$F=1$.

SALL SD $R, P S, N S, A N G, F, N P L, A L, C L, N P D, A D, C D, C L U, C D U$ )

$10 \quad$ CLLST $=$ CLU

$A N G=A N G+.5$

CALI SD (R, RS, NS, ANG, F, NPL, AL, CL, NPD, AD, CD, CLU, CDU)

IF (CLU-, OZS, GT + CLLST) COTO 10

ANCSS=ANG - ,

CLSS $=$ CLLST

FETUPN

C GET: NON-DYNAMTE DATA: SEE WHICH MODE

100 CALL SD!P, RS, NS, ANG, F, NPL, AL, CL, NPD, AD, CD, CLU, CDU)

IF (MODEDY. NE + 1 ) PET'URN

MODE $=$ MODESV

$S I=S I N(A N G / D R)$

COTO $(1: 0,200,300,400,500)$ MODESV

$C$

C MODE 1 ; SIMPLE ATTACHED FLOW

I:0 IF (ANG + LE , ANCSS , OR, ANG , LE , ANGLST, OR, ANGLST , GT , ANGSS I RETURN $M O D E=2$

C

C MODE Z: DYLAMIG PRE-STALL

200 IF (ANG. GT, ANGSS) COTOZ10

G NO DINAMIC STALL

$M O D E=1$

PETURN

$210 \quad D A D T=($ ANG - ANCLST $) /(T H-T H L S T)$

C DINAMIC, BUT ATTACHED

ANGDS=ANGSS+CAMMA*SQPT (AMAX $1(D A D T * C / 2, / R, 0)$,

IF (ANG. GT , ANGDS) COTOZ2O

CLU $=$ CLSS,$+ 1 *\{$ ANG-ANGSS $\}$

RETURN

$220 \quad M O D E=3$

C START OF VORTEX ROLLOFF

CLU $=$ CLSS $+.1 *($ ANG - ANGSS $)$

$\mathrm{THDS}=\mathrm{TH}$

$D C L=A M I N I(2,40, * D A D T * C / R)$

CLMAX $=A M A X 1(C L U, C L S S+D C L)$

C

C MODE 3 ; VORT'EX ROLLOFF MODE

300 IF!(TH-THDS) *F/C / DF, CT , 1, ) COTO 10

C INITAL VORTEX POLLOFF

CLU =AMINI (CLMAX, CLSS + . $1 *($ ANG - ANCSS ) )

$C D U=C L U * S I$

RETURN

310 IF!(TH-THDS) *R/C/DR, GT , Z) COTO 330

C FINAL VORTEX ROLLOFF

$C L U=C L M A X$ 
$C D U=C L U * 5 I$

RETURN

$330 \quad M O D E=4$

¿ S'TALLED

$\mathrm{THO}=\mathrm{TH}$

c.

LIFT DECA' MODE

$400 \quad E X P T=E X P((T H O-T H) * 2 * R / C / D R)$

IFIEXPT, LT,0.01:COTO500

C STALLED

$C L U=(C L M A X-C L U) * E X P T+C L U$

$C D U=(C L M A X * S I-C D U) * E X P T+C D U$

RETURN

C. FLOW REATTACHED

500 MODE $=1$

PETLIRN

C SAVE LAST MODE, ANGLE AND. THETA

510 MODESV $=$ MODE

ANGLST $=$ ANG

THLST $=\mathrm{TH}$

RETURN

$\mathrm{C}$

END

C

C SECTION DATA. INTERPOLATE EETWEEN 2 STATIONS

SUEROUTINE SD (R, RS, NS, ANG , F, NPL, AL, CL, NPD, AD, CD, CLU, CDU)

DIMENSION $A L(50,20), C L(50,20), A D(50,20), C D(50,20)$

DIMENSI ON NPL $(20), N P D(20), R S(20)$

COMMON /ER/ERCOTE

C FIND STATIONS WE ARE EETWEEN

DO $10 \quad I Z=2$, NS

10 CONTINUE

$20 \quad$ I $1=I 2-1$

CALL GETSEC (I 1, ANG, $F, N P L, A L, C L, N P D, A D, C D, C L 1, C D 1)$

CALL CETSEC ( I $2, A N G, F, N P L, A L, C L, N P D, A D, C D, C L Z, C D Z)$

$F I=(R S(I Z)-R) /(R S(I Z)-R S(I 1))$

$F Z=(R-R S(I 1)) /(R S(I Z)-R S(I 1))$

$C L U=C L 1 * F 1+C L Z * F Z$

$C D U=C D 1 * F 1+C D Z * F 2$

RETURN

END

$\mathrm{C}$

C SECTION DATA SUEROUTINE, VITERNA MODEL MODIFIED E' TANGLER

C

SUEROUTINE GETSEC ( I, ANG, F, NPL, AL, CL, NPD, AD, CD, CLU, CDD )

DIMENSION $A L(50,20), C L(50,20), A D(50,20), C D(50,20)$

DIMENSION NPL $(20), \operatorname{NPD}(20), \operatorname{CDDS}(4), \operatorname{ACDDS}\{4\}$

DATA CDDS, ACDDS/15, 20, 25. 27.5, 1, .175,.275, .3531

COMMON /ER/ERCODE

DATA TC, DR/ + 1.5, 5T, 29.58/

$C L U=A P O L T(I, A N G ; A L, C L, N P L(I))$

$C D D=A P O L T(I, A N G, A D, C D, N P D(I))$

C FIND AF

I $F(C D D, N E, E R C O D E, A N D$, CLU, NE , ERCODE) RETURN

$A R=17$

IF (F, GE, . 895$)$ COTO 10

$A R=2 * F /(1-F)$

CDMAX $=(1++, 065 * A R) /(.9+T C)$ 
C MAX ANGLES FOE CL AND CD IN TAELE

$\triangle E D=A D(N W D(I), I) / D P$

$A G I=A L(N F L(I), I) / D R$

$A=A N G / D P$

$E Z=(C D(N F D(I), I)-C D M A X * 5 I N(A E D): / O O S(A S D)$

$A Z=(C L(N F L(I), I)-C D M A X+S I N(A S L) * C O S(A S L)) * S I N(A S L) / C O S(A S L) *+2$

C CL

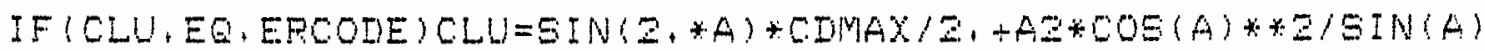

C OO FOP ISCANG 27.5

IF (CID, NE, ERCODE) RETURN

$C D D=A L O O E(C D D S, A C D D E, A N G, 4)$

C OD FOR ANGQZ,

IF (CDD, EQ, ERCODE $) C D D=C D M A X * E I N(A)+E Z * \operatorname{COS}(A)$

FETURN

$E$ EN

S

- INTEPPQLATION ROUTINE

FUNGTION APOLT (I, ANG, $A, C, N M)$

DIMENEION A $(50,20), C(50,20)$

COMMON IEP/ERCODE

APOLT $=E P C O D E$

IF (ANG, LT, A (1, I), OP, ANG , GT, A(NM, I) ) RETURN

$N=1$

$50 \quad N=N+1$

IF (A $(N, I), L, T, A N G)$ GOTO50

AFOLT $=C(N-1, I)+(C(N, I)-C(N-1, I)) *(A N S-A(N-1, I)) /(A(N, I)-A(N-1, I)$

FETUPN

END

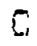

FUNCTION ALOOK $(F, X, X O, N)$

C FUNCTION TO FIND VALUE OF $F(X)$ AT $X=x O$

DIMENSION $F(N), X(N)$

COMMON IEPIERCODE

IF (EPCODE, EQ + 0, ) ERCODE =-99999,

$\mathrm{NN}=\mathrm{N}-1$

DO $10 \quad I=1$, NN

$X I=X(I)$

$X Z=X(I+1)$

$D 1=A E S(X 1-x 0)$

$D Z=A E S(X 2-x 0)$

$D O=A E S(X 1-X Z)$

IF (D), LE, DO, AND, DE, LE, DO) GOTO100

10 CONTINUE

$C \times$ NOT FOUND IN RANGE

ALOOL =ERCODE

RETURN

C calculate VALUe of $F(X 0)$

100 IF $(X 2, N E, X 1)$ GOTO 110

$A L O O K=.5 *(F(I)+F(I+1))$

RETURN

$110 \quad F A C=(X 0-X 1) /(X 2-X 1)$

$A L, O O Y=F(I)+F A C *\{F(I+I)-F(I\})$

RETURN

END 
AEROVIRONMENT ROTOR ANALYSIS PROGRAM RART D. HIBRS 1984

MOE O IN WIND SHEAR

ANALYSIS PERFORMEN ON 11-JUL-84 AT 17:27:17.

POTOR GEOMETRY

NUMBEP OF BLABES: 2 , CONE ANGLE, DEGREES 3.00

H.UF: RADIUS:

LOSS MODELS

$0:$ NONE

1: PRANJTL.

TIP LOSS MODEL: 1 HUB LOSS MODEL:

ANALYSIS PARAMETERS

E CIRCUMFERENTAL STATIONS ANALIZED OVER 0.5 POTATIINS

15 EI.EMENTS ANALIEED OVER A RAIIUS RANGE FPOM 0.052 TO :.000 POTOR ANALYZED AS WINDTURB:NE

NOrJ UNIFORM FLOWS
WIND EXPONENT:
0.149 HU HEIGHT/RADIUS:
$\begin{array}{ll}\text { TOWEP WAYE WIDTHz } & 0.000 \text { WAKE DEF ICIT: } \\ \text { TUPEUILARSE INTENSITY: } & 0.090 \text { YAW ERROP., DEGREES: }\end{array}$
$\begin{array}{ll}\text { TOWEP WAYE WIDTHz } & 0.000 \text { WAKE DEF ICIT: } \\ \text { TUPEUILARSE INTENSITY: } & 0.090 \text { YAW ERROP., DEGREES: }\end{array}$
TUREALAFCE INTENSITY: 0.000 YAW ERROP., DEGREES
TUFEULANCE FPEQUENCY/ROTOP ROTATION FREQUENCY:
$0.9 \div 4$
0.000
0.000

DIMENSI ONAL VALUES

FOTOP RADIUS:

PIITOR RATE OF ROTATION:

$19.5 \mathrm{M}$

DEISSITY:

$0.60 \mathrm{RPM}$

1. 220 KGIM*:3

ELADE . STATION DATA

\begin{tabular}{|c|c|c|c|c|c|}
\hline STAT ION & $\begin{array}{l}\text { PADIUS } \\
0.0521\end{array}$ & $\begin{array}{l}\text { CHOPD } \\
0.029 \%\end{array}$ & $\begin{array}{r}\text { TWIST } \\
0.0000\end{array}$ & $\begin{array}{c}\text { CMO } \\
1.0000\end{array}$ & $\begin{array}{c}\text { MA } \\
1.0000\end{array}$ \\
\hline 2 & 0.2085 & 0.0782 & 0.9000 & 1.0000 & 1.0000 \\
\hline 3 & 0.4972 & (1). 0.92 & 0.0900 & 1.0000 & 1.0000 \\
\hline 4 & O.62E? & $0.065{ }^{\circ}$ & 0.0000 & 1.0000 & 1.0000 \\
\hline 5 & 0.6717 & 0.0612 & 0.0000 & 1.0000 & 1.0000 \\
\hline 6 & 0.6 .23 & O.CEIE & 0.2000 & 1.0000 & 1.0000 \\
\hline 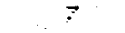 & 0.9759 & 0.0342 & 0.0000 & 1.0000 & 1.0000 \\
\hline 8 & 1.0000 & 9.0000 & 0.0000 & 1.0090 & 1.0000 \\
\hline
\end{tabular}

AIPFOIL SECTION DATA FOP STATION

ALPHA SECTION DATA FOP STATION I CL

$\begin{array}{rrrr}-4.0003 & -0.3000 & -4.2000 & 0.0025 \\ c .0500 & 0.1000 & 0.3000 & 0.0082\end{array}$

$\begin{array}{llll}4.0503 & 0.4400 & 0.3000 & 0.0082 \\ 4 & 4.3000 & 0.0095\end{array}$

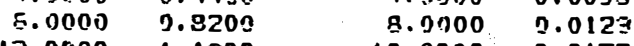

$\begin{array}{llll}12.06 c 0 & 1.1300 & 10.0000 & 0.0152\end{array}$

$\begin{array}{llll}150001 & 1.4000 & 12.0000 & 0.3202\end{array}$

$\begin{array}{rrrr}1-.0000 & 1.2000 & 14.3000 & 0.0250 \\ \therefore .0000 & 0.0000 & 1.0000 & 9.0520\end{array}$

AIFFOIL SECTION DATA TOF STATION 2 


\begin{tabular}{|c|c|c|c|c|}
\hline $\begin{array}{l}\text { ALPHA } \\
-\angle .9000\end{array}$ & $\begin{array}{l}C L \\
-0.3000\end{array}$ & & $\begin{array}{l}\text { ALPHA } \\
\text { 4. } 0 \cong 00\end{array}$ & $\begin{array}{l}\text { CD } \\
0.0085\end{array}$ \\
\hline 0.0000 & 0.1000 & & 0.0000 & 0.0082 \\
\hline 4.0000 & 0.4490 & & 4.0000 & 0.0095 \\
\hline 8. 0000 & 0.8200 & & 9.0000 & 0.0123 \\
\hline 12.0800 & 1.1300 & & 10.0000 & 0.0152 \\
\hline 15.0000 & 1.4000 & & 12.0000 & 0.0202 \\
\hline 17.0000 & 1.2000 & & 14.0000 & 0.0250 \\
\hline 0.0000 & 0.0000 & & $1=.0000$ & 0.0520 \\
\hline \multirow{2}{*}{\multicolumn{2}{|c|}{ AIPFOIL SECTION DATA }} & FOP & STATION & $\cong$ \\
\hline & & & AL.PHA & CD \\
\hline-4.0000 & -0.3000 & & $-4: 0000$ & 0.0085 \\
\hline C. 0000 & 0.1000 & & 0.0000 & 0.0092 \\
\hline $4.05 n 0$ & 0.4400 & & 4.0000 & 0.0095 \\
\hline E. . 0000 & 0.8200 & & 9.0000 & 0.0123 \\
\hline 12.000 & 1.1300 & & $10.0 \cong 00$ & 0.0152 \\
\hline 15.0000 & 1.4000 & & 12.0900 & 0.0202 \\
\hline $1 \% .0(1,0$ & 1.2000 & & 14. J00n & 0.0250 \\
\hline$\therefore .0000$ & 0.0000 & & 17.0000 & 0.0520 \\
\hline \multicolumn{2}{|l|}{ AIFFDII, 5} & FOP & STATION & 4 \\
\hline VAPHA & CL & & ALPHA & CD \\
\hline-2.9000 & -0.3000 & & -4.3000 & 0.0085 \\
\hline 5.9000 & $\begin{array}{l}0.1000 \\
0.4400\end{array}$ & & c. 0000 & 0.0082 \\
\hline 2.0000 & $\begin{array}{l}0.4400 \\
0.3200\end{array}$ & & 4.0000 & 0.0095 \\
\hline $\begin{array}{ll}E .0000 \\
E .0007\end{array}$ & $\begin{array}{l}0.3200 \\
1.1300\end{array}$ & & 10.0000 & 0.0123 \\
\hline $1=. n 000$ & 1.4000 & & 12.0000 & 0.0202 \\
\hline $1, .0000$ & 1.2000 & & 14.0000 & 0.0250 \\
\hline$\therefore 0000$ & 0.0000 & & $1 \therefore 90100$ & 0.0520 \\
\hline \multirow{2}{*}{\multicolumn{2}{|c|}{$\begin{array}{l}\text { AJPFOIL SECTION DATA } \\
\text { ALPHA CL }\end{array}$}} & FQP & STAT ION & 5 \\
\hline & & & AL.PHA & CD \\
\hline $\begin{array}{r}-4.0000 \\
0.0000\end{array}$ & -0.5000 & & -4.0000 & 0.0085 \\
\hline$\therefore$. conon & $n .4400$ & & $\begin{array}{l}0.0000 \\
4.0009\end{array}$ & $\begin{array}{l}0.0082 \\
0.0095\end{array}$ \\
\hline 8.10000 & 0.8200 & & 9.0000 & 0.0123 \\
\hline 12.0000 & $1.1 \equiv 00$ & & 10.0000 & 0.0152 \\
\hline 15.0000 & 1.4000 & & 12.0000 & 0.0202 \\
\hline 17.0000 & 1.2000 & & 14.0000 & 0.0250 \\
\hline 0.0000 & 0.0000 & & 17.0000 & 0.0520 \\
\hline \multicolumn{2}{|r|}{ SECTION DATA } & FDP. & STATION & 6 \\
\hline ALPHA & CL & & AL.PHA & \\
\hline-4.0000 & -0.3000 & & -4.0050 & 0.0095 \\
\hline 0.0000 & o. 1000 & & 0.0000 & 0.9082 \\
\hline A. 0000 & 0.4400 & & 4.0000 & 0.0095 \\
\hline 9.0000 & 0.8200 & & A. 0000 & 0.0129 \\
\hline 12.0000 & 1.1300 & & 10.0000 & 0.0152 \\
\hline 15.0000 & 1.4000 & & 12.0000 & 0.0202 \\
\hline $17.0 \cos$ & 1.2000 & & 1 1.0000 & $0.025 n$ \\
\hline 0.0000 & 0.0000 & & $1=.0300$ & 0.0520 \\
\hline AIPFOIL & SECTION DATA & Frip & STATIOHN & 7 \\
\hline ALPHA & CL & & AI.PHA & CI \\
\hline-4.0000 & $-0 . \exists 000$ & & 4.0000 & 0.05 .85 \\
\hline 0.9000 & 0.1000 & & 0.0900 & 0.0032 \\
\hline 4.0nen & n. 44ng & & 4.0000 & 0.00 .95 \\
\hline ח & c. 8200 & & 3.09010 & 0.0122 \\
\hline
\end{tabular}




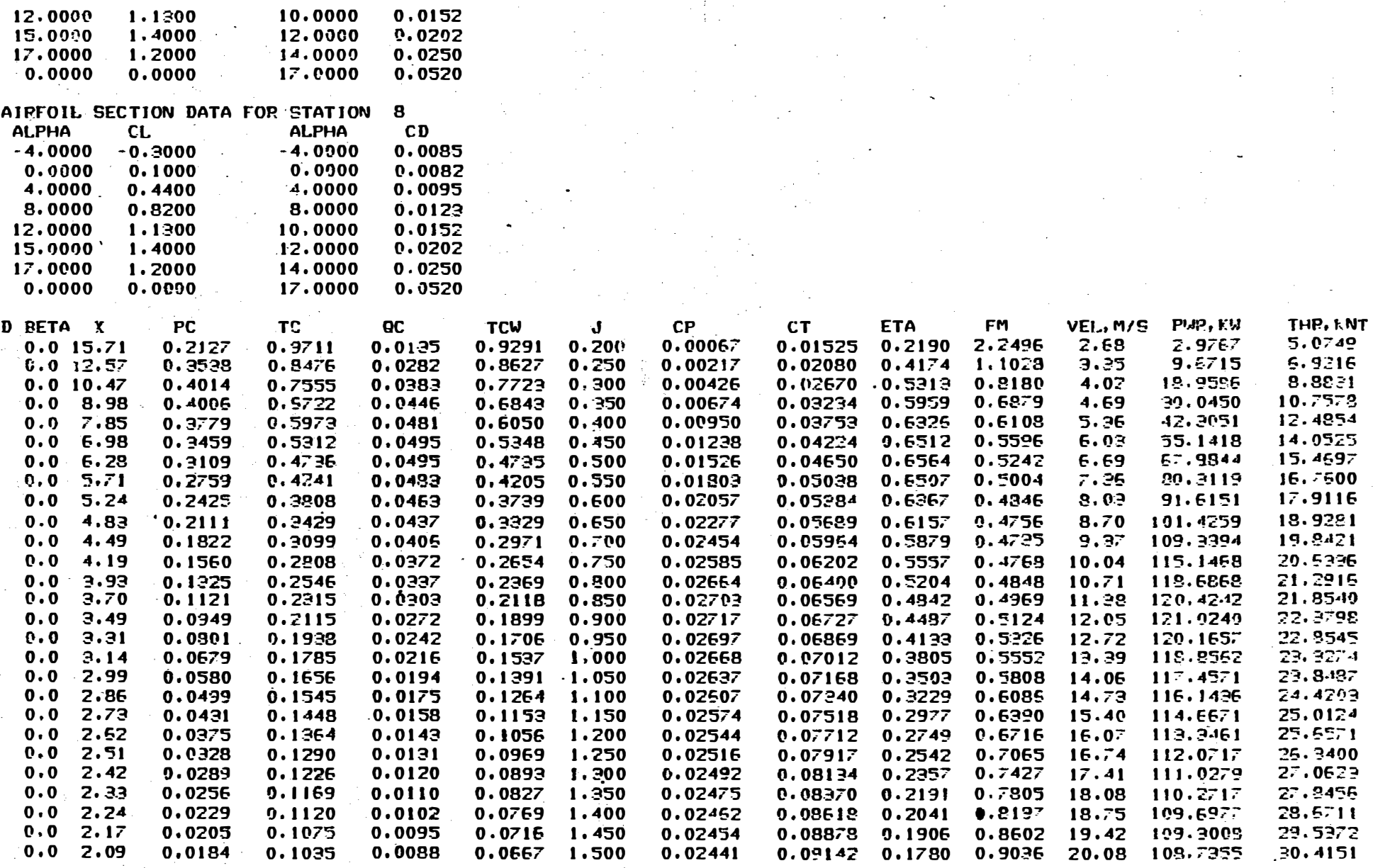




\section{AEPOVIRONMENT POTOR ANALYSIS PROGRAM}

ENERTECH 44/25 IN UNIFOPM FLOW

ANALYSIS PERFORMED ON 26-JUL-84 AT 15:18:37

POTOR GEOMETRY

MUNIEER OF BLADES: 3. CONE ANGLE, DEGREES 5.00 HUR RADIUS:

LOSS MODELS

$0:$ NONE

1: PRANDTL

TIP LOSS MODEL: I HUB LOSS MODEL: 0

ANALYSIS PARAMETERS

1 CIRCUMFEPENTAL STATIONS ANALIZED OVER 1.0 ROTATIONS

15 ELEMENTS ANALIZED OVER A RADIUS RANGE FROM 0.100 TO 1.000 ROTOR ANALYZED AS WINDTURBINE

NON UNIFORM FLOWS

$\begin{array}{llll}\text { WIND EXPONENT: } & 0.000 & \text { HUB HEIGHT/RADIUS: } & 3.640 \\ \text { TOWER WAKE WIDTH: } & 0.000 & \text { WAKE DEFICIT: } & 0.000 \\ \text { TUPEULANCE INTENSITY: } & 0.000 \text { YAW ERROR, DEGREES: } & 0.000 \\ \text { TURBULANCE FREQUENCY/ROTOR ROTATION FREQUENCY: } & 0.000\end{array}$

0.000

DIMENSI ONAL VALUES

POTOR RADIUS:

ROTOR RATE OF ROTATION:

53.00 RPM

DENS ITY:

$1.220 \mathrm{KG} / \mathrm{M} * 3$

ELADE STATION DATA

\begin{tabular}{cccccc}
\multicolumn{2}{c}{ ELADE STATION DATA } & & & \\
STATION RADIUS & CHORD & TWIST & CMO & MA \\
I & 0.1000 & 0.0665 & 5.0000 & 1.0000 & 1.0000 \\
2 & 0.6360 & 0.0909 & 2.9800 & 1.0000 & 1.0000 \\
3 & 1.0000 & 0.0753 & 0.0000 & 1.0000 & 1.0000
\end{tabular}

$\begin{array}{llllll}3 & 1.0000 & 0.0753 & 0.0000 & 1.0000 & 1.0000\end{array}$

AIRFOIL SECTION DATA FOP STATION

ALPHA CL $\quad$ ALFHA CD

$\begin{array}{llll}-4.0000 & 0.0009 & -4.0000 & 0.0130\end{array}$

$\begin{array}{llll}6.0000 & 1.0000 & 4.0000 & 0.0130\end{array}$

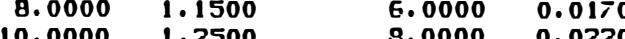

$12.0000 \quad 1.2500 \quad 1.0000 \quad 0.0220$

$14.0000 \quad 1.3500 \quad 10.0000 \quad 0.0270$

$\begin{array}{llll}14.0000 & 1.4200 & 12.0000 & 0.0430\end{array}$

$0.0000 \quad 0.0000$

$16.0000 \quad 0.0820$

AIRFOIL SECTION DATA FOP. STATION 2

$\begin{array}{rlll}\text { ALFHA } & \text { CL } & \text { ALFHA } & \text { CD } \\ -4.0000 & 0.0000 & -4.0000 & 0.0130 \\ 6.0000 & 1.0000 & 4.0000 & 0.0130 \\ 8.0000 & 1.1500 & 6.0000 & 0.0170\end{array}$

$\begin{array}{llll}8.0000 & 1.1500 & 6.0000 & 0.017\end{array}$

$\begin{array}{llll}10.0000 & 1.2500 & \mathbf{8 . 0 0 0 0} & 0.0220\end{array}$ 


\begin{tabular}{|c|c|c|c|c|c|c|c|c|c|c|c|c|c|}
\hline $\begin{array}{l}0.0 \\
0.0\end{array}$ & $\begin{array}{l}4.49 \\
4.19\end{array}$ & $\begin{array}{l}0.3887 \\
0.3615\end{array}$ & $\begin{array}{l}0.7202 \\
0.6631\end{array}$ & $\begin{array}{l}0.0866 \\
0.0863\end{array}$ & 0.6467 & 0.700 & 0.05236 & 0.13859 & 0.539 .3 & 0.7861 & $\begin{array}{l}8.29 \\
8.89\end{array}$ & 19.1229 & 4.2713 \\
\hline 0.0 & $\begin{array}{l}3.93 \\
3.70\end{array}$ & $\begin{array}{l}0.3321 \\
0.3022\end{array}$ & $\begin{array}{l}0.6119 \\
0.5649\end{array}$ & $\begin{array}{l}0.0846 \\
0.0818\end{array}$ & $\begin{array}{l}0.5394 \\
0.4930\end{array}$ & $\begin{array}{l}0.800 \\
0.850\end{array}$ & $0.0667 \%$ & 0.15379 & 0.5427 & 0.7207 & $\begin{array}{r}9.48 \\
10.08\end{array}$ & 24.3826 & $\begin{array}{l}4.5117 \\
4.7396 \\
4.9399\end{array}$ \\
\hline 0.0 & 3.49 & 0.2726 & 0.5221 & 0.0781 & 0.4503 & 0.900 & 0.07303 & 0.16609 & 0.5220 & 0.6921 & 10.66 & 29.4954 & 5. 1199 \\
\hline 0.0 & 3.31 & 0.2428 & 0.4832 & $0.0,34$ & 0.4110 & 0.950 & 0.08174 & 0.17125 & 0.502 .4 & 0.6913 & 11.26 & 29.8504 & 5.2780 \\
\hline 0.0 & 3,14 & 0.2140 & 0.4177 & 0.0681 & 0.3750 & 1.000 & 0.08403 & 0.17581 & 0.4780 & 0.7000 & 11.85 & 30.6369 & 5.4186 \\
\hline 0.0 & 2.99 & 0.1876 & 0.4152 & $0.062 \bar{T}$ & 0.3420 & 1.050 & 0.08527 & 0.17975 & 0.4518 & 0.7131 & 12.44 & $31.1+10$ & 5.5401 \\
\hline 0.0 & 2.86 & 0.1637 & 0.3852 & 0.0573 & 0.3117 & 1.100 & 0.08555 & 0.18303 & 0.4249 & 0.7303 & $13.0 ?$ & $31 \cdot 2.414$ & 5.6410 \\
\hline 0.0 & 2.73 & 0.1430 & 0.3580 & 0.0523 & 0.2844 & 1.150 & 0.08538 & 0.18593 & 0.3993 & 0.7492 & 13.63 & 31.1318 & 5.7304 \\
\hline 0.0 & 2.62 & 0.1250 & 0.37388 & 0.0478 & 0.26 .00 & 1.200 & 0.08483 & $0.188 \overrightarrow{7}$ & $0 .: \exists 745$ & 0.7714 & 14.22 & $30.9 .9: \exists$ & $5.81-9$ \\
\hline 0.0 & 2.51 & 0.1101 & 0.3130 & 0.0438 & 0.2389 & 1.250 & c.08445 & 0.19205 & 0.3518 & 0.7952 & 14.81 & 90.3416 & 5.9191 \\
\hline 0.0 & 2.42 & 0.0968 & 0.2940 & 0.0401 & 0.2200 & 1.300 & 0.08355 & 0.19509 & 0.3294 & 0.8229 & 15.40 & 30.5124 & 6.0128 \\
\hline 0.0 & 2.33 & 0.0851 & $0,2: 67$ & 0.0366 & $0.202 \bar{\gamma}$ & 1.350 & 0.08226 & 0.19806 & $0.30 ; 6$ & 0.8550 & 16.00 & $39.040 \bar{r}$ & 6.10 .45 \\
\hline 0.0 & 2.24 & 0.0754 & 0.2617 & 0.0336 & 0.1874 & 1.400 & 0.08128 & 0.20146 & 0.2882 & $0.887 \overline{7}$ & 16.59 & 29.6814 & 6.2092 \\
\hline 0.0 & 2.17 & 0.0653 & 0.2487 & 0.0310 & 0.1740 & 1.450 & 0.08052 & 0.20538 & 0.2704 & 0.9223 & $17 \cdot 13$ & 29.4048 & 6. 3299 \\
\hline 0.0 & 2.09 & 0.0603 & 0.2374 & 0.0288 & 0.1620 & 1.500 & 0.07994 & $0.209 \div 2$ & 0.2541 & 0.9586 & $17.7 i$ & 23.1942 & 6. $463^{-}$ \\
\hline 0.0 & 2.03 & 0.0544 & 0.227 .3 & 0.0268 & 0.1514 & 1.550 & 0.07956 & 0.21448 & 0.2393 & 0.9962 & $18 \cdot 37$ & 29.0536 & 6.6104 \\
\hline 0.0 & 1.96 & 0.0493 & 0.2184 & 0.0251 & 0.1419 & 1.600 & 0,07931 & 0.21960 & 0.2257 & $1.0 \exists 52$ & 18.96 & 28.9649 & 6.7682 \\
\hline 0.0 & 1.90 & 0.0449 & 0.2105 & 0.0236 & 0.13934 & 1.650 & 0.07922 & 0.22506 & 0.2133 & 1.0754 & 19.55 & $28 \cdot 9294$ & 6.9364 \\
\hline 0.0 & 1.85 & 0.0411 & 0.2034 & 0.0222 & 0.1256 & 1.700 & 0.07926 & $0.2: 3086$ & 0.2019 & 1.1167 & 20.14 & $28.94 \exists \vec{r}$ & 7.1151 \\
\hline BETA & $\boldsymbol{x}$ & PC & TC & $\mathbf{Q C}$ & TCW & $\mathbf{J}$ & CP. & CT & ETA & FM & VEL, M/ & PHR, K.W & THR, F:NT \\
\hline $\begin{array}{l}2.0 \\
2.0\end{array}$ & $\begin{array}{l}15.71 \\
12.5 \%\end{array}$ & $\begin{array}{l}-0.6010 \\
-0.0641\end{array}$ & $\begin{array}{l}1.2885 \\
1.1823\end{array}$ & $\begin{array}{l}-0.0383 \\
-0.0051\end{array}$ & $\begin{array}{l}0.8020 \\
0.8935\end{array}$ & $\begin{array}{l}0.200 \\
0.250\end{array}$ & $\begin{array}{l}-0.00189 \\
-0.00039\end{array}$ & $\begin{array}{l}0.02024 \\
0.02302\end{array}$ & $\begin{array}{l}0.4664 \\
0.0542 .\end{array}$ & -1.2168 & 2.37 & -0.6996 & 0.6239 \\
\hline 2.0 & 10.47 & 0.1796 & 1.0974 & 0.0172 & 0.9275 & 0.300 & 0.00190 & 0.03879 & 0. IEa7 & 3.2006 & 3.55 & $\begin{array}{r}0.1456 \\
0.6954\end{array}$ & 1.1954 \\
\hline 2.0 & 8.98 & 0.3069 & 1.0294 & 0.0342 & 0.9276 & 0.350 & 0.00517 & 0.04952 & 0.2981 & 1.7016 & 4.15 & 1.8869 & 1.5262 \\
\hline 2.0 & 7.85 & 0.3793 & 0.9717 & 0.0483 & 0.9046 & 0.400 & 0.00953 & 0.06105 & 0.3903 & $1.262 i$ & 4.74 & 3.4813 & 1.0817 \\
\hline 2.0 & 6.98 & 0.4236 & 0.9218 & 0.0607 & 0.8669 & 0.450 & 0.01516 & 0.07330 & 0.4595 & $1.044 \bar{i}$ & 5.33 & 5.5356 & 2.2593 \\
\hline 2.0 & 6.28 & 0.4458 & 0.8741 & 0.0710 & 0.8180 & 0.500 & 0.02188 & 0.08581 & 0.5101 & 0.9165 & 5.92 & 7.9922 & 2.6448 \\
\hline 2.0 & & 0.4482 & 0.8236 & 0.0785 & 0.7663 & 0.550 & 0.02928 & 0.09784 & 0.5441 & 0.8339 & 6.52 & 10.6934 & 3.0155 \\
\hline 2.0 & 5.24 & 0.4377 & 0.7734 & 0.0836 & 0.7119 & 0.600 & 0.03713 & 0.10934 & 0.5659 & 0.7TT0 & 7.11 & 13.5582 & 3. 3699 \\
\hline 2.0 & & 0.4194 & 0.7232 & 0.0863 & 0.6636 & 0.650 & 0.04523 & 0.11999 & 0.5800 & 0.7332 & 7.70 & 93 & 81 \\
\hline 2.0 & 4.49 & 0.3969 & 0.6735 & 0.0884 & $0.61 \geq 0$ & 0.700 & 0.05346 & 0.12960 & 0.5893 & 0.6963 & 8.29 & 19.5243 & 3.99 .45 \\
\hline 2.0 & 4.19 & 0.3717 & 0.6262 & $0.088 \overline{7}$ & 0.5649 & 0.750 & 0.06159 & $0.138: \exists 2$ & 0.5937 & 0.6664 & 8.89 & 22.4911 & 4.2630 \\
\hline 2.0 & $3 \cdot 93$ & & 0.5815 & 0.0877 & 0.5193 & 0.900 & 0.06926 & 0.14615 & 0.5924 & 0.6437 & 9.48 & 25.29 .30 & 4.50 .45 \\
\hline 2.0 & & & & 0.0859 & & 0.850 & 0.07655 & 0.15348 & 0.5868 & 0.6267 & $10.0 \vec{r}$ & 27.9551 & 4.7304 \\
\hline 2.0 & 3.49 & 0. & 0.5044 & 0.0834 & 0.4417 & 0.900 & 0.08334 & $0.1604: \exists$ & 0.5772 & 0.6152 & 10.66 & 30.4342 & 4. 94.5 \\
\hline 2.0 & & & 0.4701 & 0.0800 & 0.4068 & 0.950 & 0.08904 & 0.16660 & 0.5626 & 0.6094 & 11.26 & 32.5165 & 5.13 .18 \\
\hline 2.0 & 3.14 & 0.23932 & 0.4 .888 & 0.0761 & 0.3747 & 1.000 & 0.09393 & 0.172 & 0.5450 & 0.6077 & & 9025 & $5 .: 3114$ \\
\hline 2.0 & 2.99 & 0.2147 & 0.4101 & 0.0718 & 0.3451 & 1.050 & 0.09 & $\begin{array}{l}0.17757 \\
0.18226\end{array}$ & $0.52: 15$ & $0.611 \%$ & 12.44 & 35.6452 & 5.4728 \\
\hline 2.0 & & & & & & & & & & & & & \\
\hline 2.0 & 2.73 & 0.1704 & 0.3588 & 0.0624 & 0.2919 & 1.150 & 0.10176 & 0.18634 & 0.4749 & O. E: $\exists 0_{i}^{-}$ & 13.63 & 97.163 .1 & 5.7431 \\
\hline 2.0 & 2.62 & 0.1510 & $0.395 \%$ & $0.057 \overline{7}$ & 0.2681 & 1.200 & 0.10250 & 0.18989 & 0.4493 & 0.6439 & 14.22 & $3-.4316$ & 5.8503 \\
\hline 2.0 & 2.51 & 0.1340 & 0.3149 & 0.0533 & 0.2466 & 1.250 & 0.10278 & 0.19321 & 0.4256 & 0.6593 & 14.81 & $3 \vec{i} \cdot 5353$ & 5.9549 \\
\hline 2.0 & 2.42 & 0.1189 & 0.2961 & 0.0492 & 0.2272 & 1.300 & 0.10261 & 0.19651 & 0.4017 & 0.6774 & 15.40 & 37.4729 & 6.0566 \\
\hline 2.0 & 2.33 & 0.1061 & 0.2796 & 0.0456 & 0.2102 & 1.350 & 0.10253 & 0.20010 & 0.3796 & 0.6965 & 16.00 & 37.4139 & 6. $\mid 6 ; 1$ \\
\hline 2.0 & 2.24 & 0.0950 & 0.2646 & 0.0423 & 0.1947 & 1.400 & $0.102: \exists 4$ & 0.20363 & $0 . \exists 590$ & 0.7164 & 16.59 & $3 \bar{T}, \exists \bar{T}$ & E. 2760 \\
\hline 2.0 & 2.17 & 0.0846 & 0.2504 & 0.0390 & 0.1803 & 1.450 & 0.10125 & 0.20673 & 0.3978 & 0.7407 & 17.18 & 36.9775 & $6.3 \div 16$ \\
\hline 2.0 & 2.09 & 0.0758 & $0.2 \exists 82$ & 0.0362 & 0.1677 & 1.500 & $0.1004 \bar{T}$ & 0.21045 & 0.3183 & $0.766 ?$ & $17 . \bar{T}$ & 36.6923 & 6.48 .61 \\
\hline 2.0 & 2.03 & 0.0683 & 0.2275 & 0.0337 & 0.1565 & 1.550 & 0.09995 & 0.21467 & 0.3004 & 0.7940 & $18 \cdot 37$ & 36.5016 & 6.6163 \\
\hline $2 \cdot 0$ & 1.96 & 0.0619 & 0.2182 & 0.0316 & 0.1464 & 1.600 & 0.09964 & 0.21039 & 0.2839 & 0.8225 & 18.96 & 35.3896 & 6. \\
\hline $2 \cdot 0$ & 1.90 & 0.0564 & 0.2099 & 0.0296 & 0.1374 & 1.650 & 0.09954 & 0.22440 & J. 2688 & 0.0520 & 19.55 & 36.01524 & 6.9161 \\
\hline 2.0 & 1.85 & 0.0516 & 0.2025 & 0.0279 & 0.1294 & 1.700 & 0.09962 & $0.2298 \exists$ & 0.2550 & 0.3325 & 20.14 & $36 \cdot 3 \div 96$ & 7.0836 \\
\hline
\end{tabular}




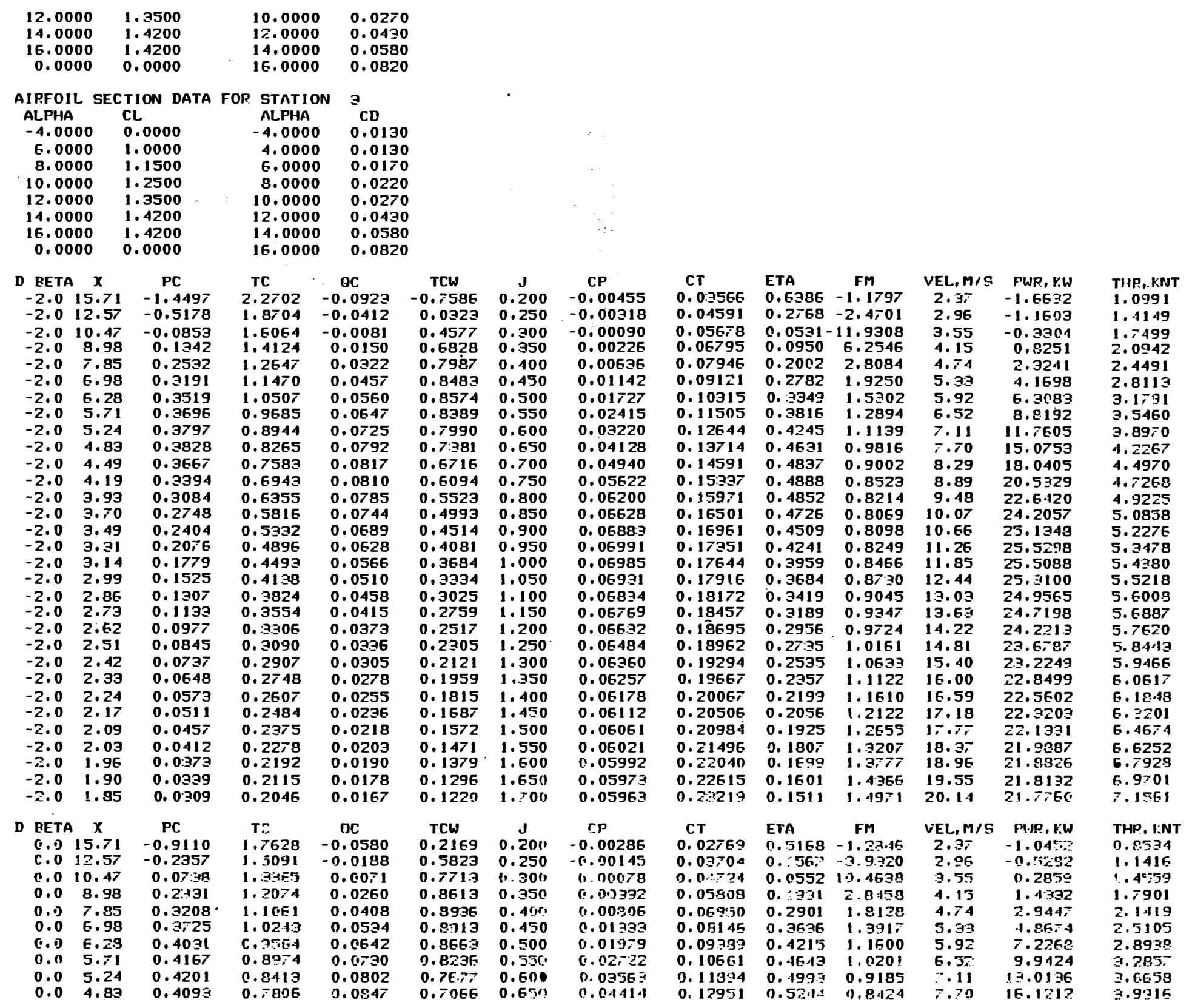


